The Relationship between the Commitment and Job Performance of Employe in the Publie Sector Organizations: The Study based on the Zonal Edueation Officers in the Eastern Province in Sri Lanka

\title{
By
}

Mrs. Stubatthimi Priyadharsan

(GS/M.Sc/M/GT/2988) 1/06)

Thesis submitted to the Faculty of Graduate Studies,

University of Sri Jayewardenepura for the award of the Degree of

Master of Science in Management. 


\title{
DECLARATION OF THE CANDIDATE:
}

"The work described in this thesis was carried out by me under the supervision of Prof. (Mrs.) R.L.S.Fernando, Senior Lecturer, Department of Public Administration, University of Sri Jayewardenepura, and a report on this has not been submitted in whole or in part to any university or any other institution for another Degree or Diploma"

\author{
Prabattee \\ Mrs.P.Subathini \\ GS / MSC / MGT / 2981 / 06
}




\section{DECLARATION OF THE SUPERVISOR:}

"I certify that the above statement made by the candidate is true and that this thesis is suitable for submission to the University for the purpose of evaluation".

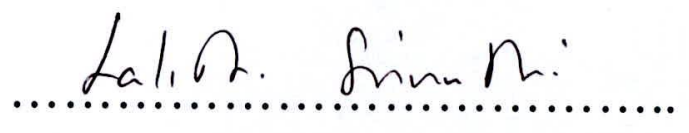

Prof. (Mrs.) R.L.S.Fernando

Supervisor 


\section{Acknowledgement}

I thank my supervisor Prof. (Mrs.) R.L.S. Fernando, Senior Lecturer of the Department of Public Administration, University of Sri Jayewardenapura for her guidance, encouragement, and feedback during the planning and writing of this thesis.

My sincere thanks go to Mr.Shayaman Udayanga, Head, Department of Entrepreneurship, Faculty of Management Studies and Commerce, University of Sri Jayewardenapura for his sincere help and guidance, which enabled me to prepare this thesis successfully.

A special word of thanks goes to all the lecturers who taught us the course and to Prof.Dr.H.H.D.N.P Opatha and Prof.R.S.Gunathunga for teaching research methodology which helped me a great deal in doing the research.

I am indebted to Dr. P.D. Nimal, course coordinator for all the support given.

I am specially grateful to the zonal director, principals and $\mathrm{A} / \mathrm{L}$ teachers for their time and their kind response to the survey.

Let me also thank any others whom I have inadvertently missed.

Finally it is my duty to thank my beloved husband and parents without whom I would never have been able to undertake this study, and my friends with whom I have been associated for the success of this thesis. 
The Relationship between the Commitment and Job Performance of Employees in the Public Sector Organizations: The Study based on the Zonal Education Officers in the Eastern Province in Sri Lanka.

\author{
Mrs.Subathini Priyadharsan
}

\begin{abstract}
Committed employees have a vital role in organizations for its survival and its competition in the rapidly changing world. This empirical study is an attempt to establish the relationship between the commitment and job performance of employees in the public sector organizations. The study is based on the Zonal Education Officers in the Eastern Province in Sri Lanka.
\end{abstract}

The main objectives of this study are to find out the relationship between employees commitment and job performance, to examine the impact of the different level of commitment on job performance and to recommend suitable strategies to improve the job performance through employee commitment.

The data were collected from a randomly selected sample of two hundred and seventy six staff from the education officers by administrating a structured questionnaire which consisted of 40 questions/statements with five points scale. The data analysis included the univariate, bivariate and multivariate analysis. The conceptual model was formulated for the relationships of employee affective commitment, normative commitment, and 
continuance commitment with employee job performance. The findings of the study show that affective commitment and normative commitment have positive relationships where as continuance commitment has a negative relationship with job performance. As per the multiple regression analysis, 57.3 percent of the variance is found in the job performance.

Key words: Job Performance, Affective Commitment, Normative Commitment, Continuance Commitment. 


\section{Contents}

Page Number

Title Page

i

Certification

ii-iii

Acknowledgement

iv

Abstract

v-vi

Table of contents

vii-ix

List of figures

$\mathbf{x}$

List of tables

$x-x i$

1 Introduction

1.1 Introduction

$1-11$

1.2 Problem Statement

11

1.3 Research Questions

12

1.4 Objectives

12

1.5 Significance of the Study

13

1.6 Scope of the Study

13

1.7 Limitation

14

1.8 Structure of the Reports

14-15 
2.1 Introduction

2.2 Theories

2.3 Employee Job Performance

2.4 Conceptualizing Job Performance

2.5 Conceptualizing Employee Commitment

2.6 Related research on commitment and job performance

2.7 Summary

3 Conceptualization and Methodology

3.1 Introduction

3.2 Conceptual Frame work 55

3.3 Conceptualizing Job Performance

3.4 Conceptualizing Employee Commitment

3.5 Hypothesis

3.6 Methodology

3.7 Summary

\section{Data Analysis and Discussion}

4.1 Introduction 71

4.2 Summary of Data Analysis

4.3 Data Presentation $73-81$

4.4 Summary of Sample Description $81-83$ 
4.5 Data Validity and Reliability

4.6 Multiple Regression Analysis

85-89

4.7 Hypothesis testing

$89-90$

4.8 Discussion of the results

$91-94$

5 Conclusion and Recommendations

5.1 Introduction

95

5.2 Conclusion

95-96

5.3 Recommendations

96-99

5.4 Implication

99

References

100-103 


\section{List of Figures}

Figure Number

Title

Page Number

2.1 Job Performance Process 33

3.1 Model of the research $\quad 55$

4.1 Relationship between the affective commitment and job performance $\quad 87$

4.2 Relationship between the normative commitment and job performance 88

4.3 Relationship between the continuance commitment and job performance 88

\section{List of Tables}

Table Number

Title

Page Number

2.1 Dimensions and Aspects of the Job Performance

2.2 Dimensions and Aspects of Employee Commitment

3.1 Dimensions and Aspects of the Job Performance

3.2 Dimensions for measuring employee organizational commitment

3.3 Eastern Province Zonal Education Officers

4.1 Summary of Data Analysis

4.2 Gender

4.3 Age 
$\begin{array}{lll}\text { 4.4 Marital Status } & 74\end{array}$

$\begin{array}{lll}4.5 & \text { Occupation } & 75\end{array}$

$\begin{array}{lll}4.6 & \text { School type } & 75\end{array}$

$\begin{array}{lll}\text { 4.7 Distance from home to organization } & 76\end{array}$

$\begin{array}{lll}\text { 4.8 Mode of transportation } & 76\end{array}$

$\begin{array}{lll}4.9 & \text { Educational Qualification } & 77\end{array}$

$\begin{array}{lll}4.10 & \text { Services } & 78\end{array}$

$\begin{array}{lll}4.11 & \text { Work Experience } & 78\end{array}$

4.12 Working Zonal Education Offices in district 79

4.13 Working Zonal Education Offices in Zones 80

4.14 Mean and Standard deviation for all variables 83

4.15 Pearson Product Moments Correlation Matrix 85

4.16 Multiple Regression Analysis 86 


\section{Appendices}

Appendix 1

Questionnaire-1 (English) 104-109

Questionnaire-2 (Tamil) 110-114

Appendix $2 \quad$ Output of the analysis

Title Page number

$\begin{array}{lll}2.0 & \text { Frequency Tables } & 115-117\end{array}$

$\begin{array}{lll}2.1 & \text { Bar charts } & 118-123\end{array}$

2.2 $\quad$ Multiple regression analysis $\quad 124-127$ 


\section{Chapter-1}

\section{Introduction}

\subsection{Introduction}

Commitment of employees can be an important instrument for improving the performance of the organizations. They are less likely to leave for another job and are more likely to perform at higher levels. Organizational commitment is the relative strength of an employee's attachment or involvement with the organization where he or she is employed.

Meyer and Allen (1991) and Dunham et al (1994) identified three types of commitment; affective commitment, continuance commitment, and normative commitment. Affective commitment is defined as the emotional attachment, identification, and involvement that an employee has with its organization and goals (Mowday et al, 1997, Meyer\& Allen, 1993; O'Reily \& Chatman). Porter et al (1974) further characterize affective commitment by three factors (1) "belief in and acceptance of the organization's goals and values, (2) a willingness to focus effort on helping the organization achieve its goals, and (3) a desire to maintain organizational membership". Mowday et al (1979) further state that affective commitment is "when the employee identifies with a particular organization and its goals in order to maintain membership to facilitate the goal" (p.225). Meyer and Allen (1997) continue to say that employees retain membership out of choice and this is their commitment to the organization.

Continuance commitment is the willingness to remain in an organization because of the investment that the employee has with "nontransferable" investments. Nontransferable 
investments include things such as retirement, relationships with other employees, or things that are special to the organization (Reichers, 1985). Continuance commitment also includes factors such as years of employment or benefits that the employee may receive that are unique to the organization (Reichers, 1985). Meyer and Allen (1997) further explain that employees who share continuance commitment with their employer often make it very difficult for an employee to leave the organization.

Normative commitment (Bolon, 1993) is the commitment that a person believes that they have to the organization or their feeling of obligation to their workplace. In 1982, Weiner discusses normative commitment as being a "generalized value of loyalty and duty". Meyer and Allen (1991) supported this type of commitment prior to Bolon's definition, with their definition of normative commitment being "a feeling of obligation". It is argued that normative commitment is only natural due to the way we are raised in society. Normative commitment can be explained by other commitments such as marriage, family, religion, etc. therefore when it comes to one's commitment to their place of employment they often feel like they have a moral obligation to the organization (Wiener, 1982).

Meyer, Allen, \& Smith (1993) say that the three types of commitment are a psychological state "that either characterizes the employee's relationship with the organization or has the implications to affect whether the employee will continue with the organization". Meyer et al (1993) continue to say that generally the research shows that those employee's with a strong affective commitment will remain with an organization because they want to, those with a strong continuance commitment remain 
because they have to, and those with a normative commitment remain because they fell that they have to. Meyer \& Allen (1997) define a committed employee as being one "stays with an organization, attends work regularly, puts in a full day and more, protects corporate assets, and believes in the organizational goals". This employee positively contributes to the organization because of its commitment to the organization.

Research on commitment outcomes examines whether the different components of commitment have certain consequences. Employee retention, attendance, organizational citizenship, and job performance are commitment outcomes that are widely studied. Reichers (1985) says that "though the literature is fairly clear with respect to the outcomes of commitment, the antecedents of commitment seem to be much more varied and inconsistent...due to the several different ways in which commitment has been defined and operationalzed" (p. 467). Various research studies take place examining the outcomes of employee commitment.

Employee attendance is the most positively related outcome to affective commitment. Steers (1997) found that employee commitment was highly related to the attendance of workers. Gellatlly (1995) found that continuance commitment was related with the how often an employee was absent. In a study examining a group of nurses Somers (1995) found those nurses with lower levels of commitment had higher levels of absences. Blau and Boal (1987) studied a group of insurance workers also found that those employees who had higher levels of commitment had lower levels of absenteeism and turnover. Retention of employee appears to be one of the most studied outcomes of organizational commitment. This is due to the numerous studies which have found a correlation 
between turnover and commitment (Porter et al, 1974; Meyer \& Allen, 1997). Porter et al (1974) found that employees with lower levels of commitment were more likely to leave then their counterparts. Meyer and Allen (1997) argue that the different components of commitment relate to different types of outcomes, therefore continuance commitment may or may not relate to employee performance.

In regards to employee performance, the research is mixed on finding relationships between employee performance and their levels of commitment. Meyer et. Al (1993) and Baugh \& Roberts, (1994) both find that committed employees had high expectations of their performance and therefore performed better. However, Meyer \& Allen (1997), continue to describe reasons why performance and commitment may not be related. Some of the factors include the seriousness with which supervisors value the appraisal process, the value of job performance by an organization and the amount of employee control over outcomes. Research has also found that those employees who are committed to their profession also have higher levels of commitment to the organization. Baugh and Roberts (1994) found that those employees who were committed to both their organization and their profession had high levels of job performance.

Citizen behavior, or extra-role behavior, has also been studied in regards to organizational commitment. Once again the research is inconclusive about the relationship between citizen behavior and organizational commitment due to the contradicting findings. For example, Meyer et al (1993) found a positive relationship between commitment and extra role behavior, while Van Dyne \& Ang, (1998) found no 
significance between the relationships. Other studies have found that there was a negative relationship between commitment and citizen behavior (Shore and Wayne, 1993).

Organizational commitment refers to the psychological attachment of workers to their workplaces (Allen \& Meyer, 1990; O’Reiily \& Chatman, 1986). Commitment to organizations is positively related to such desirable outcomes as job satisfaction (Bateman \& Stasser, 1984; Mowday, Porter, \& Steers, 1982), motivation (Mowday, Steers, \& Porter, 1979), and attendance (Mathieu \& Zajac, 1990; Steers \& Rhodes, 1978) and negatively related to such outcomes as absenteeism and turnover (Clegg, 1983; Cotton \& Tuttle, 1986). Also, Horton stated that stronger commitment could result in less turnover and absenteeism, thus increasing an organization's productivity (Schuler \& Jackson, 1996, p. 302). However, the relationship between organizational commitment and job performance is more tenuous (Becker, Billings, Eveleth, \& Gilbert, 1996). For instance, Mathieu and Zajac's (1990) Meta analysis showed that the confidence interval around the mean correlation between organizational commitment and performance included zero. Thus, they concluded "commitment has relatively little direct influence on performance in most instances" (1990:184). Because organizational commitment is an important determinant of the experience work and central to understanding and managing organizational behavior (George \& Jones, 1996, p.67).

Affective commitment has been found to be positively correlated with job challenge, degree of autonomy, and skill diversity of employees (Mathieu and zajac 1990; Dunham, grube and Castaneda 1994), participation, leader consideration and 
supervisory support (Rhodes and steers 1981; decottis and summers 1987; mottaz 1988). Studies have also shown that affective commitment is negatively related to role ambiguity or role conflict (Mathieu and zajac 1990).

Strong normative commitment is attracted to the organization by feelings of obligation and duty. Thus, it is anticipated that normative commitment will be positively related to such work behavior as job performance, work attendance, and organizational citizenship (Emanuel Camilleri, 2002).Normative commitment might have a particularly important impact on the manner in which the work is carried out.

Continuance commitment, which reflects the recognition of costs associated with leaving the organization, should be related to anything that increases perceived costs. Direct or indirect investments in the organization, side bets, represent such costs best, and were operationalized mainly by variables like age, education, and tenure (Becker, 1960). Therefore, the above demographic variables and tenure are expected to demonstrate the strongest relationship with continuance commitment. Meyer et al. (1989) found a negative relationship between continuance commitment and performance based on the expectation that people who feel 'Stacked' in an organization will not exert too much effort. Research has shown that the variable continuance organizational commitment has two dimensions: 'personal sacrifices' and 'high alternatives' (Hackett, Bycio and Hausdorf, 1994; McGee and Ford, 1987; Somers, 1993). There is little research on antecedents of the two dimensions of continuance commitment. The theoretical rationale behind the two constructs suggests that 'personal sacrifices' will be related to variables that represent side bets, namely investments that 
might be lost if one leaves the organization. Demographic variables such as age and tenure are considered good indicators of such side bets (Becker, 1960). For example, older and veteran employees will hesitate to leave the organization so as not to lose pension plans or other accumulated benefits. Conceptually, the 'low alternatives' dimension represents a construct similar to withdrawal cognitions, and thus is expected to relate to situational variables affecting stay/leave factors like job satisfaction, perceived performance, or job tension. Affective commitment correlated positively, while continuance commitment correlated negatively, with the performance of lowerlevel managers in a large food service company (Meyer et al. 1989).

According to Mathiew and Zajac (Mayer \& Schooman 1998) has revealed that commitment in the organization is positively related to job performance.

Public sector workers are partly portrayed as highly motivated and with relatively altruistic values, and partly as lazy and opportunistic (Arne Mastekaasa, 2004). Rukshana Nanayakkara (2009) identified the problem in education sector in Sri Lanka. Such as, unqualified persons perform teachers' roles in the absence of regular teachers. This is despite sufficient qualified teachers being available in the country. In 2007, 209,198 teachers were employed in 9,678 schools, at a teacher-pupil ratio of 1:19. Yet remote schools experience a dearth of teachers. Volunteers often fill the void, sometimes paid by parents, in other instances minor staff or Samurdhi assistants were reportedly working as teachers.

In-service advisors are appointed to Zonal Education Offices with the aim of improving quality of teaching in schools. However, there are allegations that they frequently 
engage in other activities such as providing paid private tuition to pupils during their working hours. Almost half of the teachers interviewed for the study stated that inservice advisors and subject directors are more of a problem than a solution. Also, the position of in-service advisors in the administrative hierarchy does not seem to be clear neither to the directors, some of whom refuted the suggestions that they come under supervision of the zonal director, nor to the zonal directors, some of whom apparently did not know about or did not want to exercise their authority over the advisors.

Under circular 2000/34 of the Ministry of Education, appointments of acting principals are prohibited. Yet appointments of performing principals outside the regulation of the Principals' Service seem to be rampant, while qualified applicants apparently are not being offered jobs. According to the Ceylon Teachers Union, half of Sri Lanka's 9,728 schools are currently headed by performing principals; most of them are recruited from the teachers' body without having sat for the relevant examination of the Principals' Service. In addition, lengthy processes seem to result in a systematic delay of appointments of regular principals. This malpractice is mirrored in the public perception. Survey findings reveal that $56 \%$ of teachers and $62 \%$ of officers agree that political appointments of performing principals are a type of corruption. Again, this practice seriously impacts on the quality of teaching, not only by bringing unqualified people into the public service, but also by affecting the morale and motivation of regularly appointed principals.

The National Teacher Transfer Policy of 10 December 2007 clearly spells out the criteria for teacher transfers. An institutional framework has been set up to implement 
the policy, with the National Transfer Board in charge of transfers in the 329 national schools, and the Provincial Transfer Boards in charge of transfers in the provincial schools. At zonal level, Teacher Transfer Committees are supposed to co-ordinate teacher transfers within the zone to ensure that schools get the teachers they need. However, this framework does not appear to be adhered to. Use of undue influence seems to be a common phenomenon in teacher transfers, with connections to politicians and officers being the most important criteria for transfer. $85 \%$ of teachers and $90 \%$ of officers interviewed in the study said that teacher transfers are affected through politicians rather than the transfer criteria, and $66 \%$ of teachers as well as $86 \%$ of officers say that premature transfers to better-off urban areas are done through political intervention. Teachers without political clout spend years in remote rural areas without getting a chance for a transfer to urban areas whereas others successfully avoid getting posted to distant areas. Besides demotivating teachers, this practice has a serious impact on equity in education, and further entrenches the quality gap between rural and urban schools, leaving remote schools at a disadvantage. Taking these things into consideration it leads to low level of commitment and job performance of employees in the organization.

Education encompasses both the teaching and learning of knowledge, proper conduct, and technical competency (Wikipedia, the free encyclopedia, 2008). It thus focuses on the cultivation of skills, trades or professions, as well as mental, moral and aesthetic development. Formal education consists of systematic instruction, teaching and training by professional teachers. There is an array of educational opportunity in the informal sphere- for this reason; society subsidizes institutions such as museums and libraries. Informal education also includes knowledge and skills learned and refined during the 
course of life, including education that comes from experience in practicing a profession. (Wikipedia, the free encyclopedia, 2008).

Consequent to the de-merger of Northern and Eastern Provincial Councils, the Eastern Provincial Council has been established at the original location of Northern and Eastern Provincial Councils in 2007. The Eastern Province comprises the administrative districts of Ampara, Batticaloa and Trincomalee. The Three administrative districts of this province comprised 45 Divisional Secretariat divisions. The province combined has a total area of 9698 sq. $\mathrm{km}$ including 390 sq. $\mathrm{km}$ of inland water. This province has a multi ethnic, multi lingual and multi religious population.

The provincial Ministry of Education is the supreme administrative body of education in the province. The provincial department of education is responsible for the administration and implementation of education activities in the Eastern Province. The ministry and provincial department of education has a net work of 13 educational zonal offices, 45 divisional education offices. A zonal director of education administrates each zone and a divisional education officer manages each division. There are 1015 schools in this province (Ministry of Education, (2007) Out of this 988 schools come under the purview of the provincial education authorities and rest of the 27 national schools function under the national schools unit of the line ministry of education. The coordination functions of the national schools in performed by the provincial department.

The Zonal Education Office, headed by a Zonal Director, is responsible for administrative work of the schools and teachers in the Zone as well as quality 
improvement of teaching and learning in schools. For quality improvement in education the Zonal office has subject specialists in different subject areas who are responsible for supervision and improvement of quality of teaching. (Ministry of Education, 2007)

Prevailing problem in Educational Officers are some of the principals close their schools before the scheduled time. Moreover teachers are reluctant to work in rural areas. (Sectoral Committee Meeting, 2007). Many zonal directors are not in their seats during duty time and in some places they close their offices before $4 \mathrm{pm}$. (Sectoral Committee Meeting, 2006). Neither do the zonal directors send the monthly supervision statement to their superiors. (Sectoral Committee Meeting, 2007). Taking these things into consideration low level of employee may lead to negative results and undermine the normal functioning of an organization. The low employee commitment has a number of disadvantages such as decrease the effectiveness and productivity of work, absenteeism and turnover, which deteriorate the work of each employee and the entire organization. Naturally, in such a situation, they can hardly be interested in a positive performance of the organization they work at.

\subsection{Problem Statement}

As discuss above researcher can see the low level of commitment in Zonal Education Officers. Therefore the problem to be addressed in this research is: "Whether there is a relationship between the commitment and job performance of employees in the Zonal Education Officers in the Eastern Province in Sri Lanka?" 


\subsection{Research Questions}

This research will attempt at finding the answer to the following research questions.

1. Is the employee affective commitment positively related to the job performance of Zonal Education Officers in the Eastern Province?

2. Is the employee normative commitment positively related to the job performance of Zonal Education Officers in the Eastern Province?

3. Is the employee continuance commitment negatively related to the job performance of Zonal Education Officers in the Eastern Province?

4. What commitment has the highest impact on job performance of Zonal Education Officers in the Eastern Province?

5. What ate the strategies that can be adopted to improve the job performance through the improvement of employee commitment of the Zonal Education Officers in the Eastern Province?

\subsection{Objectives}

The objectives of the study are as follows;

1) To find out the Relationship between employee commitment and job performance.

2) To examine the impact of the different level of commitment on job performance.

3) To recommend suitable strategies to improve the job performance through employee commitment. 


\subsection{Significance of the Study}

There is a dearth of literature in the Sri Lankan context, as research has not addressed this topic in relation to the Eastern Province of Sri Lanka previously. So this research is important to find out the degree of relationship between the commitment and job performance of employees in the Zonal Education Officers in the Eastern Province.

Public sector employees may have different relationship with commitment and job performance and this would be interesting to see what the research would find. Finding of the research will enable the Zonal Education Officers to make necessary alteration or to take corrective action in their services, which assist them in reaching best service in the education sector.

\subsection{Scope of the Study}

Research focuses on two main concepts, namely employee commitment and job performance. Employee commitment will be assessed in relation to affective commitment, normative commitment and continuance commitment. Job performance will be assessed in terms of traits, behaviors and results. According to those concepts this research has narrowed down to job performance caused by employee commitment. This research is conducted mainly in relation to public education sector in Sri Lanka. Special concern is given to the Zonal Education Officers in the Eastern Province. Only 276 samples were selected for the research purpose. It consists of zonal directors, principals and advanced level teachers who involve in teaching advanced level students. 


\subsection{Limitations}

- Responses to the questions might not be genuine and frank due to the various reasons, such as personal attitudes and confidently.

- Limited numbers of questions are included to measure the level of commitment and job performance due to practical reasons.

\section{$1.8 \quad$ Structure of the Reports}

Chapter 1:- Introduction

This briefs the concepts of job commitment of employees and job performance. Further it provides an introduction to the Education Sector of Eastern Province. The last part of the chapter is devoted to explain the research problems, research questions, research objectives, scope of the study and limitations of the research.

Chapter 2:- Literature Review

Describes the types of commitment and job performance of the employees in the organization. And also it explains how previous research studies support and proves the relationship of between the two concepts.

Chapter 3:- Conceptualization and Methodology

This chapter will explain the conceptual framework, operationalization, sampling method, method of analysis and hypothesis. 
Chapter 4:- Data analysis and Discussion

This chapter is devoted to sample description, data validity and reliability, correlation analysis, multiple regression analysis and hypothesis testing.

Chapter 5:- Conclusion

This chapter presents the finding and recommendations. 


\section{Chapter-2}

\section{Literature Review}

\section{$2.1 \quad$ Introduction}

This chapter is related to literature review. It consists of two parts. The first part of the chapter is devoted to definition of organizational commitment and job performance, types of commitment, benefits of commitment, lack of commitment, consequences of commitment and dimension and aspects of the commitment and job performance. Secondly it explains the related research on organizational commitment and job performance and relationship between the commitment and job performance.

\subsection{Theories}

It consists of related theories on organizational commitment and job performance.

\subsubsection{Commitment}

Organizational commitment has an important place in the study of organizational behavior. This is in part due to the vast number of works that have found relationships between organizational commitment and attitudes and behaviors in the workplace (Porter et al., 1974, 1976; Koch and Steers, 1978; Angle and Perry, 1981). Furthermore, Batemen and Strasser (1984) state that the reasons for studying organizational commitment are related to "(a) employee behaviors and performance effectiveness, (b) attitudinal, affective, and cognitive constructs such as job satisfaction, (c) characteristics of the employee's job and role, such as responsibility and (d) personal characteristics of the employee such as age, job tenure". 
Multiple definitions of organizational commitment are found in the literature. Bateman and Strasser, 1984 state that organizational commitment has been operationally defined as "multidimensional in nature, involving an employee's loyalty to the organization, willingness to exert effort on behalf of the organization, degree of goal and value congruency with the organization, and desire to maintain membership". Mowday, Steers, and Porter (1979) identified commitment-related attitudes and commitmentrelated behaviors. Porter et al. (1974) Schultz, discuss three major components of organizational commitment as being "a strong belief in and acceptance of the organization's goals, a willingness to exert considerable effort on behalf of the organization, and a definite desire to maintain organizational membership". Sheldon (1971) defines commitments as being a positive evaluation of the organization and the organizations goals. According to Buchanan (1974) most scholars define commitment as being a bond between an individual (the employee) and the organization (the employer).

\subsubsection{Organizational Commitment}

Organizational commitment is employee's commitment to the organization. It has two facets; one the organization's perspective and the other employee's. Commitments develop naturally. Commitment can be in form of the nature of relationship between an employee and the organization or relationship to a variety of entities. Commitment can be observed as an attitude or mindset (attitudinal commitment) where the commitment arises due to convergence of goals and values and develops prospectively. Commitment can be behavioral where it develops post membership in retrospect which facilitates rationalization of continuance in an organization or a course of action. 
Organizational commitment has been defined as "a psychological state that characterizes an employee's relationship with an organization and has implications for the decision to continue membership of the organization" (Meyer and Allen 1991).

There are three components of organizational commitment.

1. Affective commitment refers to employee's identification, or strong emotional attachment and involvement in the organization.

2. Continuance commitment refers to an awareness of the costs associated with leaving the organisation.

3. Normative commitment reflects an obligation to continue with the organisation.

Although, initially literature suggested the presence of a second classification of commitment in form of compliance, identification and internalization (O'rielly, Chatman and Caldwell 1991); it is now considered that identification and internalization are mechanisms through which commitment develops (Meyer and Allen 1997). Thus commitment is a multidimensional construct.

Usually Commitment is viewed as commitment to an organisation represented by the top management and its goals and values (Meyer and Allen 1997; reichers 1986). However commitment can be to multiple entities since organisations can be viewed as a coalition of groups and the groups can be nested (Lawler 1992). This multiple constituency frame work is useful if the intention is to measure commitment to a set of groups in an organisation. Commitment as a construct is distinct from other work commitment constructs such as job involvement, work ethic, work group attachment etc (Meyer, Allen and Smith 1993). 


\section{There are certain elements which lead to employee's commitment. These elements}

are:

1. Commitment is an attitude:-

Commitment is an attitude a psychological frame of mind which motivates people to work towards certain goals. So for a commitment to exist in a person they must have a positive attitude. Negative attitude is one of the major reasons for non-committrd approach. It will be necessary to mention here that one of the toughest jobs is to change people's attitude. Managers can train employees with new skills and impart them with new knowledge but quite often than not they find it extremely difficult to effect changes in people's attitude.

\section{Use of resources:-}

Committed people to use their total resources, which include going extra mile for achieving goals assigned to them. According to Dennis G. MacCarthy (1993) the author of the best seller book" The Loyalty Link" most employees give 60 percent of their time and attention for their jobs. It is enough to do what must be done in most cases. But to achieve excellence employees need to give $100 \%$ commitment. For example, if an employee who drives a delivery truck, all that he ought to know the customer address and the number of the cartons for delivery. An ordinary driver will deliver it at the doorstep. However committed drivers will not just dump them at the door step, rather they will go an extra mile of helping the customer to take it inside the store. That extra 40 percent effort is called discretionary effort, which can be called commitment. 


\section{Achievement of goals:-}

The third dimension of commitment is goal orientation. Committed people not only work hard but also are also smart enough to know the ultimate results, which are expected of them. Commitment thus means striving till the achievement of ultimate goals.

In addition to the three major elements that account for employees' commitment the following other qualities are commonly found in committed employees.

1. Understanding and total support to the company's vision and goals:Committed employees understand, share and support the company's vision and goals and consistently try towards achieving them. It will be a mistake to call a person committed just because the person is staying in the company. If the same person does not share the company's aspirations and goals, he cannot be called a committed person. In fact it will be good for the company that he leaves the company, so that the company will be a able to replace him and hire a better person.

2. Consider their company as a good place to work in:-

Another criterion for employees' commitment is their perception of the company they work for. If they find their company as one of the best places to work in they will be urged to work longer and stay in the company.

\section{Positive and "can do" attitude:-}

Positive attitude is one of the greatest qualities of people as it inspires them to work harder and smarter. Positive attitude towards one's company's goals, bosses, fellow employees can also enhance a person's commitment. 


\section{Customers focus:-}

Customers are the most important people who should be the priority of everyone in the organization. Employees must do everything to serve customers, which in turn will lead to satisfied customers. At the end of the day customers satisfaction counts more than any other thing and by focusing their efforts towards customers satisfaction employees can accomplish this goal. In essence real commitment means having a customer focus, which include producing goods and services which meet or exceed customer's satisfaction.

5. Seeking continuous improvement:-

Lastly, another factor which entitles employees to be called "committed" is their desire to seek new knowledge, skills and attitudes which help them and their companies in getting excellent results. An organization consists of its people and if people do not renew their capabilities it can lead to their demise.

\section{Benefits of Commitments}

1. The key to excellence:-

Commitment is the key for achieving excellence. In fact with commitment excellence is predictable in business, personal and other areas and without it failure and mediocrity is predictable. No business, organization or person can dream of excellence without total commitment. So to inspire people to achieve excellence we have to fist gain their total commitment. 
2. Make things happen:-

The hardest step in achieving excellence is commitment, without which nothing can happen. So to make things happen a company needs employees who are committed and loyal.

\section{Leads to loyalty:-}

Committed employees will stay loyal with the companies than those who are not committed. The main reason is their desire to complete the things they start and grow along with the company. Non-committed people on the other hand are just killing time and the moment they spot a better opportunity elsewhere they would quit the existing company.

\section{Job satisfaction:-}

One of the major dissatisfies for people is not achieving result they work for. And no one can achieve any good result without total commitment. So when a person is committed he/she achieves better results which in then positively reinforces their ego and thus leads to job satisfaction. And job satisfaction is one of the key drivers for people to work harder and stay longer in their companies.

\section{Commitment leads to better customer satisfaction:-}

Committed employees go the extra mile to satisfy customers. This leads to loyal customers and loyal customers' means good business. In fact according to a research loyal customers are more profitable than new customers. 


\section{Factors indicate the causes of lack of employee commitment:}

\section{Poor reward and recognition:-}

People will not feel like doing their best and will settle for mediocrity when they feel that their employers' commitment in terms of reward and recognition is lacking. Commitment is a mutual phenomenon when employers what to get the best from their employees and do not reciprocate it with proper reward and recognition people will not give their commitment.

\section{Dead-end jobs:-}

Work, which does not offer opportunities for growth and promotion, is one of the greatest reasons for employees' de-motivation and non-commitment. A recent study carried out by " The Loyalty Institute " of AON consulting in USA found out that jobs which deprive employees from self development and growth opportunities leads to high dissatisfaction and employees disloyalty.

\section{Managing by intimidation:-}

Mistreating people, and managing them by threats, screams and embarrassment also leads to employee's dissatisfaction, which in turn weaken their commitment. In a best seller book " The Loyalty Link" Dennis G. McCarthty has identified managing by intimidation as one of the seven ways which undermine employees loyalty.

\section{Negative working environment:-}

Non-acceptance by colleagues, poor cooperation too much politics, and other negative behaviors by colleagues, supervisors and other people in the company can also hamper 
commitment. At the end of the day people want piece of mind, which if not available in the work environment will discourage them to show total support to its company.

\section{No job security:-}

One of the major needs of employees is job security. If the employee feels that he/she can lose his/her job anytime then they would not be committed towards the achievement of the company.

\section{Negative attitude:-}

Some people by nature are not committed to anything and anyone and as such they would not be committed to their employer. Commitment is an attitude and those who lack it will find it difficult to totally commit themselves to their jobs.

\subsubsection{Types of Employee Commitment}

The concept of employment commitment lies at the heart of any analysis of Human Resource Management. Indeed, the rationale for introducing Human Resource Management policies is to increase levels of commitment so positive outcomes can ensue; such is the importance of this construct. Yet, despite many studies on commitment, very little is understood of what managers mean by the term 'commitment' when they evaluate someone's performance and motivation. The literature defines commitment as an employee's level of attachment to some aspect of work. Various authors have been instrumental in identifying types of employee commitment as critical constructs in understanding the attitudes and behaviors of employees in an organization. 
A three-component conceptualization of organizational commitment In a model of commitment developed recently by Meyer \& Allen (1987)., the three approaches outlined above were labeled 'affective', 'continuance' and 'normative' commitment, respectively. Although common to these approaches is a link between the employee and organization that decreases the likelihood of turnover, it is clear that the nature of that link differs. Employees with strong affective commitment remain because they want to, those with strong continuance commitment because they need to, and those with strong normative commitment because they feel they ought to do so. Affective, continuance and normative commitment are best viewed as distinguishable components, rather than types, of attitudinal commitment; that is, employees can experience each of these psychological states to varying degrees. Some employees, for example, might feel both a strong need and a strong obligation to remain, but no desire to do so; others might feel neither a need nor obligation but a strong desire, and so on. The 'net sum' of a person's commitment to the organization, therefore, reflects each of these separable psychological states. Given their conceptual differences, it seems reasonable to suggest that each of the three components of commitment develop somewhat independently of the others as a function of different antecedents. It has been suggested (Mowday etal., 1982) that the antecedents of affective attachment to the organization fall into four categories: personal characteristics, job characteristics, work experiences and structural characteristics. As Meyer \& Allen (1987) pointed out, however, the strongest evidence has been provided for work experience antecedents, most notably those experiences that fulfill employees' psychological needs to feel comfortable within the organization and competent in the work-role. It is proposed that the continuance component of organizational commitment will also develop on the basis of two factors: the magnitude 
and/or number of investments (or side-bets) individuals make and a perceived lack of alternatives. These predictions derive from the theoretical work of Becker (I960) and Farrell \& Rusbult (1981; Rusbult \& Farrell, 1983). According to Becker, individuals make side-bets when they take an action that increases the costs associated with discontinuing another, related, action. Consider, for example, employees who invest considerable time and energy mastering a job skill that cannot be transferred easily to other organizations. In essence, they are 'betting' that the time and energy invested will pay off. Winning the bet, however, requires continued employment in the organization.

According to Becker, the likelihood that employees will stay with the organization will be positively related to the magnitude and number of side-bets they recognize. Like investments, the lack of employment alternatives also increases the perceived costs associated with leaving the organization (Farrell \& Rusbult, 1981; Rusbult \& Farrell, 1983). Therefore, the fewer viable alternatives employees believe are available, the stronger will be their continuance commitment to their current employer. Finally, it is proposed that the normative component of organizational commitment will be influenced by the individual's experiences both prior to (familial/cultural socialization) and following (organizational socialization) entry into the organization (Wiener, 1982). With respect to the former, we might expect, for example, that an employee would have strong normative commitment to the organization if significant others (e.g. parents) have been long-term employees of an organization and/or have stressed the importance of organizational loyalty. With respect to organizational socialization, it is proposed that those employees who have been led to believe - via various organizational practices - that the organization expects their loyalty would be most likely to have strong normative commitment to it. 


\section{$>\quad$ Affective commitment}

Employees' emotional bond to their organization (i.e.., their affective commitment (AC)) has been considered an important determinant of dedication and loyalty. Affectively committed employees are seen as having a sense of belonging and identification that increase their involvement in the organization's activities, their willingness to pursue the organization's goals, and their desire to remain with the ollen, 1991;Mowday, Porter \& Steers, 1982). In agreement with this view, studies have found associations between $\mathrm{AC}$ and absenteeism, performance, and turnover (Mathieu \& Zajac, 1990; Meyer \& Allen, 1997; Mowday et al., 1982), with turnover being most strongly related to AC ( Meyer \& Allen, 1997). Concerning antecedents of AC, Meyer and Allen (1997,p.45) noted that work experiences such as organization rewards, procedural justice, and supervisor support have demonstrated stronger association with AC than have structural features of the organization or personal characteristics of employees.

\section{Antecedents of affective commitment:}

These can be classified as organizational characteristics; person characteristics and work experience. Generally it has been seen that, employees in forming attitudes about organisations are more tuned to day to day work experiences and are less focused to macro variables.

Although some studies have shown decentralization to result in higher affective commitment, however the evidence is neither strong nor consistent (Mathieu and Zajac 1990). Significant positive correlation has been reported between perceptions of fairness (organisational justice) and affective commitment (Kim and Mauborgne 1993). 
Research on person characteristics has shown that gender, marital status and educational achievements and affective commitment are unrelated (Mathieu and zajac 1990). A weak positive relation with age, organisational tenure and perceived competence has also been reported (Mathieu and zajac 1990).

Affective commitment has been found to be positively correlated with job challenge, degree of autonomy, and skill diversity of employees (Mathieu and zajac 1990; Dunham, grube and Castaneda 1994), participation, leader consideration and supervisory support (Rhodes and steers 1981; decottis and summers 1987; mottaz 1988). Studies have also shown that affective commitment is negatively related to role ambiguity or role conflict (Mathieu and zajac 1990).

\section{$>\quad$ Normative Commitment}

Normative commitment (Bolon, 1993) is the commitment that a person believes that they have to the organization or their feeling of obligation to their workplace. In 1982 , Weiner discusses normative commitment as being a "generalized value of loyalty and duty". Meyer and Allen (1991) supported this type of commitment prior to Bolon's definition, with their definition of normative commitment being "a feeling of obligation". It is argues that normative commitment is only natural due to the way we are raised in society. Normative commitment can be explained by other commitments such as marriage, family, religion, etc. therefore when it comes to one's commitment to their place of employment they often feel like they have a moral obligation to the organization (Wiener, 1982). 


\section{Antecedents of Normative Commitments:}

Based on the extensive literature review, hundreds of studies examined the antecedents of the normative commitment. The wide range of the antecedents of commitment can be grouped into three categories: (i) personal characteristics, e.g., professional qualification, identification, acceptance, belongingness, internalization, etc.; (ii) Taskrelated characteristics, e.g., task nature, role difficulty and assessment; and (iii) organizational characteristics, e.g., senior supportiveness, centralization of authority and clarification (Mathieu and Zajac 1990).

\section{$>\quad$ Continuance Commitment}

Continuance commitment is the willingness to remain in an organization because of the investment that the employee has with "nontransferable" investments. Nontransferable investments include things such as retirement, relationships with other employees, or things that are special to the organization (Reichers, 1985). Continuance commitment also includes factors such as years of employment or benefits that the employee may receive that are unique to the organization (Reichers, 1985). Meyer and Allen (1997) further explain that employees who share continuance commitment with their employer often make it very difficult for an employee to leave the organization.

\section{Antecedents of Continuance Commitment:}

Continuance commitment refers to commitment based on the costs that the employee associates with leaving the organisation [due to the high cost of leaving]. Potential antecedents of continuance commitment include age, tenure, career satisfaction and intent to leave. Age and tenure can function as predictors of continuance commitment, primarily because of their roles as surrogate measures of investment in the organisation. 
Tenure can be indicative of non-transferable investments [close working relationship with coworkers, retirement investments, career investments and skills unique to the particular organisation]. Age can also be negatively related to the number of available alternative job opportunities. Career satisfaction provides a more direct measure of career related investments, which could be at risk if the individual leaves the organisation. In general, whatever employees perceive as sunk cost, resulting from leaving the organisation, are the antecedents of continuance commitment.

\subsubsection{Relationship between the Organizational Commitment and Job Performance}

Most of the empirical studies have concentrated on the effects of affective commitment and some on continuance commitment. Research on affective commitment has been the least (Meyer and Allen 1997). Research evidence shows that all the three components of commitment are negatively related to employee turnover, intention to leave (Allen and Meyer 1996). Affective commitment has been found to be negatively correlated to voluntary absence from work (Meyer et al 1993; Somers 1995); positively related to better work performance as measured by both self reported measures( Meyer et al 1993) and objective measures( bashaw and grant 1994). Employees have been shown to focus their commitment to activities which they believe to be valued by organisation (as indicated by information put out by organisations) or are valuable to organisation (shim and steers 1994). The effect of commitment on performance is only to the extent that it is unconstrained by ability (competence) or access to resources (angle and Lawson 1994) and control over outcomes (decottis and summers 1987). Continuance commitment has been shown to have no significant relationship with voluntary absence from work (Somers 1995). 
Commitment has usually been studied as an individual level variable. Studies have also looked at commitment as an organisation/ group level variable. Ostroff (1992) showed that aggregation of commitment scores of individuals is meaningful when there has been consensus among members of the group. The correlation between commitment at group level and performance has shown to be stronger than what was seen at individual level. Such aggregation is more appropriate when performance is a result of highly interdependent activities of individuals (ostroff 1993).

People with high affective commitment have been shown to actively do extra role or organisational citizenship behaviors. These behaviors go over and above work related behavior as dictated by job description and organisational policy. They include providing extra help to co workers, being considerate, volunteering for special activities, and making suggestions when problems arise (Meyer and Allen 1997).

Commitment has been found to be related to the way employees respond to dissatisfaction at work. High affective commitment was positively correlated to with willingness to suggest improvements, accept things as they are and negatively correlated with tendency to withdraw (Meyer et al 1993).

The results of several investigations indicate that employees with strong Affective Commitment work harder and more effectively at their jobs than employees with weak affective Commitment ( Johnston and Snizek, 1991; see Meyer and Allen, 1997, for a review; Meyer, Allen, and Smith, 1993). For example, Meyer and Allen (1997) found positive relationships between Affective Commitment and self-reported measures of overall job performance. To a lesser extent, this relationship has also been found for Normative Commitment; however, substantially fewer studies have examined this 
relationship (Allen and Meyer, 1996; Dunham, Grube, and Casteneda, 1994; Meyer, Allen, and Smith, 1993). Finally, research on Continuance Commitment shows few positive relationships with self-reported measures of on-the-job behaviors (Angle and Lawson, 1994; Meyer, Allen, and Smith, 1993).

\subsubsection{The Consequences of Commitment}

The most widely studies behavioral correlate of commitment has been tenure in the organization, or its observe, turnover. The hypothesized negative relations between commitment and turnover ( or turnover intention) has been found in studies using measures purported to reflect affective and normative commitment. The generalizability of the commitment has been -turnover link has been confirmed in recent meta-analytic studies (Cotton \& Tuttle 1986; Steel \& Ovalle 1984). In view of this evidence, commitment has been incorporated as a major variable in several models of the turnover process.

Research conducted to examine the link between commitment and on the job behavior has yielded mixed results. Commitment was found, for example to be positively related to attendance behavior in some studies (Blau 1986; Farrell \& Petersen 1984, Pierce \& Dunham 1987; Steers 1977; Terborg, Lee, Smith, Davis, \& Turbin 1982) but not in others. Similarly commitment was shown to correlate positively with individual-or group level indices of performance in some studies. Employees willingness to contribute to organizational effectiveness will be influenced by the nature of the commitment they experience. Consider for example the relation between continuance commitment and turnover. Although a high level of continuance commitment might be sufficient to tie an individual to an organization, it is not necessarily the case that an 
individual low in continuance commitment will leave. Despite a low need to remain, an employee might stay because of desire or obligation.

\subsection{Employee Job Performance}

Performance management is an ongoing, continuous process of communicating and clarifying job responsibilities, priorities and performance expectations in order to ensure mutual understanding between supervisor and employee (Virginia University Human Resource Services, 2005). It is a philosophy which values and encourages employee development through a style of management which provides frequent feedback and fosters teamwork. It emphasizes communication and focuses on adding value to the organization by promoting improved job performance and encouraging skill development. Figure 2.1 explain the Performance Management involves clarifying the job duties, defining performance standards, and documenting, evaluating and discussing performance with each employee. (Virginia University Human Resource Services,2005)

Figure 2.1: Employee Job Performance Process

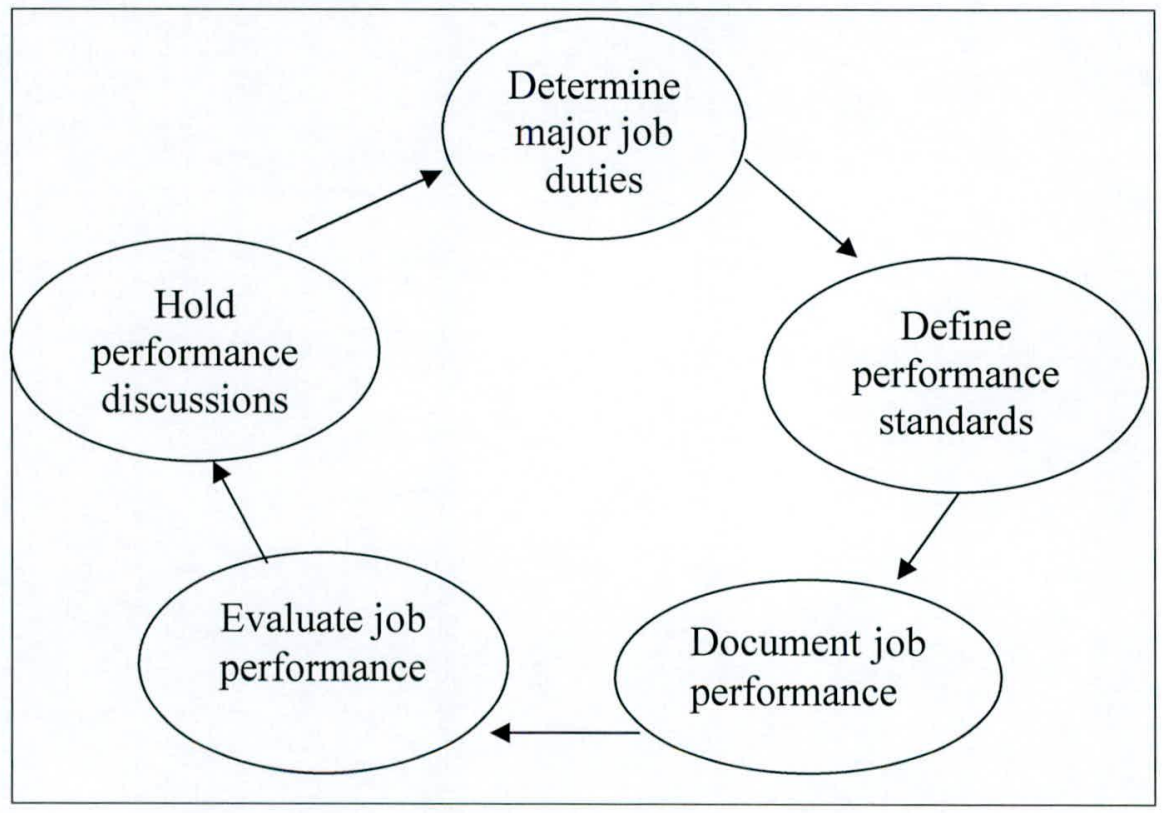

Source: Virginia University Human Resource Services, 2005 


\title{
Performance Measurement
}

Though the term performance measurement has been used since the late 1970s, there has not been a universal definition for the term. The Government Accountability Office (GAO), 1980, and Citizen-Driven Government Performance, 2004) defined performance measurement as "an assessment of an organization's performance, including the measures of:

$>\quad$ Productivity, which quantifies the outputs and inputs of an organization and expresses the two as a ratio. Generally, the ratio is expressed as output to input.

$>$ Effectiveness, which determines the relationship of an organization's, outputs to what an organization is intended to accomplish. Quality, which examines an output or the process by which an output is produced. Quality is indicated by attributes such as accuracy (or error rate), thoroughness, and complexity.

Timeliness, which evaluates the time involved producing an appropriate output. (Citizen-Driven Government Performance, 2004)

\section{The Factors Affecting Performance}

According to the (Cook J. \& Wall T.D :1980) explains the following factors are affecting the job performance

\begin{abstract}
Ability
Character traits, skills and knowledge which are used in the performance. It is always present and will not vary widely over short periods of time. (Cook J. \& Wall T.D :1980)
\end{abstract}




\section{Effort}

The amount of manual or mental energy that a person is prepared to expend on a job to reach a certain level of performance. Can vary according to incentive and motivation. (Cook J. \& Wall T.D :1980)

\section{Motivation}

Many people who are not motivated keep their performance to an acceptable level by expending only $20-30 \%$ of their ability, managers who know how to motivate their employees can achieve $80-90 \%$ ability levels and consequently higher levels of performance. (Cook J. \& Wall T.D :1980).

Maslow defines the following motivational factors.

- Basic needs - food clothing

- Safety needs - security, avoidance of risk/harm

- Social needs - friendship, acceptance, group

- Esteem needs - responsibility, recognition

- Self realization - independence, creativity

\section{Equity \& Expectation}

Basically, people expect to be treated equally, within the company and as others are in similar companies; they expect to get a certain reward for a certain effort; and they expect to get promoted if they undergo training. All these factors are inter-related and affect the amount of effort people are prepared to put in. (Cook J. \& Wall T.D (1980) 


\section{Environmental factors}

Those factors over which an individual has no control, e.g.: the job may have been completed under severe time constraints, with a lack of adequate resources, or by using obsolete equipment; there may have been conflicting priorities or information overload, such that the individual was confused and under stress; other staff and departments may have been less than cooperative; the restrictive policies of the organization may have prevented the individual from using her initiative and imagination to the extent that she wished; the quality of the supervision exercised may have been defective - some people need encouragement and support, whereas others like to be left to get on with the job. Cannot be used as excuses for poor performance, but they do have a modifying effect. (Cook J. \& Wall T.D (1980)

\subsubsection{Performance evaluation criteria and standards}

According to the (Opatha, 2002) explains the following performance evaluation criteria and standards

\section{$>$ Traits}

Traits refer to particular qualities or characteristics the employee possesses. Traits of employees can be assessed. Example job knowledge, cooperation, trust, honesty, initiative and loyalty. Traits are needed to understand and use appropriate behaviors for success. (Opatha, 2002)

\section{$>$ Behaviors}

Behaviors are the ways the employee acts in relation to the job. Basically behaviors involve particular activities carried out by the employee in performing the job. 
Examples include punctuality, attendance, planning works, organizing works, developing subordinates and controlling works. (Opatha, 2002)

\section{$>$ Results}

Results are outcomes produced by the employee. Outcomes or outputs of the employee can be assessed to do performance evaluation. Examples include number of units produced, number of units sold etc. (Opatha, 2002)

\subsection{Conceptualizing Job Performance}

Table 2.1 Dimensions and Aspects of the Job Performance

\begin{tabular}{|c|c|}
\hline Dimensions & Aspects \\
\hline \multirow[t]{5}{*}{ Traits } & Job knowledge \\
\hline & Cooperation \\
\hline & Dependability \\
\hline & Interpersonal relations \\
\hline & Communication skills \\
\hline \multirow[t]{5}{*}{ Behaviors } & Planning work \\
\hline & Organizing work \\
\hline & Punctuality \\
\hline & Attendance \\
\hline & Speed \\
\hline \multirow[t]{3}{*}{ Results } & Efficiency achievement \\
\hline & Completion of work on schedule \\
\hline & Quality of work \\
\hline
\end{tabular}

Source: Opatha 2003, cited by Kottawatta, 2007 


\section{Definition:}

\section{Dependability}

Dependability is a value showing the reliability of a person to others because of his/her integrity, truthfulness, and trustfulness, traits that can encourage someone to depend on him/her.

"Dependability (is) the collective term used to describe the availability performance and its influencing factors: reliability performance, maintainability performance and maintenance support performance"

Dependability can be thought of as being composed of three elements: such as attributes threats and means.

\section{Cooperation}

Cooperation or co-operation is the process of working or acting together. In its simplest form it involves things working in harmony, side by side, while in its more complicated forms, it can involve something as complex as the inner workings of a human being or even the social patterns of a nation. It is the alternative to working separately in competition. Cooperation can also be accomplished by computers, which can handle shared resources simultaneously, while sharing processor time.

Cooperation is the process by which the components of a system work together to achieve the global properties. In other words, individual components that appear to be "selfish" and independent work together to create a highly complex, greater-than-thesum-of-its-parts system. 


\section{Interpersonal relations}

Interpersonal Relations is a theory of interpersonal relations, introduced by William Schutz in 1958. This theory mainly explains the interpersonal underworld of a small group. The theory is based on the belief that when people get together in a group, there are three main interpersonal needs they are looking to obtain - affection/openness, control and inclusion

These categories measure how much interaction a person wants in the areas of socializing, leadership and responsibilities, and more intimate personal relations.

\section{Communication}

Communication is the activity of conveying meaningful information. Communication requires a sender, a message, and an intended recipient, although the receiver need not be present or aware of the sender's intent to communicate at the time of communication; thus communication can occur across vast distances in time and space. Communication requires that the communicating parties share an area of communicative commonality. The communication process is complete once the receiver has understood the message of the sender.

\section{Planning of work}

A work plan is a standard business management tool used for planning tasks during a specific time period. Work Plans commonly summarize different components of a job and how they will be implemented throughout that time span. Significance of the work planning is by creating a reference point, one can look at tasks that must be accomplished, problems that need to be solved, and/or workloads that should be prioritized and scheduled. Employees tend to be more efficient when they create a work 
plan. Stress can also be reduced when an overview of a worker's to-do list is typed or written on paper, rather than internalized.

\section{Organizing work}

Organizing is the act of rearranging elements following one or more rules. Anything is commonly considered organized when it looks like everything has a correct order or placement. But it's only ultimately organized if any element has no difference on time taken to find it. In that sense, organizing can also be defined as to place different objects in logical arrangement for better searching. Organizations are groups of people frequently trying to organize some specific subject, such as political issues.

\section{Punctuality}

Punctuality is the characteristic of being able to complete a required task or fulfill an obligation before or at a previously-designated time. "Punctual" is often used synonymously with "on time." Punctual can also, when talking about grammar, mean to be accurate.

Some cultures have an unspoken understanding that actual deadlines are different from stated deadlines; for example, it may be understood in a particular culture that people will turn up an hour later than advertised. In this case, since everyone understands that a 9 am meeting will actually start around $10 \mathrm{am}$, no one is inconvenienced when everyone turns up at $10 \mathrm{am}$.

In cultures which value punctuality, being late is tantamount to showing disrespect for another's time and may be considered insulting. In such cases, punctuality may be enforced by social penalties, for example by excluding low-status latecomers from 
meetings entirely. Such considerations can lead on to considering the value of punctuality in econometrics and to considering the effects of non-punctuality on others in queuing theory.

\section{Attendance}

Attendance is the act or fact of attending (being present at) work. Also, attendance is used to define the number of persons present on a particular day at work. An attendance policy provides the guidelines and expectations for employee attendance at work as defined, written, disseminated, and implemented by an organization.

Additionally, employees for whom attendance is tracked often perform jobs that are interdependent on other employees being in attendance. Such jobs include production line work in a manufacturing facility.

\section{Speed work}

Speed work is any running workout in which you run faster than your normal pace for a certain time or distance, or intervals. In between those fast intervals, you typically recover at a slower-than-normal pace.

\section{Quality of work}

"Quality itself has been defined as fundamentally relational: 'Quality is the ongoing process of building and sustaining relationships by assessing, anticipating, and fulfilling stated and implied needs.'

Quality of work is a term that had been used to describe the broader job-related experience an individual has. Quality of work related concepts are job satisfaction, 
workplace stress and quality of life. Whilst there has, for many years, been much research into job satisfaction and more recently an interest has arisen into the broader concepts of stress and subjective well being, the precise nature of the relationship between these concepts has still been little explored. Stress at work is often considered in isolation, wherein it is assessed on the basis that attention to an individual's stress management skills or the sources of stress will prove to provide a good enough basis for effective intervention. Alternatively, job satisfaction may be assessed, so that action can be taken which will enhance an individual's performance. Somewhere in all this, there is often an awareness of the greater context, whereupon the home-work context is considered, for example, and other factors, such as an individual's personal characteristics, and the broader economic or cultural climate, might be seen as relevant. In this context, subjective well-being is seen as drawing upon both work and non-work aspects of life.

\section{Job knowledge}

The degree of understanding about objectives, duties, responsibilities and methodology of the job.

\section{Efficiency achievement}

Uses resources (time, money, talent) in an efficient and cost-effective manner; develops new ways to enhance productivity; reengineers processes to improve efficiency. Assesses and manages risk in the introduction of new and creative solutions to challenges. 


\subsection{Conceptualizing Employee Commitment}

Table 2.2 Dimensions for measuring employee organizational commitment

\begin{tabular}{|l|l|}
\hline \multicolumn{1}{|c|}{ Dimensions } & \multicolumn{1}{|c|}{ Aspects } \\
\hline \multirow{4}{*}{ Loyalty to the organization } & High level effort \\
\cline { 2 - 2 } & Acceptance of job assignment \\
\cline { 2 - 2 } & Preference to work \\
\cline { 2 - 2 } & Work to retain \\
\cline { 2 - 2 } & Caring about the fate of the organization \\
\hline Personal identification & Express about organization \\
\cline { 2 - 3 } & Feeling of inspiration of the organization \\
\cline { 2 - 3 } & Feeling of the quality of the organization \\
\hline Belief in and acceptance of values and & Feelings of employee's values and \\
\hline \multirow{3}{*}{ goals of the organization } & organizational values \\
\hline & Feeling of choice of the organization \\
\hline
\end{tabular}

Source: Meyer \& Allen 1991, cited by Kottawatta, 2007

\section{Definition:}

\section{Loyalty}

Loyalty is faithfulness or a devotion to a person, country, group, or cause. Loyalty presented a different definition of the concept. Loyalty is a virtue indeed a primary virtue, the heart of all the virtue the central duty amongst all the duties.

From this definition, Royce constructs a moral framework based upon loyalty, using the notion of loyalty to loyalty itself. In order to do so, Royce distinguishes good causes 
from evil causes, by defining good causes as those that promote loyalty to loyalty. In other words, loyalty to such a cause enables, promotes, or otherwise furthers the abilities of other people to be loyal to their causes. A cause that destroys the object of someone else's legitimate loyalty cannot be good. From this can be derived the virtues of truthfulness, justice, benevolence, and courtesy.

\section{Job satisfaction}

"Job satisfaction is defined as "the extent to which people like (satisfaction) or dislike (dissatisfaction) their jobs" (Spector, 1997, p. 2). This definition suggests job satisfaction is a general or global affective reaction that individuals hold about their job. While researchers and practitioners most often measure global job satisfaction, there is also interest in measuring different "facets" or "dimensions" of satisfaction. Examination of these facet conditions is often useful for a more careful examination of employee satisfaction with critical job factors. Traditional job satisfaction facets include: co-workers, pay, job conditions, supervision, nature of the work and benefits." (Williams)

\section{Internalization}

Internalization has different definitions depending on the field that the term is used in. Internalization is the opposite of externalization. Generally, internalization is the long term process of consolidating and embedding one's own beliefs, attitudes, and values, when it comes to moral behavior. The accomplishment of this may involve the deliberate use of psychoanalytical or behavioral methods.

When changing moral behavior, one is said to be "internalized" when a new set of beliefs, attitudes, and values replaces or habituates the desired behavior. Internalization 
is also often associated with learning (for example, learning ideas or skills) and making use of it from then on. The notion of internalization therefore also finds currency in application in education, learning and training and in business and management thinking.

\section{Obligation}

An obligation is a requirement to take some course of action, whether legal or moral. There are also obligations in other normative contexts, such as obligations of etiquette, social obligations, and possibly in terms of politics, where obligations are requirements which must be fulfilled. These are generally legal obligations, which can incur a penalty for unfulfilment, although certain people are obliged to carry out certain actions for other reasons as well, whether as a tradition or for social reasons. Obligations vary from person to person: for example, a person holding a political office will generally have far more obligations than an average adult citizen, who they will have more obligations than a child. ' Obligations are generally granted in return for an increase in an individual's rights or power.

\section{Level of effort}

Level of effort is a support type project activity which must be done to support other work activities or the entire project effort. It usually consists of short amounts of work which must be repeated periodically.

\section{Turnover}

In a human resources context, turnover or staff turnover or labour turnover is the rate at which an employer gains and loses employees. Simple ways to describe it are "how long employees tend to stay" or "the rate of traffic through the revolving door." Turnover is 
measured for individual companies and for their industry as a whole. If an employer is said to have a high turnover relative to its competitors, it means that employees of that company have a shorter average tenure than those of other companies in the same industry. High turnover may be harmful to a company's productivity if skilled workers are often leaving and the worker population contains a high percentage of novice workers.

Like recruitment, turnover can be classified as 'internal' or 'external'. Internal turnover involves employees leaving their current positions and taking new positions within the same organization. Both positive (such as increased morale from the change of task and supervisor) and negative (such as project/relational disruption) effects of internal turnover exist, and therefore, it may be equally important to monitor this form of turnover as it is to monitor its external counterpart. Internal turnover might be moderated and controlled by typical HR mechanisms, such as an internal recruitment policy or formal succession planning.

\section{Attitudes}

Organizational context is important in the determination of attitudes and behaviors (Rousseau, 1978). More than twenty years ago, Rousseau (1978, p. 522) noted "recognition is growing that both individual differences and characteristics of organizational settings are germane to all phases of organizational research." Organizational context is important in the determination of attitudes and behaviors (Rousseau, 1978). 


\section{Organizational values}

Organizational values define the acceptable standards which govern the behaviour of individuals within the organization. Without such values, individuals will pursue behaviours that are in line with their own individual value systems, which may lead to behaviours that the organization doesn't wish to encourage.

In a smaller, co-located organization, the behaviour of individuals is much more visible than in larger, disparate ones. In these smaller groups, the need for articulated values is reduced, since unacceptable behaviours can be challenged openly. However, for the larger organization, where desired behaviour is being encouraged by different individuals in different places with different sub-groups, an articulated statement of values can draw an organization together.

Clearly, the organization's values must be in line with its purpose or mission, and the vision that it is trying to achieve. So to summarize, articulated values of an organization can provide a framework for the collective leadership of an organization to encourage common norms of behaviour which will support the achievement of the organization's goals and mission.

\section{Employees' value}

Values can be defined as broad preferences concerning appropriate courses of action or outcomes. As such, values reflect a person's sense of right and wrong or what "ought" to be. "Equal rights for all", "Excellence deserves admiration", and "People should be treated with respect and dignity" are representative of values. Values tend to influence attitudes and behavior. For example, if you value equal rights for all and you go to work 
for an organization that treats its managers much better than it does its workers, you may form the attitude that the company is an unfair place to work; consequently, you may not produce well or may perhaps leave the company. It is likely that if the company had a more egalitarian policy, your attitude and behaviors would have been more positive.

\section{Choice of the organization}

Choice consists of the mental process of thinking involved with the process of judging the merits of multiple options and selecting one of them for action.

\subsection{Related research on Organizational Commitment and Job Performance}

George and Jones (1996) define committed employees give a big contribution to organizations because they perform and behave on achieving organizations' goals. Furthermore, workers who are committed to their organization are happy to be members of it, believe in and feel good about the organization and what it stands for, and intend to do what is good for the organization. Thus, we could say that there is a relationship between organizational commitment and job performance. However, surprisingly, previous research suggested that organizational commitment is largely unrelated to job performance (Mathieu \& Zajac, 1990). In addition, Mowday et al. has also concluded that the link between commitment and performance is largely nonexistent (1982). Organizational commitment refers to the psychological attachment of workers to their workplaces (Allen \& Meyer, 1990; O’Reiily \& Chatman, 1986). Commitment to organizations is positively related to such desirable outcomes as job satisfaction (Bateman \& Stasser, 1984; Mowday, Porter, \& Steers, 1982), motivation (Mowday, Steers,\& Porter, 1979), and attendance (Mathieu \& Zajac, 1990; Steers \& Rhodes, 
1978) and negatively related to such outcomes as absenteeism and turnover (Clegg, 1983; Cotton \& Tuttle, 1986). Also, Horton stated that stronger commitment could result in less turnover and absenteeism, thus increasing an organization's productivity (Schuler \& Jackson, 1996, p. 302). However, the relationship between organizational commitment and job performance is more tenuous (Becker, Billings, Eveleth, \& Gilbert, 1996). For instance, Mathieu and Zajac's (1990) Meta analysis showed that the confidence interval around the mean correlation between organizational commitment and performance included zero. Thus, they concluded "commitment has relatively little direct influence on performance in most instances" (1990:184). Because organizational commitment is an important determinant of the experience work and central to understanding and managing organizational behavior (George \& Jones, 1996, p.67).

There are three new findings that explain more specifically about commitment performance relationship. Definitions used in those researches are little bit different. Term 'commitment' intended is employee commitment and is larger than the meaning of organizational commitment. It means commitment owned by employees. Each researcher has different focus. Then, term 'performance' has similar meaning to job performance. It does not only mean individual performance but also might mean organizational performance. So it depends on which meaning the researchers want to use. Those findings by Stephen L. Fink, Thomas E. Becker et al., and Birgit Benkhoff will be explained as follows.

Stephen L.Fink (1992) explains that employee commitment is only one of many factors affect performance, but certainly is a key factor. He defines commitment as an attitude that develops from a process called identification, which occurs when one experiences 
something, someone, or some idea as an extension of oneself. While all research on commitment treats it only in terms of identification with organization, that is, its goals, values, and mission, on the other hand, he focuses on three-dimensional concept including identification with the work itself and with co-workers. He is sure that these are equally important because they can have powerful effects upon employee performance. As basis of his research he makes an interactive model that proposes 1 . Good management practices result in an effective reward system and employee commitment, 2. An effective reward system results in enhanced employee commitment and employee performance, 3. Employee commitment results in enhanced employee performance .

The finding of Thomas E. Becker, Robert S. Billings, Daniel M. Eveleth, \& Nicole L. Gilbert (1996), the conclusion that commitment is largely unrelated to job performance is based upon the conventional view of commitment, which is that employee attachment involves "the relative strength of an individual's identification with and involvement in a particular organization" (Mowday et al., 1982:27). In contrast to this conventional view, a number of theorists and researchers have begun to view employee commitment as having multiple foci and bases (Becker et al., 1996). Foci commitment are the individuals and group to whom an employee is attached (Reichers, 1985). Bases of commitment are the motives engendering attachment (O'Reilly \& Chatman, 1986). It has been known for some time that employees can be committed to such foci as professions (Gouldner, 1958) and unions (Gordon, Beauvais, \& Ladd, 1984), as well as to organizations (Mowday et al., 1982). Recent research has suggested that workers can also be differentially committed to occupations, top management, supervisors, coworkers, and customers (Becker, 1992; Meyer, Allen, \& Smith, 1993; Reichers, 1986). 
With respect to the bases of commitment, early research suggested that different motivational processes underlie single attitudes. According to Kelman (1958), compliance occurs when people adopt attitudes and behaviors in order to obtain specific rewards or to avoid specific punishments. Identification occurs when people adopt attitudes and behaviors in order to be associated with a satisfying, self-defining relationship with another person or group. Finally, internalization occurs when people adopt attitudes and behaviors because their content is congruent with the individuals' value systems.

Randall for instance, in a Meta analysis on the consequences of commitment suggested that further research should explore "different models to account for the organizational commitment-work outcome relationship" (1990:376). Significant and strong relationship between commitment and job performance (Fink, 1993; Becker et al., 1996; Benkhoff, 1997). However, we should notice that each finding above results in specifically different things. Fink finds that there is significant correlation between employee performance and commitment in all categories (work, co-worker, and organization but the two last findings suggests that commitment to supervisors is positively related to performance and is strongly associated with performance than is commitment to organizations (Becker et al., 1996; Benkhoff, 1997). Furthermore, commitment based on internalization of supervisory and organizational values is related to performance (Becker et al., 1996).

Emanuel Camilleri (2002) identifies strong affective commitments are more valuable employees to the organization. Strong affective employee commitment feels emotional attachment to the organization, and then this individual will have a higher motivation 
level to contribute meaningfully to the organization than would an employee with weak affective commitment .Therefore, those employees with strong affective commitment will choose to be absent less often and will be motivated to give a high performance.

Affective commitment correlated positively, while continuance commitment correlated negatively, with the performance of lower-level managers in a large food service company (Meyer et al. 1989). Somers and Birnbaum (2000) confirmed the same result, that only affective commitment is associated with desirable outcomes, when analyzing the data from professional employees of a medical center. According to the literature review researcher identified affective commitment has positive relationship with job performance.

Allen and Meyer (1990) identify continuance commitment represents cognitive attachment between employees and their organizations because the costs of leaving organizations outweigh the benefits. Costs may include loosing a good pay and other forms of material benefits, established networks or contacts, image, necessity to reallocate, job search expenses, etc. Employees remain with the organization because the costs of doing otherwise are too high. It is possible that this type of commitment could create feelings of resentment or frustration that could lead to inappropriate work behavior and job performance (Emanuel Camilleri, 2002).

The research results supports to explain the continuance commitment is negative relationship with job performance. John P. Meyer, David J. Stanley, Lynne Herscovitch and Laryssa Topolnytsky (2002) Continuance commitment was unrelated or related negatively. Marthieu and Zajac (1998) have found that affective commitment to the organization is positively related to the job performance. It was also found that the relation between continuance commitment and performance was not significant. Mayer 
and Schooman (1998) states the relationship between continuance commitment to the organization and performance was negatively. Based on the literature review it could be concluded that continuance commitment has negative relationship with job performance.

Emanuel Camilleri (2002) defines as an employee with strong normative commitment is attracted to the organization by feelings of obligation and duty. Thus, it is anticipated that normative commitment will be positively related to such work behavior as job performance, work attendance, and organizational citizenship .Normative commitment might have a particularly important impact on the manner in which the work is carried out.

Previously conducted studies show a significant relationship between normative commitment and perceived employees' performance. For example, Muhammad et al (2010) in their article titled "The Impacts of Organizational Commitment on Employee Job Performance" has the positive relationship between the normative commitment and job performance. According to the literature review researcher found that normative commitment has positive relationship with job performance.

\subsection{Summary}

Organizational commitment has emerged as an important construct in organizational research owing to its relationship with work-related constructs such as absenteeism, turnover, job satisfaction, job-involvement and leader-subordinate relations. Affective organizational commitment is conceptualized as "an individual's attitude towards the organization, consisting of a strong belief in, and acceptance of, an organization's goals, willingness to exert considerable effort on behalf of the organization and a strong desire 
to maintain membership in the organization". Continuance commitment can be conceptualized as the propensity for employees to feel committed to their organization based on their perceptions of the associated costs of leaving the organization. Normative commitment can be conceptualized as the belief that "employees have a responsibility to their organization".

Performance is measured through the traits, behavior and results. Traits refer to particular qualities or characteristics the employee possesses. Behaviors are the ways the employee acts in relation to the job. Results are outcomes produced by the employee. Outcomes or outputs of the employee can be assessed to do performance evaluation.

According to the literature review researcher could be concluded that affective commitment and normative commitment has positive relationship with job performance, whilst continuance commitment has negative relationship with job performance. 


\section{Chapter-3}

\section{Conceptualization and Methodology}

\subsection{Introduction}

This chapter attributes how the research has been conducted and evaluates the relationship between the commitment and job performance. It initially deals with the methodology used in collection of sufficient data and information from the respondents and in transferring them into meaningful to drive the findings and take decisions. The conceptual model clearly expresses the relation and link between the dependent and independent variable of this research study.

\subsection{Conceptual Framework}

Organizational commitment is considered to be one of the foremost important and crucial outcomes of the human resource strategies. And the employee commitment is seen as the key factor in achieving job performance (Sahnawaz \& Juyal, 2006).

The following model (Figure 3.1) will be used the conceptual framework for the analysis.

Figure 3.1 Model of the research

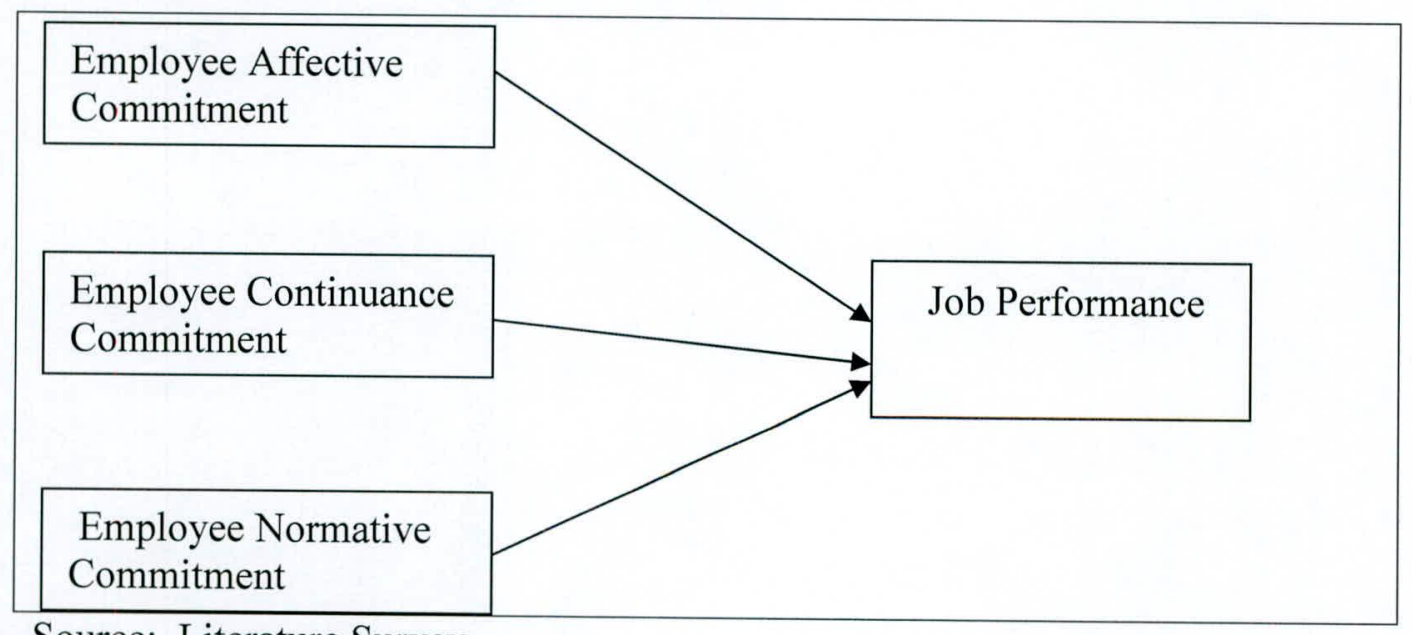

Source: Literature Survey 


\subsection{Conceptualizing Job Performance}

Performance can be described in general as outcome variables of an employee (Gilbert \& Ford 1999). In this study what has been considered is task related performance. Performance can be viewed in different perspectives. It can be seen as productivity, out put, effectiveness and many other variables connected to task.

Job performances are measured through the traits, behaviors and results.

Table 3.1 Dimensions and Aspects of the Job Performance

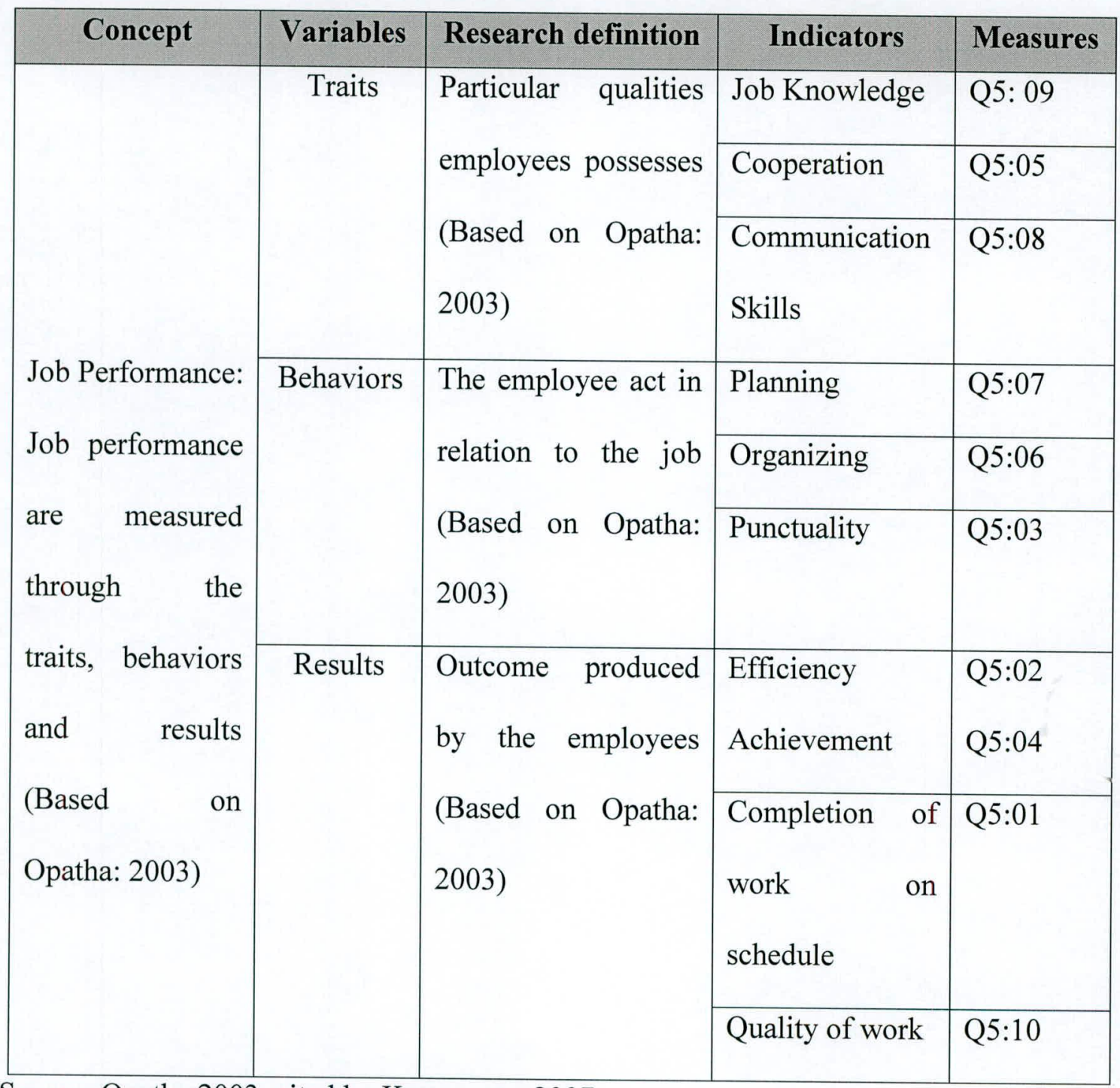

Source: Opatha 2003, cited by Kottawatta, 2007 


\section{Definition:}

\section{Traits:}

Traits refer to particular qualities or characteristics the employee possesses. Traits of employees can be assessed. Example job knowledge, cooperation, trust, honesty, initiative and loyalty. Traits are needed to understand and use appropriate behaviors for success. (Opatha, 2002)

\section{Behaviors:}

Behaviors are the ways the employee acts in relation to the job. Basically behaviors involve particular activities carried out by the employee in performing the job. Examples include punctuality, attendance, planning works, organizing works, developing subordinates and controlling works. (Opatha, 2002)

\section{Results:}

Results are outcomes produced by the employee. Outcomes or outputs of the employee can be assessed to do performance evaluation. Examples include number of units produced, number of units sold etc. (Opatha, 2002)

\section{Job knowledge:}

The degree of understanding about objectives, duties, responsibilities and methodology of the job. (Opatha, 2002)

\section{Cooperation:}

Attitude towards the work peers and superiors and the ability to understand and help solve problems of others. (Opatha, 2002) 


\section{Dependability:}

The ability to do required activities under a minimum supervision. (Opatha, 2002)

\section{Interpersonal relations:}

Interact positively and sensitivity with people. (Illinois Institute of Technology, 1998)

\section{Communication skills:}

Ability to communicate and interact with customers and the staff effectively. (Opatha, 2003)

\section{Planning work:}

Develop plans and organize tasks and resources to accomplish work objectives. (Illinois Institute of Technology, 1998)

\section{Organizing work:}

Deciding how best to do organizational activities and resources.

(Ricky W. Griffin, Texas A\&M University,1997)

\section{Punctuality:}

Tendency to arrive at work place at the right time. (Opatha, 2002)

\section{Attendance:}

Faithfulness in coming to work. (Opatha, 2002)

\section{Speed:}

The individual's ability to complete the work assigned with the utmost expedition for better customer service and higher productivity. (Opatha, 2003) 


\section{Efficiency achievement:}

Uses resources (time, money, talent) in an efficient and cost-effective manner; develops new ways to enhance productivity; reengineers processes to improve efficiency. Assesses and manages risk in the introduction of new and creative solutions to challenges. (Achievement and Competency Enhancement System (ACES) 2006)

\section{Completion of work on schedule:}

The employee is able to manage time effectively and produce high quality work. Ability to create and meet deadlines. Ability to recognize and properly plan priorities. (Opatha, 2002)

\section{Quality of work:}

General excellence of output with consideration to accuracy, thoroughness and neatness. (Opatha, 2002)

\subsection{Conceptualizing Employee Commitment}

Different dimensions of commitment

Kanter, 1993 explained how commitment could be different according to behavioral requirement imposed on members by the organizations. According to Luthans (1998) he categories the commitment in three types such as continuance commitment, affective commitment and normative commitment. Two views of employee organizational commitment, such as attitudinal approach and the behavioral approach. Organizational behavior researches describe commitment as an attitudinal approach. Social psychologist describes it as behavioral commitment (Luthans, 1998). 
Table 3.2 Dimensions for measuring employee organizational commitment

\begin{tabular}{|c|c|c|c|c|}
\hline Concept & Variables & $\begin{array}{l}\text { Research } \\
\text { definition }\end{array}$ & Indicators & Measures \\
\hline \multirow{5}{*}{$\begin{array}{l}\text { Employee } \\
\text { Commitment: }\end{array}$} & \multirow[t]{5}{*}{$\begin{array}{l}\text { Affective } \\
\text { Commitment }\end{array}$} & \multirow{5}{*}{$\begin{array}{l}\text { Strong emotional } \\
\text { attachment in the } \\
\text { organization } \\
\text { (Based on Meyer } \\
\text { and Allen :1991) }\end{array}$} & Loyalty & $\begin{array}{l}\text { Q2:01/Q2:02 } \\
\text { Q2:03 }\end{array}$ \\
\hline & & & $\begin{array}{l}\text { Organizational } \\
\text { goals }\end{array}$ & Q2:07/Q2:10 \\
\hline & & & $\begin{array}{l}\text { Acceptance of } \\
\text { job assignment }\end{array}$ & Q2:09 \\
\hline & & & $\begin{array}{l}\text { Preference to } \\
\text { work }\end{array}$ & Q2:04/Q2:05 \\
\hline & & & Work retain & Q2:06/Q2:08 \\
\hline \multirow{5}{*}{$\begin{array}{l}\text { Three } \\
\text { components of } \\
\text { organizational } \\
\text { commitment } \\
\text { such as } \\
\text { affective, } \\
\text { normative and } \\
\text { continuance }\end{array}$} & \multirow[t]{5}{*}{$\begin{array}{l}\text { Normative } \\
\text { Commitment }\end{array}$} & \multirow{5}{*}{$\begin{array}{l}\text { Obligation to } \\
\text { continue with the } \\
\text { organization } \\
\text { (Based on Meyer } \\
\text { and Allen :1991) }\end{array}$} & Obligation & $\begin{array}{l}\text { Q3:01/Q3:05 } \\
\text { Q3:10 }\end{array}$ \\
\hline & & & Loyalty & Q3:02/Q3:03 \\
\hline & & & Nature of task & Q3:08 \\
\hline & & & Internalization & $\begin{array}{l}\text { Q3:04/Q3:06 } \\
\text { Q3:09 }\end{array}$ \\
\hline & & & $\begin{array}{l}\text { Quality of } \\
\text { organization }\end{array}$ & Q3:07 \\
\hline $\begin{array}{l}\text { commitment } \\
\text { (Based on }\end{array}$ & \multirow[t]{5}{*}{$\begin{array}{l}\text { Continuance } \\
\text { Commitment }\end{array}$} & \multirow{5}{*}{$\begin{array}{l}\text { Awareness of the } \\
\text { costs associated } \\
\text { with leaving the } \\
\text { organization } \\
\text { (Based on Meyer } \\
\text { and Allen: 1991) }\end{array}$} & $\begin{array}{l}\text { Employees } \\
\text { attitudes }\end{array}$ & Q4:02/Q4:10 \\
\hline Meyer and & & & Turnover & Q4:05 \\
\hline \multirow[t]{3}{*}{ Allen:1991) } & & & Job alternatives & $\begin{array}{l}\text { Q4:01/Q4:03 } \\
\text { Q4:06/Q4:08 }\end{array}$ \\
\hline & & & Dissatisfaction & Q4:04 Q4:09 \\
\hline & & & $\begin{array}{l}\text { Organizational } \\
\text { value }\end{array}$ & Q4:07 \\
\hline
\end{tabular}

Source: Meyer \& Allen 1991, cited by Kottawatta, 2007 


\section{Definitions:}

\section{Loyalty to the organization:}

Employee loyalty can be defined as employees being committed to the success of the organization and believing that working for the organization is their best option. (Loyalty Research Center,2007)

\section{Personal identification:}

Personal identification occurs when an individual's beliefs about his or her organization become self-referential or self- defining.( Pratt (1998)

\section{Organization values:}

All organizations operate according to overall values, or priorities in the nature of how they carry out their activities. These values are the personality, or culture, of the organization. (Carter McNamara, 1997)

\section{Organization goals:}

Organizations members often work to achieve several overall accomplishments, or goals, as they work toward their mission. (Carter McNamara, 1997)

\section{High level effort:}

The physical or mental vigor needed to do something to achieve the organization goals. (Dictionary, 2006)

\section{Acceptance of job assignment:}

Position of acceptance job responsibility (Online dictionary, 2007)

\section{Preference to work:}

A greater liking for one alternative over another or others. (Dictionary, 2006) 


\section{Work to retain:}

The person is continued to have work in the organization. (Dictionary, 2006)

\section{Fate of the organization:}

The development of events outside a person's control, regarded as decided in advance by supernatural power. (Dictionary, 2006)

\section{Express about organization:}

Express the organization over all values, goals and belief. (Carter McNamara, 1997)

\section{Inspiration of the organization:}

The process of being filled with a feeling or with the urge to do something. (Dictionary, 2006)

\section{Quality of the organization:}

accuracy and thoroughly applies requisite knowledge and skills necessary to complete the work. (Illinois Institute of Technology, 1998)

\section{Employee's values:}

Creating a common positive workplace culture, attitudes, integrity, productivity, flexibility and etc. (Marklund, 2008)

\section{Choice of the organization:}

Choice consists of the mental process of thinking involved with the process of judging the merits of multiple options and selecting one of them for action. (Wikipedia, the free encyclopedia, 2008) 


\section{Job satisfaction:}

"The measurement of one's total feelings and attitudes towards one's job" (Graham, 1982, p. 68).

\subsection{Hypothesis}

Based on the above conceptual framework the following hypotheses are formulated.

H0: There is no relationship between employee affective commitment and job performance of Zonal Education Officers in Eastern Province in Sri Lanka.

$\mathrm{H} 1$ : There is a positive relationship between employee affective commitment and job performance of Zonal Education Officers in Eastern Province in Sri Lanka.

$\mathrm{H} 0$ : There is no relationship between employee normative commitment and job performance of Zonal Education Officers in Eastern Province in Sri Lanka.

$\mathrm{H} 2$ : There is a positive relationship between employee normative commitment and job performance of Zonal Education Officers in Eastern Province in Sri Lanka.

H0: There is no relationship between employee continuance commitment and job performance of Zonal Education Officers in Eastern Province in Sri Lanka.

H3: There is a negative relationship between employee continuance commitment and job performance of Zonal Education Officers in Eastern Province in Sri Lanka. 


\subsection{Methodology}

Research methodology is described in terms of methods, population, instruments and procedures used for data collection as well as procedures used in the data analysis.

\subsubsection{Population, Sample and Selection of the Sample}

Huysamen (1994, p. 38) defines a population as encompassing "the total collection of all members, cases or elements about which the researcher wishes to draw conclusions." This research includes a total population of 2637 (Cadre Position as at 01-09-2007, Zonal Education Officers in Eastern Province) comprising principals, advanced level teachers and zonal directors.

According to Sekaran (2003, p. 266), sampling is "the process of selecting a sufficient number of elements from the population, so that a study of the sample and an understanding of its properties or characteristics would make it possible for us to generalize such properties or characteristics to the population elements." Accordingly a systematic random sample was used to ensure enough representation of the population. Ten percent of the total population is taken into consideration for this study. For example where as the total population of principals amounts to 679 , the selected samples are restricted to approximately 70 . And among $1945 \mathrm{~A} / \mathrm{L}$ teachers only about 200 samples are selected. In addition two zonal directors are selected from each district. Altogether 276 samples are selected for purpose of research. 
The following table 3.3 represents the sample of the Zonal Education Officers in the Eastern Province in Sri Lanka.

Table 3.3 Eastern Province - Zonal Education Officers

\begin{tabular}{|l|l|c|c|c|c|c|c|}
\hline $\begin{array}{l}\text { Eastern } \\
\text { Province }\end{array}$ & Zones & $\begin{array}{l}\text { Zonal } \\
\text { Directors }\end{array}$ & Sample & Principal & Sample & $\begin{array}{l}\text { A/L } \\
\text { Teachers }\end{array}$ & Sample \\
\hline Trincomalee & Trincomalee & 01 & 01 & 61 & 6 & 197 & 20 \\
\cline { 2 - 8 } & Muthur & 01 & 01 & 85 & 9 & 170 & 17 \\
\cline { 2 - 8 } & Kantale & 01 & - & 05 & 1 & 78 & 8 \\
\hline Batticaloa & Batticaloa & 01 & 01 & 82 & 8 & 209 & 22 \\
\cline { 2 - 9 } & Kalkudah & 01 & - & 38 & 4 & 53 & 5 \\
\cline { 2 - 9 } & Paddiruppu & 01 & - & 58 & 6 & 443 & 46 \\
\cline { 2 - 8 } & Batticaloa & 01 & 01 & 41 & 4 & 85 & 9 \\
\hline Ampara & central & & & & & & \\
\cline { 2 - 9 } & Kalmunai & 01 & 01 & 70 & 7 & 227 & 23 \\
\cline { 2 - 9 } & Akkaraipattu & 01 & 01 & 64 & 7 & 162 & 17 \\
\cline { 2 - 8 } & Sammanthurai & 01 & - & 49 & 5 & 83 & 9 \\
\cline { 2 - 8 } & Ampara & 01 & - & 67 & 7 & 154 & 16 \\
\cline { 2 - 8 } & Mahaoya & 01 & - & 28 & 3 & 32 & 3 \\
\cline { 2 - 8 } & Dehiattakandiya & 01 & - & 31 & 3 & 52 & 5 \\
\hline Total & 13 & $\mathbf{0 6}$ & 679 & $\mathbf{7 0}$ & 1945 & $\mathbf{2 0 0}$ \\
\hline
\end{tabular}

Source: Cadre Position as at 01-09-2007, Zonal Education Officers in Eastern Province 


\subsubsection{Data Collection}

The research study using the questionnaire, most of the items based on other researches, namely Roderick D. Iverson and Donna M. Buttigieg (1998), Isaiah O.Ugboro (2003), Aaron Cohen (2007) and Fonseka (2000). Most of the questionnaires collected by researcher. And also research assistant administered the questionnaire.

The questionnaire is structured in to 5 sections:

- The first part inquires in to the personal details

- The second part measures affective commitment

- The third part measures normative commitment

- The fourth part measures continuance commitment

- The fifth part measures job performance

\subsubsection{Measures}

Employee affective commitment, continuance commitment and normative commitment are considerable independent variables to effective job performance. Pearson correlation and multiple regressions analysis will be performed to obtain the relationship between employee commitment and effective job performance.

\section{Measuring Personal Characteristics}

The population consists of zonal directors, principals and Advanced Level teachers. The personal characteristics include sex, age, marital status, occupation, type of school, distance from home to work organization, modes of transportation, educational qualification/ Services, work experience, zonal education officers district and zones. 


\section{Measuring Employee Commitment}

Employee commitment will be measured by a 30-item questionnaire devised by

Roderick D. Iverson and Donna M. Buttigieg (1998), Isaiah O.Ugboro (2003), and Aaron Cohen (2007). There are 3 dimensions identified.

Dimension 1 - Loyalty to the organization

Dimension 2- Personal identification

Dimension 3- Belief in and acceptance of values and goals of the organization

A five point likert scale use to measure the respondent commitment to the organization.

1- Strongly disagree

2-Disagree

3-Neither disagree/ Agree

4-Agree

5-Strongly agree

\section{Measuring Employee Job Performance}

The performance of Zonal Education Officers use to measure a 10 item questionnaire devised by Opatha 2003.

There are 3 dimensions identified.

Dimension 1- Traits (Traits refer to particular qualities or characteristics the employee possesses)

Dimension 2- Behaviors (Behaviors are the ways the employee acts in relation to the job)

Dimension 3- Results (Results are outcomes produced by the employee) 
Employee job performance measure by the response questionnaire. A five point likart scale use for this purpose.

1- Strongly disagree

2-Disagree

3-Neither disagree/ Agree

4-Agree

5-Strongly agree

\subsubsection{Methods of Data Analysis}

The following statistical tools are use to find the relationship between the employee commitment and employee job performance. The dependent variable in the analysis is the measure of job performance and independent variable in the analysis are affective commitment, normative commitment and continuance commitment.

Statistical Software Package-SPSS (14.0 version) was a tool for compiling and processing data.

Univariate analysis: Descriptive statistics use to analyze each variable. Frequency tables will be used. These frequency plots will be presented as tables and charts.

Pearson Correlation - Based on the Algina, J., \& Keselman, H. J. (1999) provides a measure of index for the strength and direction of any linear relationship between two variables. When the points are more concentrated, the value of $r$ is higher.

Multiple regression- In multiple regressions a whole set of statistical information use to predict the dependent variable. It addresses the combined of many independent 
variables on the dependent variable. Hence variable are used as the predictors of performance.

$$
\mathrm{P}=\mathrm{B} 0+\mathrm{B} 1 \mathrm{~A}+\mathrm{B} 2 \mathrm{~N}+\mathrm{B} 3 \mathrm{C}+\mathrm{K}
$$

Where $\mathrm{A}=$ Affective commitment, $\mathrm{N}=$ Normative commitment, $\mathrm{C}=$ Continuance commitment and $\mathrm{P}=\mathrm{J}$ ob Performance and $\mathrm{B} 0, \mathrm{~B} 1, \mathrm{~B} 2, \mathrm{~B} 3$ are constants and $\mathrm{K}$ is the error term. Hence in this analysis it is assumed that the dependent variable can be represented as a linear relationship with the independent variable.

\subsubsection{Hypothesis testing}

\section{$\underline{\text { Correlation analysis }}$}

The alternative hypothesis is defined as following,

$\mathrm{H}_{\mathrm{a}}$ : The two given variables are associated

When $\mathrm{p}<0.05$ reject $\mathrm{H}_{\mathrm{o}}$ and accept $\mathrm{H}_{\mathrm{a}}$

Where $\mathrm{r}=$ correlation coefficient

\section{$\underline{\text { Hypotheses testing in regression analysis }}$}

Alternative hypothesis defined as following

$\mathrm{H}_{1}$ : At least one $\mathrm{b}$ is not zero

When $\mathrm{p}<0.05$ reject $\mathrm{H}_{\mathrm{o}}$ and accept $\mathrm{H}_{1}$

Where $\beta=$ beta 


\subsection{Summary}

The research methodology utilized in the present study was addressed in this chapter. More specifically, the selection of the sample, the measuring instruments used and the rationale for their inclusion, as well as the statistical methods employed in testing the research hypotheses were discussed. 


\section{Chapter-4}

\section{Data Analysis and Discussion}

\subsection{Introduction}

Analyzing the data amassed and presented for the purpose of reaching conclusion is the heart of any research. In this process all the collected data from 276 respondents have been categorized and analyzed on the following basis. Even though various mode of analysis are applied and be preferred, for this study powerful bivariate, multivariate analysis has been adopted using the latest SPSS computer package.

\subsection{Summary of Data Analysis}

The following table 4.1 explains the summary of data analysis.

\section{Table 4.1 Summary of data analysis}

\begin{tabular}{|c|c|c|c|c|}
\hline $\begin{array}{l}\text { Analysis } \\
\text { Order }\end{array}$ & Variable & $\begin{array}{l}\text { Representa } \\
\text { tion }\end{array}$ & Indicators & Reasons \\
\hline $\begin{array}{l}\text { Data } \\
\text { presentation }\end{array}$ & $\begin{array}{l}\text { Personal Characterizes: } \\
\text { Gender, Age, Marital } \\
\text { status, Occupation, Type of } \\
\text { School, Distance, Mode of } \\
\text { transportation, Educational } \\
\text { qualification/ Services, } \\
\text { Work experience, } \\
\text { Working Zonal Offices } \\
\text { Districts and Zones }\end{array}$ & $\begin{array}{l}\text { Frequency } \\
\text { tables, bar } \\
\text { chart }\end{array}$ & $\begin{array}{l}\text { Frequency } \\
\text { cumulative } \\
\text { percentage }\end{array}$ & $\begin{array}{l}\text { A bar chart displays } \\
\text { the count for each } \\
\text { distinct value or } \\
\text { category as a } \\
\text { separate } \\
\text { allowing you to } \\
\text { compare categories } \\
\text { visually. }\end{array}$ \\
\hline $\begin{array}{l}\text { Univariate } \\
\text { Analysis }\end{array}$ & $\begin{array}{l}\text { Affective commitment, } \\
\text { Normative commitment, } \\
\text { Continuance commitment, } \\
\text { Job performance }\end{array}$ & $\begin{array}{l}\text { Statistics } \\
\text { frequency } \\
\text { tables }\end{array}$ & $\begin{array}{l}\text { mean, } \\
\text { standard } \\
\text { deviation of } \\
\text { mean } \\
\text { variance }\end{array}$ & $\begin{array}{l}\text { Statistics that } \\
\text { measure the spread } \\
\text { or variation in the } \\
\text { data }\end{array}$ \\
\hline
\end{tabular}




\begin{tabular}{|c|c|c|c|c|}
\hline $\begin{array}{l}\text { Reliability } \\
\text { analysis }\end{array}$ & $\begin{array}{l}\text { Affective commitment, } \\
\text { Normative commitment, } \\
\text { Continuance commitment } \\
\text { Job Performance }\end{array}$ & Alpha value & Alpha value & $\begin{array}{l}\text { Reliability analysis } \\
\text { procedure calculates } \\
\text { a number of } \\
\text { commonly used } \\
\text { measures of scale } \\
\text { reliability and also } \\
\text { provides information } \\
\text { about the } \\
\text { relationships } \\
\text { between individual } \\
\text { items in the scale }\end{array}$ \\
\hline $\begin{array}{l}\text { Bivariate } \\
\text { analysis } \\
\text { Correlation } \\
\text { analysis }\end{array}$ & $\begin{array}{l}\text { Affective commitment, } \\
\text { Normative commitment, } \\
\text { Continuance commitment, } \\
\text { Job performance }\end{array}$ & Correlation & $\begin{array}{l}\text { Correlation } r \text {, } \\
\text { significant } \\
\text { level }\end{array}$ & $\begin{array}{l}\text { Pearson's correlation } \\
\text { coefficient is a } \\
\text { measure of linear } \\
\text { association. }\end{array}$ \\
\hline $\begin{array}{l}\text { Hypothesis } \\
\text { testing }\end{array}$ & AC-JP, NC-JP, CC-JP & $\begin{array}{l}\text { Correlation } \\
\text { Regression }\end{array}$ & $\begin{array}{l}\text { Correlation, } \mathrm{r} \\
\text { Regression- } \\
\text { beta }\end{array}$ & $\begin{array}{l}\text { A useful hypothesis } \\
\text { is a testable } \\
\text { statement which may } \\
\text { include a prediction }\end{array}$ \\
\hline $\begin{array}{l}\text { Multiple } \\
\text { regression }\end{array}$ & $\begin{array}{l}\text { Affective commitment, } \\
\text { Normative commitment, } \\
\text { Continuance commitment, } \\
\text { Job performance }\end{array}$ & $\begin{array}{l}\text { Model } \\
\text { summary, } \\
\text { ANOVA, } \\
\text { Coefficients }\end{array}$ & $\begin{array}{l}\text { R, R Square } \\
\text {, Significant, } \\
\text { Beta }\end{array}$ & $\begin{array}{l}\text { A statistical measure } \\
\text { that attempts to } \\
\text { determine the } \\
\text { strength of } \\
\text { the relationship } \\
\text { between one } \\
\text { dependent variable } \\
\text { and a series of other } \\
\text { changing variables. }\end{array}$ \\
\hline
\end{tabular}




\subsection{Data Presentation}

The information was obtained through 276 structured questionnaires. Personal information was obtained from the first part of the questionnaire. It consists of sex, age, marital status, occupation, type of school, distance from home to work organization, modes of transportation, educational qualification/ services, work experience, Zonal Education Officers district and zones.

\subsubsection{Gender}

Table 4.2

Gender

\begin{tabular}{|c|c|c|}
\hline Gender & No of Respondents & Percentage (\%) \\
\hline Male & 131 & 47.5 \\
\hline Female & 145 & 52.5 \\
\hline Total & 276 & 100.0 \\
\hline
\end{tabular}

Source: Survey data

The above table has shown the overall status of gender distribution in Zonal Education Officers in Eastern Province. Out of 276 respondents sample taken 131 are male and 145 are female, with the percentage of $47.5 \%$ and $52.5 \%$ respectively in the selected sample.

\subsubsection{Age}

Age was categorized by eight classes, those are $<30,30-35,36-40,41-45,46-50,51-55,56-$ 60 and above 60 years. Based on the data which was collected from the respondents, the age distribution of overall zonal directors, principal and $\mathrm{A} / \mathrm{L}$ teachers are described in table 4.3. 
Table 4.3

Age

\begin{tabular}{|c|c|c|}
\hline Age (years) & No of Respondents & Percentage (\%) \\
\hline$<30$ & 29 & 10.5 \\
\hline $30-35$ & 31 & 11.2 \\
\hline $36-40$ & 30 & 10.9 \\
\hline $41-45$ & 58 & 21.0 \\
\hline $46-50$ & 57 & 20.7 \\
\hline $51-55$ & 40 & 14.5 \\
\hline $56-60$ & 30 & 10.9 \\
\hline$>60$ & 1 & .4 \\
\hline Total & 276 & 100.0 \\
\hline
\end{tabular}

Source: Survey data

The majority of the respondents $(56.2 \%, \mathrm{n}=135)$ are in the age group of $41-55$ years, while $33 \%(n=90)$ are in the age group 30-40 years. Thirty respondents $(11 \%)$ fall in the age category $56-60$ years, and a further $.4 \%(n=01)$ of the respondents are in the age group above 60 years old.

\subsubsection{Marital Status}

Table 4.4

Marital Status

\begin{tabular}{|c|c|c|}
\hline Marital Status & No of Respondents & Percentage (\%) \\
\hline Married & 222 & 80.4 \\
\hline Single & 54 & 19.6 \\
\hline Total & 276 & 100.0 \\
\hline
\end{tabular}

Source: Survey data 
The above table discloses that two hundred and twenty two respondents are married and rests of the 54 respondents are single in the working station.

\subsubsection{Occupation}

\section{Table 4.5 Occupation}

\begin{tabular}{|c|c|c|}
\hline Occupation & No of Respondents & Percentage (\%) \\
\hline A/L teacher & 200 & 72.5 \\
\hline Principal & 70 & 25.4 \\
\hline Zonal director & 6 & 2.2 \\
\hline Total & 276 & 100.0 \\
\hline
\end{tabular}

Source: Survey data

In accordance to deployment category that 200 respondents were in $\mathrm{A} / \mathrm{L}$ teacher, 70 respondents are served as principal and rest of the 6 respondents are carrying duties as Zonal Directors.

\subsubsection{School Type}

Table 4.6 School Type

\begin{tabular}{|c|c|c|}
\hline Types of School & No of Respondents & Percentage (\%) \\
\hline Zonal Director & 6 & 2.2 \\
\hline 1AB & 148 & 53.6 \\
\hline $1 \mathrm{C}$ & 122 & 44.2 \\
\hline Total & 276 & 100.0 \\
\hline
\end{tabular}

Source: Survey data

The above table has shown the no of respondents distributed in types of school. Hundred and forty eight respondents are performed in from $1 \mathrm{AB}$ school, rest of the 122 respondents are come under the IC school. Zonal Directors are taking into consideration of Zonal Education employees. 


\subsubsection{Distance from home to organization}

Table 4.7 Distance from home to organization

\begin{tabular}{|c|c|c|}
\hline Distance $(\mathbf{K m})$ & No of Respondents & Percentage (\%) \\
\hline$<5$ & 112 & 40.6 \\
\hline $5-10$ & 85 & 30.8 \\
\hline $11-15$ & 62 & 22.5 \\
\hline $16-20$ & 13 & 4.7 \\
\hline $21-25$ & 2 & .7 \\
\hline$>25$ & 2 & .7 \\
\hline Total & 276 & 100.0 \\
\hline
\end{tabular}

Source: Survey data

Table 4.7 describes the distance from home to organization. Majority of the respondents (112) fall on below $5 \mathrm{~km}$ distance from home to organization. $53 \%$ of the respondents (147) come under the category of $5-15 \mathrm{~km}$ from their working stations. Far distance travelled respondents are 15 , which is $5 \%$ that shows $16-25 \mathrm{Km}$. last and least 2 respondents are travelled far away from residence to working station.

\subsubsection{Mode of Transportation}

Table 4.8 Mode of transportation

\begin{tabular}{|c|c|c|}
\hline $\begin{array}{c}\text { Mode of } \\
\text { Transportation }\end{array}$ & No of Respondents & Percentage (\%) \\
\hline Walk & 24 & 8.7 \\
\hline Bicycle & 32 & 11.6 \\
\hline Motor bike & 84 & 30.4 \\
\hline Bus & 96 & 34.8 \\
\hline Train & 23 & 8.3 \\
\hline Others & 17 & 6.2 \\
\hline Total & 276 & 100.0 \\
\hline
\end{tabular}

Source: Survey data 
The above table shows that twenty four respondents are very close to the working station. Twelve percentages of the respondents are using the bicycle, eighty four respondents are using the motor bike, thirty five percentages of the respondents are using the bus and twenty three respondents are using the train. Very few respondents (17) are using their mode of convenience.

\subsubsection{Educational Qualification}

Table 4.9 Educational Qualification

\begin{tabular}{|c|c|c|}
\hline $\begin{array}{c}\text { Educational } \\
\text { Qualification }\end{array}$ & No of Respondents & Percentage (\%) \\
\hline Diploma & 13 & 4.7 \\
\hline PGDM & 39 & 14.1 \\
\hline Degree & 172 & 62.3 \\
\hline Master degree & 52 & 18.8 \\
\hline Total & 276 & 100.0 \\
\hline
\end{tabular}

Source: Survey data

The Zonal Education Officers academic qualification has been categorized by four levels. Table 4.9 shows that thirteen respondents are have the diploma qualification. Thirty nine respondents gained the PGDM. Majority of the respondents (172) possessing the degree qualification. Rest of the 52 respondents yield the master degree in their field. 


\subsubsection{Services}

Table 4.10 Services

\begin{tabular}{|c|c|c|}
\hline Services & No of Respondents & Percentage (\%) \\
\hline Non applicable & 176 & 63.8 \\
\hline SLEAS II & 6 & 2.2 \\
\hline SLPS II-2 & 11 & 4.0 \\
\hline SLPS-1 & 7 & 2.5 \\
\hline SLPS II-1 & 49 & 17.8 \\
\hline SLTS & 27 & 9.8 \\
\hline Total & 276 & 100 \\
\hline
\end{tabular}

Source: Survey data

Respondents are categorized in service wise; most of the respondents (176) don't have come under purview of any services. It indicated those are the $\mathrm{A} / \mathrm{L}$ teachers in the schools. Six zonal directors are come under the SLEAS II service in the zonal education offices. Majority of the principals (67) are serving with the service of SLPSII-2,SLPS-1 and SLPSII-1. Rest of the 27 respondents is having the SLTS services.

\subsubsection{Work Experience}

Table 4.11 Work Experience

\begin{tabular}{|c|c|c|}
\hline Work Experience (Period) & No of Respondents & Percentage (\%) \\
\hline$<5$ & 42 & 15.2 \\
\hline $05-10$ & 58 & 21.0 \\
\hline $11-15$ & 46 & 16.7 \\
\hline $16-20$ & 51 & 18.5 \\
\hline $21-25$ & 45 & 16.3 \\
\hline$>25$ & 34 & 12.3 \\
\hline Total & 276 & 100.0 \\
\hline
\end{tabular}

Source: Survey data 
The table 4.11 describes majority of the respondents $(47 \%, n=130)$ have performed 16 or more years experience in their working field. The second biggest group of respondents, 21\% $(\mathrm{n}=58)$ have 05-10 years working experience. A further 46 respondents $(17 \%)$ have $11-15$ years experience. Only $15 \%$ of the respondents $(n=42)$ are below level of five years experience in their field.

\subsubsection{Working Zonal Education Offices in districts}

Table 4.12 Working zonal education offices in districts

\begin{tabular}{|c|c|c|}
\hline District & No of Respondents & Percentage (\%) \\
\hline Trincomalee & 62 & 22.5 \\
\hline Batticaloa & 107 & 38.8 \\
\hline Ampara & 107 & 38.8 \\
\hline Total & 276 & 100.0 \\
\hline
\end{tabular}

Source: Survey data

Table 4.12 describes the $39 \%$ of the respondents (107) come from the Batticaloa and Ampara districts. Rest of the 62 respondents comes from the Trincomalee district.

\subsubsection{Working Zonal Education Offices in Zones}

Eastern Province territory have the three district, those are Trincomalee, Batticalo and Ampara. Trincomalee district are divided by three zones such as Trincomalee, Muthur and Kantale. Batticaloa districts are enveloped in four zones, such as Batticaloa, Kalkuda, Paddiruppu, Batticaloa central. Ampara district are administrated by six zones, such as Kalmunai, Akkaraipattu, Sammanthurai, Ampara, Mahaoya and 
Dehiyatakandiya. According to the research purpose researcher selected 276 respondents from the thirteen zones.

The table 4.13 illustrated the working Zonal Education Offices in zones basis

Table 4.13 Working zonal education offices in zones

\begin{tabular}{|l|c|c|}
\hline \multicolumn{1}{|c|}{ Zones } & No of Respondents & Percentage (\%) \\
\hline Trincomalee & 27 & 9.8 \\
\hline Muthur & 27 & 9.8 \\
\hline Kantale & 9 & 3.3 \\
\hline Batticaloa & 31 & 11.2 \\
\hline Kalkudah & 9 & 3.3 \\
\hline Paddiruppu & 52 & 18.8 \\
\hline Batticaloa central & 14 & 5.1 \\
\hline Kalmunai & 31 & 11.2 \\
\hline Akkaraipattu & 25 & 9.1 \\
\hline Sammanthurai & 14 & 5.1 \\
\hline Ampara & 23 & 8.3 \\
\hline Mahaoya & 6 & 2.2 \\
\hline Dehiattakandiya & 8 & 2.9 \\
\hline Total & 276 & 100.0 \\
\hline
\end{tabular}

Source: Survey data

Zonal education offices are divided into 13 zones. Table 4.13 explains the employees working zone clearly. About 57 respondents are (20\%) working in the Trincomalee and Muthur zones. Majority of the 52 respondents are serving in the Paddiruppu zone. 
Fourteen no of respondents are working in the Batticaloa central and Sammanthurai. Seventy nine respondents are working in the Kalmunai, Akkaraipattu and Ampara zones. A very few employees (14) are working in the Mahaoya and Dhiattankandiya zones.

\subsection{Summary of Sample Description}

According to the survey data, the research results indicate lack of support for the association between from Zonal Education Officers commitment and job performance. About 73 percentages of the respondents are A/L teachers, 25 percent are principals and 2 percent zonal directors. About 47 percent are male and 53 percent are female. Out of the 276 only 54 respondents are unmarried. Age was categorized into 8 levels. Majority of the sample appears under 45 years age groups. Distances are categorized into 6 levels. About 41 percent of the respondents come under $5 \mathrm{~km}$ and 31 percent of the respondents $5-10 \mathrm{~km}$ distance from home to work organization. Mode of transportation is categorized into six levels. About 31 percent of the respondents use the motor cycle, 9 percent of the respondents walk, 35 percent of the respondents use the bus, 12 percent use the bicycle, and 15 percent use the train and others modes of convenience. About 94 percent respondents are degree holders. Work experience is categorized into 6 levels, majority of the respondents, about 21 percent, have 5-10 years experience, 18 percent of the respondent 16-20 years, and 17 percent of the respondent 11-15 years.

Based on the above facts indicated that married women staff are well balanced to manage their job arena and home affairs. Most of the teachers are only prefer to work within town area not to rural side. As the better results rural communities are facing the huge rate of under staffing in teaching sector. 
Below 35 years employees are not up to mark of experience in their work. Most of the employees are depending on the bus transport it is tricky and unsure to come on time. As these factors contribute towards a low level of commitment and unsatisfactory job performance among the employees.

In the univariate analysis is carried out with the measure of mean and standard deviation. Employee commitment and job performance are measured by the five point likart scale method. The numerical values have been given below.

1- Strongly disagree

2-Disagree

3-Neither disagree/ agree

4-Agree

5-Strongly agree

Hence the decisions rule for employee commitment:

$1 \leq \mathrm{Xi} \leq 2.5 \quad$ Low level of employee commitment in Zonal Education Officers in Eastern Province.

$2.5<\mathrm{Xi} \leq 3.5 \quad$ Moderate level of employee commitment in Zonal Education Officers in Eastern Province.

$3.5<\mathrm{Xi} \leq 5$ High level of employee commitment in Zonal Education Officers in Eastern Province. 
Decision rule for employee job performance:

$1 \leq \mathrm{Xi} \leq 2.5 \quad$ Low level of employee job performance in Zonal Education Officers in Eastern Province.

$2.5<\mathrm{Xi} \leq 3.5 \quad$ Moderate level of employee job performance in Zonal Education Officers in Eastern Province.

$3.5<\mathrm{Xi} \leq 5 \quad$ High level of employee job performance in Zonal Education Officers in Eastern Province

Table 4.14 Mean and Standard deviation for all variables

\begin{tabular}{|l|l|l|}
\hline Variables & Mean & SD \\
\hline Affective commitment & 2.7459 & .77963 \\
\hline Normative commitment & 2.9433 & .89220 \\
\hline Continuance commitment & 2.0082 & .60905 \\
\hline Job Performance & 3.7040 & 0.82990 \\
\hline
\end{tabular}

Source: Survey data

The table 4.14 shows the mean value and standard deviation of variable in respect of the Zonal Education Officers in the Eastern Province. Almost all variables are approximately having a mean value close to 3 on the measurement scale. However the factor job performance earned the highest mean value of 3.7040, whilst the factor continuance commitment earned the lowest mean value of 2.0082 . The factors affective and normative commitment are indicated that moderate level of commitment of employees in the zonal education officers; even as continuance commitment shows the low level of commitment in zonal education officers in Eastern Province. 


\subsection{Data Validity and Reliability}

Validity refers to the extent to which an instrument measures what it is supposed to measure and a measuring instrument is valid when it does what is intended to do. Dunn (2001) defined the validity as the degree to which an observation or a measurement corresponds to the construct that was supposed to be observed or a measurement. The questionnaire provides an adequate coverage by embodying an adequate number of items that represent variables of interest ensuring the content validity of the instrument. Reliability of the variables, Cronbach's coefficient alpha was calculated to evaluate the reliability of the measures. An alpha level of 0.70 or above is generally considered to be accepted (Cronbach, 1951). All the measures in survey exceed this threshold. Affective commitment (alpha $=0.941$ ), normative commitment (alpha=0.961 ), continuance commitment $($ alpha $=0.803)$ and job performance $($ alpha $=0.954)$.

\section{Analysis and Findings}

Two statistical tools were applied to the data; correlation and multiple regressions. Correlation is not the same as multiple regression but the two are related. Multiple regressions found the best predict of employee commitment towards employee job performance. The correlation quantified the magnitude and direction of the relationship between commitment and job performance.

\section{Correlation of the research variables}

For the purposes of determining whether a statistically significant relationship exists between employee commitment and job performance, the Pearson Product Moment Correlation Coefficient was used. It provides an index of the strength, magnitude and direction of the relationship between employee commitment and job performance 
(Sekaran, 2003), therefore suitable for the purposes of the present study since the study attempted to describe the relationship between commitment and job performance. Pearson product moment correlation matrix of the research variables included in the study is shown in table 4.15. The correlation matrix shows statistically significant correlations in the expected direction between commitment and job performance. According to the correlation analysis, affective commitment $(p<0.01)$, normative commitment $(p<0.01)$ positively correlated and continuance commitment $(p<0.01)$ negatively correlated with job performance.

\section{Table 4.15 Pearson Product-Moment Correlation Matrix for All Variables}

\begin{tabular}{lllll}
\hline Variable & JP & AC & NC
\end{tabular}

Code

JP

$$
1.00
$$

$\mathrm{AC}$

$.546^{* *}$

1.00

NC

$.593 * *$

$.350 * *$

1.00

$\mathrm{CC}$

$-.603 * *$

$-.363 * *$

$-.436^{* *}$

1.00

** Correlation is significant at the 0.01 level (1-tailed).

$\mathrm{JP}=\mathrm{J}$ ob Performance, $\mathrm{AC}=$ Affective Commitment, $\mathrm{NC}=$ Normative Commitment, $\mathrm{CC}=$

Continuance Commitment

\subsection{Multiple Regression Analysis}

Multiple regressions are a multivariate statistical technique. It is used for find the relationship between dependent and independent variables. It provides a method to predict the changes in the dependent variable in response to changes in more than one 
independent variable. Hence, it allows the researcher to determine the relative importance of each predictor as well as to ascertain the collective contribution of the independent variables (Sekaran, 2003).

Table 4.16:

\begin{tabular}{llll}
\hline Predictor & $\begin{array}{l}\text { Standardized } \\
\text { Regression } \\
\text { Coefficient }\end{array}$ & T-Value & Significa \\
\hline Affective Commitment & 0.322 & 6.919 & 0.000 \\
Normative Commitment & 0.313 & 7.439 & 0.000 \\
Continuance Commitment & -0.472 & -7.624 & 0.000 \\
Constant & 2.848 & 11.654 & \\
$\mathrm{R}$ & 0.757 & & \\
$\mathrm{R}^{2}$ & 0.573 & &
\end{tabular}

Adjusted $\mathrm{R}^{2}$

F

Significant level
Multiple Regression Results

0.569

121.818

$95 \%$

Source: Survey data

The results indicate that an affective commitment $(\mathrm{p}<0.05)$ and normative commitment $(p<0.05)$ have the positively influencing to the job performance. However continuance commitment has the negatively influencing to the job performance $(p<0.05)$ the beta coefficient is negative $(\beta=-0.472)$.

The value of coefficient of determination (R Square) as indicates that almost fifty seven $(57 \%)$ of the variance in perceived employees' performance can be accounted for by 
affective commitment, continuous commitment and normative commitment of zonal education employees in eastern province. The F value is 121.818 , which is significantly at $95 \%$ confidential level, which suggests that the three independent variables have significantly explained 57.3 percent of the variable in the job performance. As shown in the figure 4.1 and 4.2 indicated the positively influencing with affective and normative commitment with job performance. Even as figure 4.3 explains the negatively influencing between the continuance commitment and job performance

\section{Figure 4.1 Relationship between the Affective Commitment and Job Performance.}

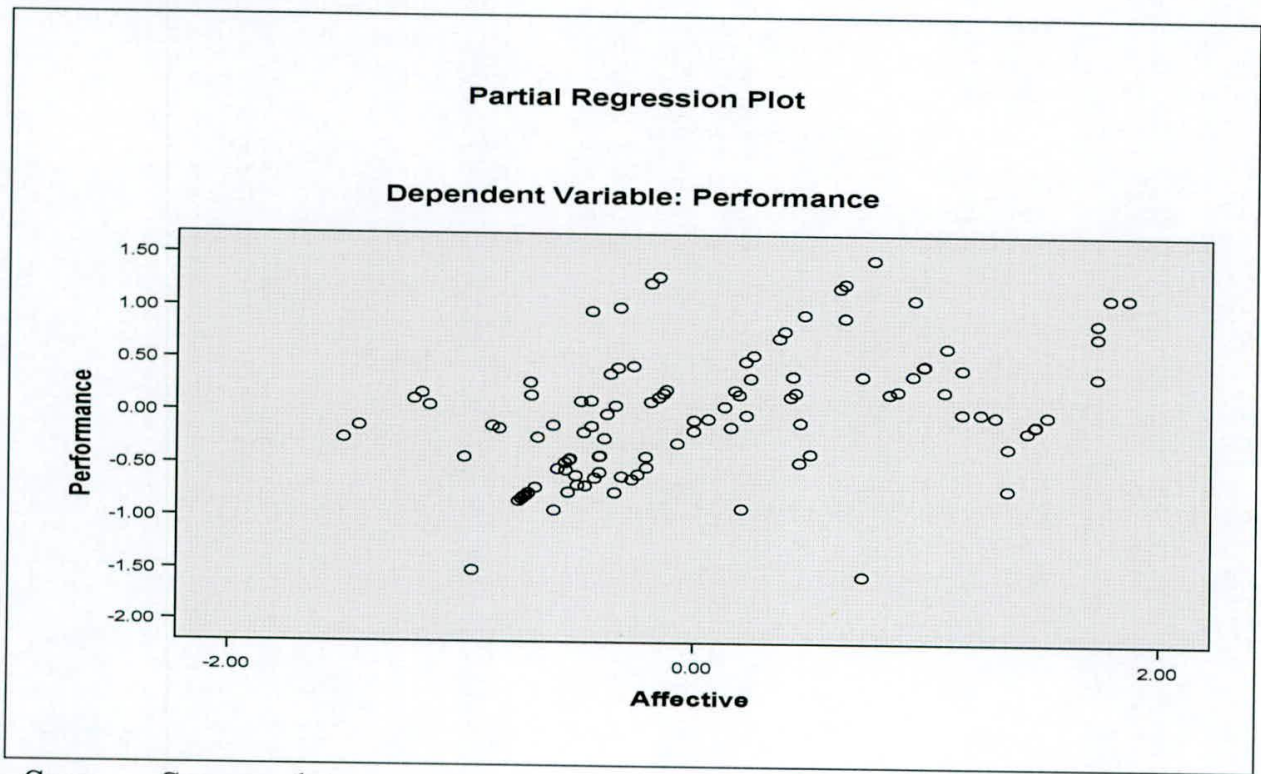

Source: Survey data

The above figure explains the affective commitment has positive relationship with job performance in Zonal Education Officers. 
Figure 4.2 Relationship between the Normative Commitment and Job Performance

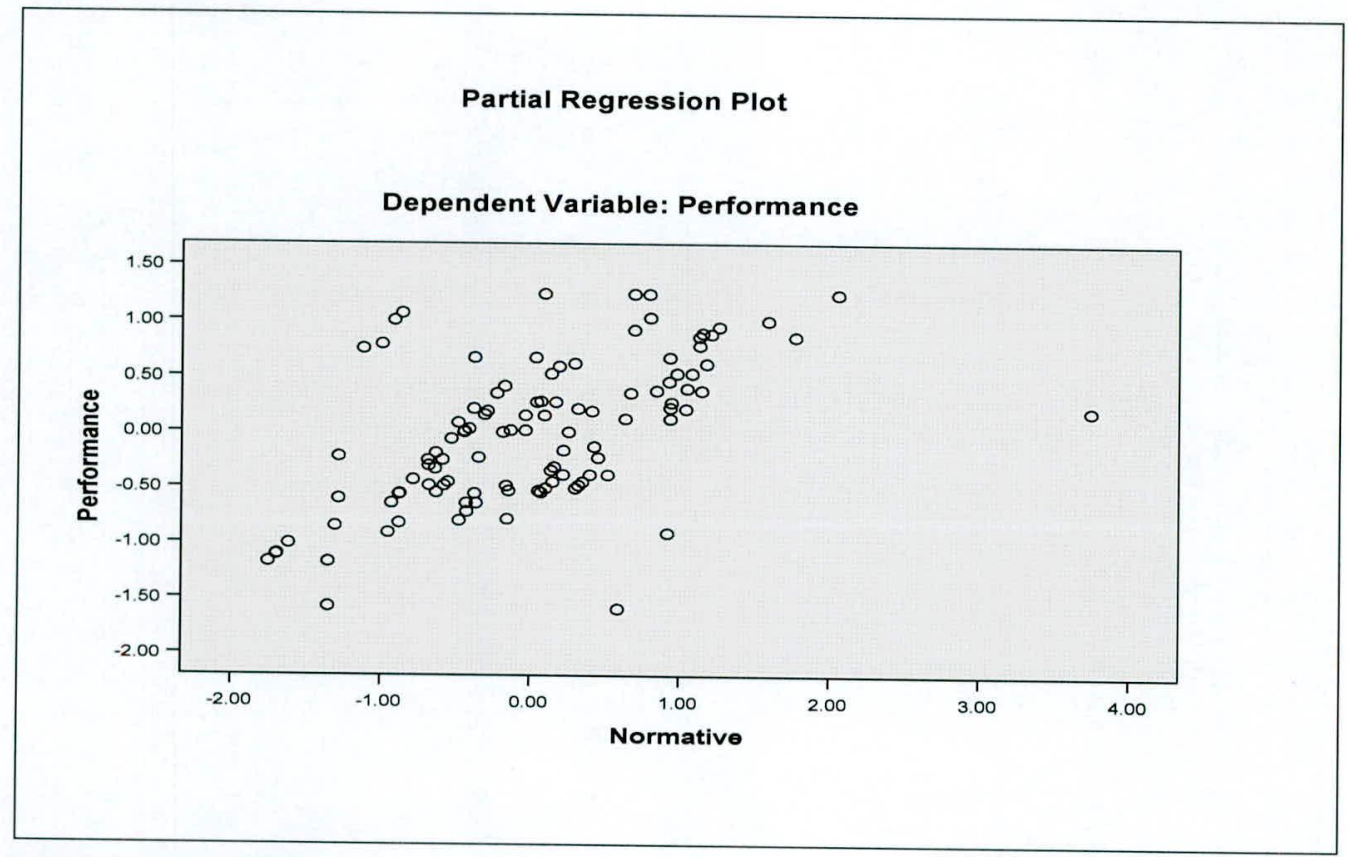

Source: Survey data

As mention above figure 4.2 explains the normative commitment has the positive relationship with job performance of Zonal Education Officers.

Figure 4.3 Relationships between the Continuance Commitment and Job Performance

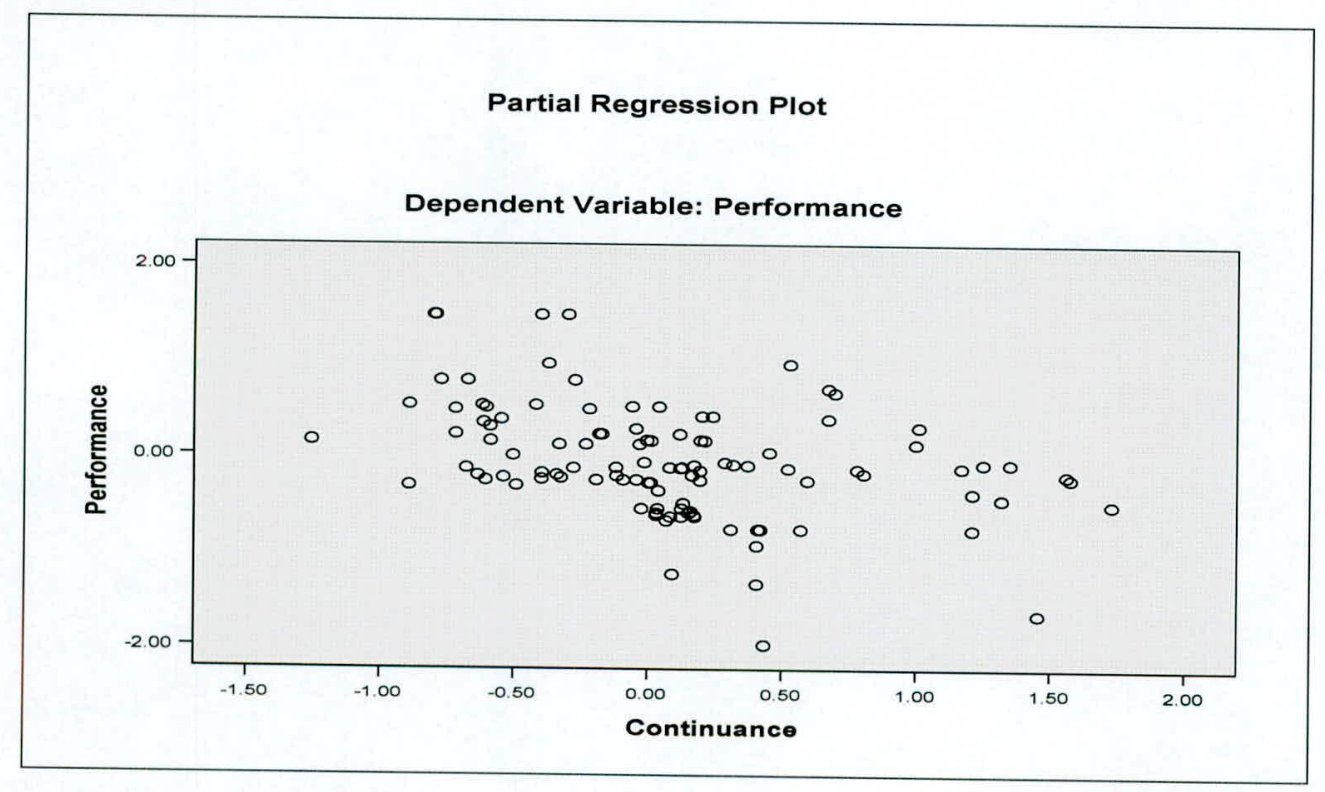

Source: Survey data 
Figure 4.3 describes continuance commitment has negative relationship with job performance of employees in the Zonal Education Officers in Eastern Province.

\subsection{Hypothesis testing}

\subsubsection{Test of hypothesis 1}

$\mathrm{H}_{01}$ : There is no relationship between employee affective commitment and job performance of Zonal Education Officers in Eastern Province in Sri Lanka.

$\mathrm{H}_{1}$ : There is a positive relationship between employee affective commitment and job performance of Zonal Education Officers in Eastern Province in Sri Lanka.

Correlation analysis shows a positive relationship between the affective commitment and job performance $(r=0.546 \mathrm{p}$ value 0.000$)$. Hence reject $\mathrm{H}_{01}$ since $r \neq 0, p$ value is less than 0.01 , that is job performance and affective commitment are positively correlated at $99 \%$ confidential level.

Regression analysis too supports this findings by giving the value of $(\beta=0.322 p$ value 0.000). Hence reject $\mathrm{H}_{01}$ since $\beta \neq 0, \mathrm{p}$ value is less than 0.05 , that is job performance and affective commitment have a positively influencing at $95 \%$ confidential level.

\subsubsection{Test of Hypothesis 2}

$\mathrm{H}_{02}$ : There is no relationship between employee normative commitment and job performance of Zonal Education Officers in Eastern Province in Sri Lanka.

$\mathrm{H}_{2}$ : There is a positive relationship between employee normative commitment and job performance of Zonal Education Officers in Eastern Province in Sri Lanka. 
Correlation analysis describes a positive relationship between the normative commitment and job performance $(r=0.593 \mathrm{p}$ value 0.000$)$. Hence reject $\mathrm{H}_{02}$ since $\mathrm{r} \neq 0$, $\mathrm{p}$ value is less than 0.01 that is job performance and normative commitment are positively correlated at $99 \%$ confidential level.

Regression analysis too support this finding by giving value $(\beta=0.313 \mathrm{p}$ value 0.000$)$, Hence reject $\mathrm{H}_{02}$ since $\beta \neq 0$, p value is less than the 0.05 , positively influencing with normative and job performance at $95 \%$ confidential level.

\subsubsection{Test of Hypothesis 3}

$\mathrm{H}_{03}$ : There is no relationship between employee continuance commitment and job performance of Zonal Education Officers in Eastern Province in Sri Lanka.

$\mathrm{H}_{3}$ : There is a negative relationship between employee continuance commitment and job performance of Zonal Education Officers in Eastern Province in Sri Lanka.

Correlation analysis describes a negative relationship between the continuance commitment and job performance $(r=-0.603 p$ value 0.00$)$ Hence reject $\mathrm{H}_{03}$ since $\mathrm{p}$ value less than 0.01 , that is job performance and continuance commitment are negatively correlated at $99 \%$ confidential level.

In the regression analysis too support the above findings ( $\beta=-0.472, p$ value 0.000 ). According to the value reject $\mathrm{H}_{03}$ since $\mathrm{p}$ value less than 0.05 , continuance commitment is negatively influencing with job performance at 95\% confidential level. 


\subsection{Discussion of the results}

The study assumed that affective commitment, normative commitment is positively associated with job performance. And also continuance commitment is negatively related with job performance. It was examined whether those hypothesized variable are determinants factors of Zonal Education Officers in the eastern province, the multiple regression model was employed.

The study focused upon the relationship between the independent variable and the dependent variable. As noted in the literature, employee commitment contains the concept of comprising three dimensions: loyalty to the organization, personal identification and belief in and acceptance of values and goals of the organization. The cronbach alpa coefficient for affective commitment (alpha=0.941), normative commitment (alpha $=0.961$ ) and continuance commitment (alpha=0.803). These variables are indicating a high level of reliability. As discussed in the literature, the employee job performance has the three dimensions: traits, behaviors and results. The cronbach alpa coefficient for job performance (alpha=0.954).

According to the related literature, job performance aspects are job knowledge, cooperation, dependability, interpersonal relations, communication skills, planning work, organizing work, punctuality, attendance, speed, efficiency achievement, completion of work on schedule and quality of work (Opatha 2003)

Employee commitment aspects are high level effort, acceptance of job assignment, preference to work, work to retain, caring about the fate of the organization, express about organization, feeling of inspiration of the organization, feeling of the quality of 
the organization, feelings of employee's values and organizational values, feeling of choice of the organization (Opatha 2003)

It is hypothesized that there is a positive relationship between employee affective commitment and job performance of Zonal Education Officers in Eastern Province in Sri Lanka. Correlation analysis shows a positive relationship between the affective commitment and job performance ( $\mathrm{r}=0.546 \mathrm{p}$ value 0.000$)$ at $99 \%$ confidential level. Regression analysis also support by giving the value of $(\beta=0.322 \mathrm{p}$ value 0.000$)$ in 95 $\%$ confidential level.

The research study support to explain the affective commitment and job performance is positive relationship. Allen and Meyer (1990) found a significant positive correlation between the affective and normative commitment scales. Emanuel Camilleri, (2002) Strong affective commitments are more valuable employees to the organization. Strong affective employee commitment feels emotional attachment to the organization. Hacket Bycio and Hausdorf (1998) found that affective commitment to the organization was positively related to the job performance. John P. Meyer, David J. Stanley, Lynne Herscovitch and Laryssa Topolnytsky (2002) affective commitment had the strongest and most favorable correlations with organization-relevant (attendance, performance, and organizational citizenship behavior).

A number of studies have found a positive relationship between affective commitment and self reported performance or work effort (Baugh \& Roberts, 1994; Bycio, Hackett, \& Allen, 1995; Darden, Hampton \& Howell, 1989; Ingram, Lee, \& Dkinner, 1989; 
Johnston \& Snizek, 1991; Leong, Randall, \& Cote,1994; Meyer, Allen, \& Smith, 1993; Randall, Fedor \& Longenecker, 1990; Sager \& Jonhston, 1989; Sakes, 1995)

It was hypothesized that there is a positive relationship between employee normative commitment and job performance of Zonal Education Officers in Eastern Province in Sri Lanka. Correlation analysis explained a positive relationship between the normative commitment and job performance $(\mathrm{r}=0.593 \mathrm{p}$ value 0.000$)$ at $99 \%$ confidential level. Regression value too support this by giving value $(\beta=0.313 \mathrm{p}$ value 0.000$)$ at $95 \%$ confidential level.

The research study support to explain the normative commitment and job performance is positive relationship. Allen and Meyer (1990) found a significant positive correlation between the affective and normative commitment scales. John P. Meyer, David J. Stanley, Lynne Herscovitch and Laryssa Topolnytsky (2002) Normative commitment was also associated with desirable outcomes. Emanuel Camilleri, (2002) normative commitment will be positively related to such work behavior as job performance, work attendance, and organizational citizenship.

It is hypothesized that there is a negative relationship between employee continuance commitment and job performance of Zonal Education Officers in Eastern Province in Sri Lanka. Correlation analysis describes a negative relationship between the continuance commitment and job performance $(r=-0.603 \mathrm{p}$ value 0.000$)$ at $99 \%$ confidential level. Regression analysis also support by giving the value of ( $\beta=-0.472$ $\mathrm{p}$ value 0.000 ) at $95 \%$ confidential level. 
This research has highlighted many problems pertaining to employees at various levels. As for the zonal directors they fail to submit the monthly supervision reports to their superiors and they show no interest in participating in the computer training programmes provided to them. The in-service advisors who are supported to supervise the schools they are responsible for have a tendency to neglect certain schools especially those in the rural areas. As far as the teachers are concerned although training is provided to them their performance is not properly evaluated. To make matters worse, many of the teachers prefer to work in the town leaving the rural schools to face a shortage of staff. Thus the highest rates of teacher understaffing in rural communities. As these factors contribute towards a lack of commitment and unsatisfactory job performance among the employees.

The research results supports to explain the continuance commitment is negative relationship with job performance. John P. Meyer, David J. Stanley, Lynne Herscovitch and Laryssa Topolnytsky (2002) Continuance commitment was unrelated or related negatively. Marthieu and Zajac (1998) have found that affective commitment to the organization is positively related to the job performance. It was also found that the relation between continuance commitment and performance was not significant. Mayer and Schooman (1998) states the relationship between continuance commitment to the organization and performance was negatively.

Those variables affective commitment, normative commitment and continuance commitment shows 57.3 percent of the variance in the job performance. Further research finds the rest of the 42.7 percent of the variance. 


\section{Chapter-5}

\section{Conclusion and Recommendations}

\section{$5.1 \quad$ Introduction}

Chapter five discusses the most salient results emanating from the results obtained in the study. Conclusions are drawn based on the obtained results and integrated with existing literature. Moreover, practical implications of the research findings are highlighted and recommendations for future research are outlined.

\subsection{Conclusion}

Employee commitment has long been a focus of study for those interested in the design and management of organizations. Positive benefits of a committed workforce are recognized as an important determinant of organizational effectiveness. This study was primarily done to understand effects of Zonal Education Officers commitment on their job performance.

The main objectives of this study are to find out the relationship between employees commitment and job performance, to examine the impact of the different level of commitment on job performance and to recommend suitable strategies to improve the job performance through employee commitment. The dimensions of measuring the employee commitment through the affective, normative and continuance commitment. Dimensions and aspect of the job performance are traits, behavior and results. The data were collected from a randomly selected 276 respondents from the zonal education offices by administrating the structured questionnaire. 
The results indicated that the affective commitment $(p<0.5)$, normative commitment $(p<0.5)$ are positively associated with the job performance at $95 \%$ confidential level. Continuance commitment is $(\mathrm{p}<0.5)$ negatively correlated at $95 \%$ confidential level in the job performance of public sector organizations.

This study mainly identifies the impact of affective commitment, continuous commitment and normative commitment on employees' job performance. Correlation analysis showed that all three dimensions of organizational commitment had a significant relationship with perceived employees performance in this study. Regression analysis identified that almost 57.3 percent of the variance in perceived employees performance are due to affective commitment, continuous commitment and normative commitment. Regression analysis also found that affective commitment and normative commitment are strong predictors of employees job performance. Further research finds the rest of the 42.7 percent of the variance in the direction. This study would help the educational department employees to increase the employee commitment and job performance of their jobs.

\subsection{Recommendations}

Based on the research finding the following suggestions could be made for improving the job performance through the employee commitment in the Zonal Education Officers in Eastern Province in Sri Lanka.

Low commitment of employees may lead to negative results and undermine the normal functioning of an organization or, at any rate, decrease the effectiveness of work of employees considerably. The low employee commitment has a number of disadvantages 
which deteriorate the work of each employee and the entire organization. To put it more precisely, low commitment leads to the low level of interest of employees in their work. Consequently, if employees are not sufficiently interested in their work they will naturally work worse than they can. In other words, the low commitment decreases the effectiveness and productivity of work for employees are not really interested in their work and its outcomes. Naturally, in such a situation, they can hardly be interested in a positive performance of the organization they work at.

Mintzberg (1996) argues that control in the public sector is normative and it is attitudes grounded in values and beliefs that matter. He holds that there is no substitute for human dedication and an organization without human commitment is like a person without a soul. This, he states, is particularly true for what he terms client-oriented services "such as health care and education, which can never be better than the people who deliver them".

Zonal Education Officers were discussed in this research has different motivational needs such as work itself, achievement, responsibility, recognition and advancement, factors that generally cause a deep commitment to job performance for most employees. Achievement is a very important variable in employees' commitment. This achievement brings to the workers feeling that he has done something of which he or she could naturally be proud of. Superior might also decide to make use of awarding system to recognize those employees who perform their job well. One would feel highly satisfied when he or she obtains a reward for their hard work and outstanding performance with innovation. 
Encourage the Zonal Education Officers to improve their skill development. The development of generic skills that is necessary for effective functioning in personal life, inter-personal relationships, employment/economic activities and society. Examples of such skills are critical and divergent thinking, creativity, initiative, leadership, problem solving, decision making, responsibility and team work. These are the products of the totality of the education process.

To provide the job satisfaction reflects individual's immediate reactions to the job. These reactions influence the development of the individual's commitment to the organization after forming comprehensive valuations of the employing organizations, its values, expectations and one's own future in it. Workers who are more satisfied with their jobs are more committed with high level of job performance in their organizations.

Working condition is important factor impact on the employee's job satisfaction and commitment. Organization wants to create the peaceful environment to their employees, it useful to increase the organizational commitment.

Provide the bank loan facilities to staff, it will more helpful to purchase the motorbike in loan basis, it may reduce the transportation difficulties and leads to the employee commitment at work.

To provide adequate training zonal directors, principals and teachers should form an integral part of a package of sound personnel development and placement policies. Increase the training program are helped to increase the commitment in their job of employees. Employees should be trained to the present situation, according to the information technology for help to increase the job knowledge, introduce internet 
section for search information. Indeed, providing sufficient promotion and posting to employees would significantly increase the job satisfaction because promotions reflect valued signals about a person's self-worth.

To provide the adequate transport facilities and quarters to teachers and principals in the rural area. It will help to increase the commitment and job performance.

\subsection{Implication}

This research has a number of important implications in relation to the zonal education officers in the eastern province of Sri Lanka. About 68 teachers (Ministry of education, Trincomalee 2009) are working on a reemployment basis in the Eastern Province. Some zones have acting zonal directors such as muthur, batticaloa, kalmunai and kalkuda. As a result there is an additional work load to the employees. Therefore the activities of the education department seem to be solely dependent on the younger generation. This will probably help to increase the commitment and job performance, which is a positive sign.

Overall, this research provides some guidance to researchers, public sector officials, and others to improve their job performance through employee commitment.

Employee commitment is one of important factors to boost job performance in workplaces. It is suggested that high quality performance can be facilitated through the development of higher employee commitment.

-End- 


\section{References}

Aaron Cohen (1999) Relationships among five forms of commitment an empirical assessment, Journal of Organizational Behavior, pp 285-308.

Abubakr Suliman (2000) Is continuance commitment beneficial to organizations? Commitment-performance relationship a new looks Journal of Managerial Psychology, Vol 15 No 5 pp 407-422.

Algina, J., Keselman, H. J. (1999). Comparing squared multiple correlation coefficients Examination of a confidence interval and test significance. Psychological Methods,4(1),76-83.

Annual Administrative Report-2007, Zonal Education Office, Akkaraipattu.

Becker, T.E and Billings, R.S. (1993). "Profile of commitment: An empirical test", Journal of Organization Behavior, 14 Pp 177-190

Bruce A.Rayton (2006) Examining the interconnection of job satisfaction and organizational commitment an application of the bivariate probit model, The International Journal of Human Resource Management, Vol 17, No 1 pp-143

Cook J.Wall T.D (1980); Commitment and Personal Need Non-Fulfillment, Journal of Occupational Psychology Vol 53,p-29-52

Eddy Madiono Sutanto, (1999), the Relationship between Employee Commitment and Job Performance, Journal Manajemendan Kewirausahaan, Vol 1 
Education Statistics (2008) Planning Secretariat-Eastern Province.

Farrell, D. \& Rusbult, C.E. (1981). Exchange variables as predictors of job satisfaction, job commitment and turnover: The impact of rewards, costs, alternatives and investment. Organizational Behavior and Human performance, 27 Pp 78-95

Isaiah O.Ugboro (2003) Influence of Managerial Trust on Survivors Perceptions of Job Insecurity and Organizational Commitment in a Post Restructuring and Downsizing Environment. Journal of Behavioral and Applied Management Vol 4, pp 23

John P. Meyer, Natalie J. Allen (2001), A Three Component Conceptualization of Organizational Commitment, The University of Western Ontario

John P.Meyer, Thomas E.Becker (2004), Employee Commitment and Motivation: A Conceptual Analysis and Integrative Model. Journal of Applied Psychology, Vol. 89, No. 6, 991-1007

Jonathon R.B. Halbeslebe, Anthony R.Wheeler M. Ronald Buckley (2008), clarifies the relationship between organizational commitment and job performance Extending the conservation of resources model pp 35-38, 2008 Nova Science Publishers, Inc.

Keith Macky and Peter Boxall (2007) The relationship between high performance work practices and employee attitudes an investigation of additive and interaction effects. The International Journal of Human Resource Management Vol 18, No 4, pp-538-549 
Kottawatta K.H.H (2007) Impact of Attitudinal Factors on Job Performance of Executives and Non-Executive Workers in Apparel Industry in Sri Lanka. Sri Lankan Journal of Human Resource Management, Vol 1, pp 53-70

Linda Rhoades, Robert Esienberger Stephen Armeli (2001), Affective Commitment to the OrganizationThe contribution of Perceived Organizational Support, Journal of Applied Psychology, 2001, Vol 86, No-5, 825-836

Luthans, F (1998) Organizational Behavior, $8^{\text {th }}$ Edition, Irwin/Mc Graw-Hill. U.S.A

Mathieu, J.E. \& Zajac, D. (1990). A review and Meta analysis of the antecedents, correlate and consequences of organizational commitment. Psychological Bulletin, 108 Pp 171-194

Ministry of Education, Cultural Affairs Sports Eastern Province-Administration Report, 2007

Mowday, R.T., Steers, R.M, \& Porter, L.W. (1979). The measurement of organizational commitment. Journal of vocational behavior, vol-14, Pp 224-247

Natalie J.Allen, John P.Meyer (1990), The measurement and antecedents of affective, continuance and normative commitment to the organization, Journal of Occupational Psychology (1990), 63, 1-18 Printed in Great Britain

Opatha H.H.D.N.P (2002) Performance Evaluation of Human Resources. 2nd edition, Published by the Institute of Management and Science. 
O’Reilly, C., and Chatman, J. (1986). "Organizational Commitment and Psychological Attachment : The Effects of Compliance, Identification and Internalization on Pro social Behavior". Journal of Applied Psychology, Pp 492-499

Rajendran Muthuveloo Raduan che Rose (2005), Typology of Organizational Commitment, American Journal of Applied Science. Pp- 1078-1081

Robert R.Sinclair, Jennifer S.Tucker and Jennifer C.Cullen (2005), Performance Differences among four Organizational Commitment Profiles, Journal of Applied Psychology, Vol. 90, No. 6, 1280-1287

Sheldon, Mary (1971). Investment and involvement as mechanisms producing commitment to the organization. Administrative Science Quarterly, 16 Pp 143-150

Smeenk S.G.A, Eisinga R.N, Teelken J.C and Doorewaard J.A.C.M (2006) The effects of HRM practices and antecedents on organizational commitment among university employees. The International Journal of Human Resource Management, Vol 17, No 12, pp2039-2044

Sundas Warsi, Noor Fatima and Shamim A.Sahibzada (2009), Study on Relationship Between Organizational Commitment and its Determinants among Private Sector Employees of Pakistan, International Review of Business Research Papers, Vol. 5 No. 3 April 2009 Pp. 399- 410

Wiener, Y. (1982). Commitment in Organizations: A Normative View. Academy of Management Review, 7, 418-428 


\section{Appendix-1}

\section{Questionnaire}

Mrs.P.Subathini,

M.Sc. (Management) Program,

Faculty of Graduate Studies,

University of Sri Jayewardenepura, Nugegoda.

Sri Lanka.

Dear Sir/Madam,

I'm M.Sc student of University of Sri Jayewardenepura, I engage on a research titled "The Relationship between the Commitment and Job Performance of Employees in the Public Sector Organizations: The Study based on the Zonal Education Officers in the Eastern Province in Sri Lanka." as a partial fulfillment of the Master of Science in Management (M.Sc) Degree. This study is mainly for the academic purpose and the information furnished would be treated confidentially. I would be very much grateful if you kindly fill the questionnaire and hand over to me.

Yours Faithfully

P.Subathini

(A student of M.Sc programme) 


\section{A. Personal Information}

1. Sex (Mark "X" Appropriately)

\begin{tabular}{|l|l|l|}
\hline 1 & Male & \\
\hline 2 & Female & \\
\hline
\end{tabular}

2. Age

\begin{tabular}{|l|l|l|}
\hline 1 & Less than 30 years & \\
\hline 2 & $30-35$ year & \\
\hline 3 & $36-40$ year & \\
\hline 4 & $41-45$ year & \\
\hline 5 & $46-50$ year & \\
\hline 6 & $51-55$ year & \\
\hline 7 & $56-60$ year & \\
\hline 8 & More than 60 year & \\
\hline
\end{tabular}

3. Marital Status

\begin{tabular}{|l|l|l|}
\hline 1 & Married & \\
\hline 2 & Unmarried & \\
\hline 3 & Divorce & \\
\hline 4 & Separate & \\
\hline
\end{tabular}

4. Occupation

\begin{tabular}{|l|l|l|}
\hline 1 & $\begin{array}{l}\text { Advanced Level } \\
\text { Teacher }\end{array}$ & \\
\hline 2 & Principal & \\
\hline 3 & Zonal director & \\
\hline
\end{tabular}

5. Type of School

\begin{tabular}{|l|l|l|}
\hline 1 & IAB & \\
\hline 2 & IC & \\
\hline
\end{tabular}

6. Distance from your home to work organization $(\mathrm{Km})$

\begin{tabular}{|l|l|l|}
\hline 1 & Less than $5 \mathrm{~km}$ & \\
\hline 2 & $5-10 \mathrm{~km}$ & \\
\hline 3 & $11-15 \mathrm{~km}$ & \\
\hline 4 & $16-20 \mathrm{~km}$ & \\
\hline 5 & $21-25 \mathrm{~km}$ & \\
\hline 6 & More than $25 \mathrm{~km}$ & \\
\hline
\end{tabular}




\section{Mode of transportation}

\begin{tabular}{|l|l|l|}
\hline 1 & Walk & \\
\hline 2 & Bicycle & \\
\hline 3 & Motor bike & \\
\hline 4 & Bus & \\
\hline 5 & Train & \\
\hline 6 & Others..................... & \\
\hline
\end{tabular}

8. Educational Qualification and Designation-Services

\begin{tabular}{|c|c|c|c|c|c|c|c|c|c|c|c|c|c|c|}
\hline \multirow[b]{2}{*}{ Designation } & \multicolumn{5}{|c|}{$\begin{array}{l}\text { Educational } \\
\text { Qualification }\end{array}$} & \multicolumn{8}{|c|}{ Services } & \multirow{2}{*}{ 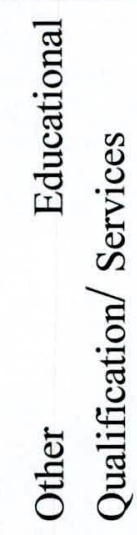 } \\
\hline & $\frac{\text { ฮี }}{\frac{\tilde{0}}{0}}$ & S & : & 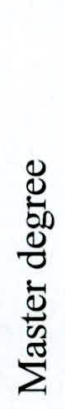 & $\frac{9}{2}$ & $\underset{\infty}{\infty}$ & 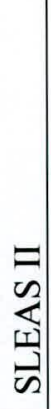 & 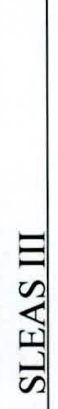 & $\frac{-}{\tilde{n}}$ & $\begin{array}{l}- \\
= \\
\tilde{n} \\
\vec{n} \\
\bar{n}\end{array}$ & $\begin{array}{l}\sim \\
= \\
\tilde{\alpha} \\
\bar{\omega}\end{array}$ & 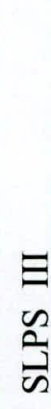 & $\frac{n}{\pi}$ & \\
\hline $\begin{array}{l}\text { Teacher } \\
\text { (for A/L } \\
\text { Students ) }\end{array}$ & & & & & & & & & & & & & & \\
\hline Principal & & & & & & & & & & & & & & \\
\hline Zonal director & & & & & & & & & & & & & & \\
\hline
\end{tabular}

9. Work experience

\begin{tabular}{|l|l|l|}
\hline 1 & Less than 5 year & \\
\hline 2 & $05-10$ year & \\
\hline 3 & $11-15$ year & \\
\hline 4 & $16-20$ year & \\
\hline 5 & $21-25$ year & \\
\hline 6 & More than 25 year & \\
\hline
\end{tabular}

10. Working Zonal Education Offices in District

\begin{tabular}{|l|l|l|}
\hline 1 & Trincomalee & \\
\hline 2 & Batticaloa & \\
\hline 3 & Ampara & \\
\hline
\end{tabular}


11. Working Zonal Education Offices in Zones.

\begin{tabular}{|l|l|l|l|}
\hline \multicolumn{3}{|c|}{ Zones } & \\
\hline Trincomalee & & Kalmunai & \\
\hline Muthur & & Akkaraipattu & \\
\hline Kantale & & Sammanthurai & \\
\hline Batticaloa & & Ampara & \\
\hline Kalkudah & & Mahaoya & \\
\hline Paddiruppu & & Dehiattakandiya & \\
\hline Batticaloa central & & & \\
\hline
\end{tabular}

B. Employee Affective Commitment

Please mark ' $x$ ' in the appropriate box of the following questions

1. Strongly Disagree

2. Disagree

3. Neither Disagree/Agree

4. Agree

5. Strongly Agree

\begin{tabular}{|c|c|c|c|c|c|c|}
\hline & Item & 1 & 2 & 3 & 4 & 5 \\
\hline 1 & I feel a sense of belonging to my organization & & & & & \\
\hline 2 & I feel emotionally attached to this organization & & & & & \\
\hline 3 & I feel I'm a part of the family at my organization & & & & & \\
\hline 4 & $\begin{array}{l}\text { This organization has a great deal of personal meaning for } \\
\text { me }\end{array}$ & & & & & \\
\hline 5 & I enjoy discussing my organization with people outside it & & & & & \\
\hline 6 & I'm extremely glad that I chose this organization to work & & & & & \\
\hline 7 & My values and the institute's values are very similar & & & & & \\
\hline 8 & I would like to work for this institute for the long term & & & & & \\
\hline 9 & I would accept almost any type of job assignment & & & & & \\
\hline 10 & $\begin{array}{l}\text { This organization really inspires the very best in me in the } \\
\text { way of job performance. }\end{array}$ & & & & & \\
\hline
\end{tabular}


C. Employee Normative Commitment

Please mark ' $x$ ' in the appropriate box of the following questions

1. Strongly Disagree

2. Disagree

3. Neither Disagree/Agree

4. Agree

5. Strongly Agree

\begin{tabular}{|l|l|l|l|l|l|l|}
\hline & Item & 1 & 2 & 3 & 4 & 5 \\
\hline 1 & I feel an obligation to remain with my current employer & & & & & \\
\hline 2 & This organization deserves my loyalty & & & & \\
\hline 3 & I feel dedication gratifying & & & & \\
\hline 4 & $\begin{array}{l}\text { I would give advance notice if I took a job with another } \\
\text { institute }\end{array}$ & & & & \\
\hline 5 & $\begin{array}{l}\text { I believe people who have been trained in a profession have } \\
\text { responsibility to stay }\end{array}$ & & & & \\
\hline 6 & I would not leave my organization right now & & & & \\
\hline 7 & I would transfer to another location if they like & & & \\
\hline 8 & I volunteer to do extra tasks that are not required by my job \\
\hline 9 & $\begin{array}{l}\text { I don't support organizations who compete with this } \\
\text { organization }\end{array}$ & & & & & \\
\hline 10 & I owe a great deal to my organization & & & \\
\hline
\end{tabular}

D. Employee Continuance Commitment

Please mark ' $x$ ' in the appropriate box of the following questions

1. Strongly Disagree

2. Disagree

3. Neither Disagree/Agree

4. Agree

5. Strongly Agree

\begin{tabular}{|c|c|c|c|c|c|c|}
\hline & Item & 1 & 2 & 3 & & 5 \\
\hline 1 & $\begin{array}{l}\text { Staying in this institute is a matter of necessity as much as I } \\
\text { desire }\end{array}$ & & & & & \\
\hline 2 & I feel very little loyalty to this organization & & & & & \\
\hline 3 & $\begin{array}{l}\text { I'm not afraid of what might happen if I quit my job without } \\
\text { having another one }\end{array}$ & & & & & \\
\hline 4 & I sometimes dissatisfied with occupation & & & & & \\
\hline 5 & $\begin{array}{l}\text { If I could go into a different profession other than the current } \\
\text { profession, which paid the same, I would probably take it }\end{array}$ & & & & & \\
\hline 6 & I like to change my profession & & & & & \\
\hline 7 & There are no pressure to continue to do the work & & & & & \\
\hline 8 & $\begin{array}{l}\text { I feel that I have more options to consider leaving my } \\
\text { organization }\end{array}$ & & & & & \\
\hline 9 & I feel my educational qualification is not relevant to my job & & & & & \\
\hline 10 & I don't have any personal development in this work & & & & & \\
\hline
\end{tabular}


E. Employee Job Performance

Please mark ' $x$ ' in the appropriate box of the following questions

1. Strongly Disagree

2. Disagree

3. Neither Disagree/Agree

4. Agree

5. Strongly Agree

\begin{tabular}{|c|c|c|c|c|c|c|}
\hline & Item & 1 & 2 & 3 & 4 & 5 \\
\hline 1 & I work in a methodical way & & & & & \\
\hline 2 & I have received training relevant to the job & & & & & \\
\hline 3 & I finish my work on time & & & & & \\
\hline 4 & I try to achieve all the organizations goals & & & & & \\
\hline 5 & My subordinates are corporate to share the work & & & & & \\
\hline 6 & I motivate the subordinate to do the work effectively & & & & & \\
\hline 7 & I do every thing with a preplanned manner & & & & & \\
\hline 8 & I communicate openly and honesty with others & & & & & \\
\hline 9 & I always update the job knowledge and skills & & & & & \\
\hline 10 & I take decisions based on the subordinate suggestions & & & & & \\
\hline
\end{tabular}


கிழக்கு மாகாண பாடசாலை கல்வியுடன் தொடர்புடைய அலுவலர்களின் வினைத்திறனுக்கும் அாப்பணிப்புக்கும் இ இடையிலான தொடா்பினை ஆராய்வதற்கான வினாக்கொத்து.

A. தனிப்பட்ட தகவல்

பின்வரும் கூற்றுக்கள் தொடா்பாக உங்களின் உடன்பாட்டினை புள்ளடி (X) இடுவதன் மூலமாக தெரியப்படுத்துக.

1. பால்

\begin{tabular}{|l|l|l|}
\hline 1 & ஆண் & \\
\hline 2 & பெண் & \\
\hline
\end{tabular}

2. வயது

\begin{tabular}{|l|l|l|}
\hline 1 & 30 வயதிற்கு குறைந்த & \\
\hline 2 & $30-35$ வயது & \\
\hline 3 & $36-40$ வயது & \\
\hline 4 & $41-45$ வயது & \\
\hline 5 & $46-50$ வயது & \\
\hline 6 & $51-55$ வயது & \\
\hline 7 & $56-60$ வயது & \\
\hline 8 & 60 வயதிற்கு மேற்பட்ட & \\
\hline
\end{tabular}

3. திருமண நிலை

\begin{tabular}{|l|l|l|}
\hline 1 & திருமணமானவா் & \\
\hline 2 & திருமணமாகாதவா & \\
\hline
\end{tabular}

4. தொழில்

\begin{tabular}{|l|l|l|}
\hline 1 & $\begin{array}{l}\text { உயாதரர வகுப்பு } \\
\text { மாணவா்களுக்குரிய } \\
\text { ஆசிரியார }\end{array}$ & \\
\hline 2 & அதிபா & \\
\hline 3 & $\begin{array}{l}\text { வலயக்கல்வி } \\
\text { பணிப்பாளா }\end{array}$ & \\
\hline
\end{tabular}

5. பாடசாலையின் வகை

\begin{tabular}{|l|l|l|}
\hline 1 & $1 \mathrm{AB}$ & \\
\hline 2 & $1 \mathrm{C}$ & \\
\hline
\end{tabular}


6. உங்களுடைய வீட்டிலிருந்து அலுவலகத்திற்கான துாரம் $(\mathrm{km}) \ldots \ldots$

\begin{tabular}{|l|l|l|}
\hline 1 & $5 \mathrm{~km}$ கு குறைந்த & \\
\hline 2 & $5-10 \mathrm{~km}$ & \\
\hline 3 & $11-15 \mathrm{~km}$ & \\
\hline 4 & $16-20 \mathrm{~km}$ & \\
\hline 5 & $21-25 \mathrm{~km}$ & \\
\hline 6 & $25 \mathrm{~km} \mathrm{கு} \mathrm{மேற்பட்ட}$ \\
\hline
\end{tabular}

7. போக்குவரத்து ஊடகம்

\begin{tabular}{|l|l|l|}
\hline 1 & நடை மூலம் & \\
\hline 2 & துவிச்சக்கர வண்டி மூலம் & \\
\hline 3 & மோட்டார் சைக்கிள் மூலம் & \\
\hline 4 & பஸ் வண்டி மூலம் & \\
\hline 5 & புகை வண்டி மூலம் & \\
\hline 6 & வேறு வகை........ & \\
\hline
\end{tabular}

8. கல்வித்தகமை பதவி- சேவை

\begin{tabular}{|c|c|c|c|c|c|c|c|c|c|c|c|c|c|c|}
\hline \multirow[b]{2}{*}{ பதவி } & \multicolumn{5}{|c|}{ கல்வித்தகமை } & \multicolumn{8}{|c|}{ சேவை } & \multirow{2}{*}{ 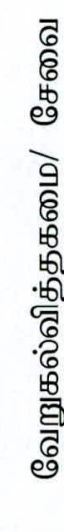 } \\
\hline & $\frac{\text { हี }}{\frac{0}{0}}$ & 方 & $\begin{array}{l}0 \\
\stackrel{d}{0} \\
0 \\
0\end{array}$ & 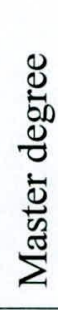 & $\frac{9}{2}$ & 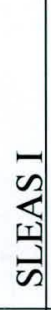 & $\begin{array}{l}= \\
\sum_{\infty}^{\infty} \\
\frac{\infty}{2}\end{array}$ & 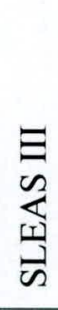 & 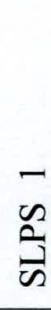 & $\bar{\Xi}$ & $\begin{array}{l}\sim \\
= \\
\omega \\
\tilde{n} \\
\bar{n}\end{array}$ & $\begin{array}{l}\Xi \\
\tilde{\Xi} \\
\tilde{\sigma}\end{array}$ & $\frac{n}{\omega}$ & \\
\hline $\begin{array}{l}\text { உயா்தர வகு } \\
\text { மாணவா்களு } \\
\text { ஆசிரியார }\end{array}$ & & & & & & & & & & & & & & \\
\hline அதிபा் & & & & & & & & & & & & & & \\
\hline $\begin{array}{l}\text { வலயக்கல்வி } \\
\text { பணிப்பாளா }\end{array}$ & & & & & & & & & & & & & & \\
\hline
\end{tabular}

9. தொழில் அனுபவம்

\begin{tabular}{|l|l|l|}
\hline 1 & 5 வருடத்திற்கு குறைவு & \\
\hline 2 & $05-10$ வருடம் & \\
\hline 3 & $11-15$ வருடம் & \\
\hline 4 & $16-20$ வருடம் & \\
\hline 5 & $21-25$ வருடம் & \\
\hline 6 & 25 வருடத்திற்கு மேல் & \\
\hline
\end{tabular}


10. கடமையாற்றும் வலயக்கல்வி அலுவலகம் அமைந்துள்ள மாவட்டம்

\begin{tabular}{|l|l|l|}
\hline 1 & திருகோணமலை & \\
\hline 2 & மட்டக்களப்பு & \\
\hline 3 & அம்பாறை & \\
\hline
\end{tabular}

11. கடமையாற்றும் வலயக்கல்வி அலுவலகம்

\begin{tabular}{|l|l|l|l|}
\hline திருகோணமலை & & கல்முனை & \\
\hline மூதுாா & & அக்கறைப்பற்று & \\
\hline கந்தளாய் & & சம்மாந்துறை & \\
\hline மட்டக்களப்பு & & அம்பாறை & \\
\hline கல்குடா & மகாஓயா & \\
\hline பட்டிருப்பு & & தெகியத்தகண்டிய & \\
\hline மத்திய மட்டக்களப்பு & & & \\
\hline
\end{tabular}

B. ஊழியர்களின் அர்ப்பணிப்பு தன்மை

பின்வரும் கூற்றுக்கள் தொடர்பாக உங்களின் உடன்படிக்கையினை தெரிவிப்பதற்காக பொருத்தமான இலக்கத்தினை பெட்டியினுள் இடுக.

\begin{tabular}{|l|l|}
\hline முற்றாக நிராகரித்தல் & 01 \\
\hline நிராகரித்தல் & 02 \\
\hline கூறமுடியவில்லை & 03 \\
\hline உடன்படுதல் & 04 \\
\hline முழுமையாக உடன்படுதல் & 05 \\
\hline
\end{tabular}

Affective Commitment - உணர்வுபூர்வமான அர்ப்பணிப்பு

\begin{tabular}{|c|c|c|c|c|c|c|}
\hline & விடயம் & 1 & 2 & 3 & 4 & 5 \\
\hline 01 & $\begin{array}{l}\text { நான் கடமையாற்றும் } \\
\text { உணர்கின்றேன். }\end{array}$ & & & & & \\
\hline 02 & நான் உணர்வு பூர்வமாக இன் நிறுவனத்தில் இணைந்துள்ளேன். & & & & & \\
\hline 03 & நான் இ இன் நிறுவனத்தில் ஒரு குடும்ப அங்கத்தவராக உணர்கின்றேன். & & & & & \\
\hline 04 & எனக்கென்றொரு தனிப்பட்ட அந்தஸ்த்து உண்டு என உணர்கின்றேன். & & & & & \\
\hline 05 & $\begin{array}{l}\text { என்னுடைய நிறுவனத்தைப் } \quad \text { பற்றி } \\
\text { சந்தோசமடைகின்றேன். }\end{array}$ & & & & & \\
\hline 06 & $\begin{array}{l}\text { நான் இன் நிறுவனத்தில் சேவையாற்ற } \text { கிடைத்ததையிட்டு } \text { மிகவும் } \\
\text { சந்தோசமடைகின்றேன். }\end{array}$ & & & & & \\
\hline 07 & என்னுடைய இலக்கும்நிறுவன இலக்கும் ஒன்றாக இருக்கின்றது. & & & & & \\
\hline 08 & $\begin{array}{l}\text { இன் நிறுவனத்தில் நீண்டகாலமாக } \\
\text { உள்ளேன். }\end{array}$ & & & & & \\
\hline 09 & 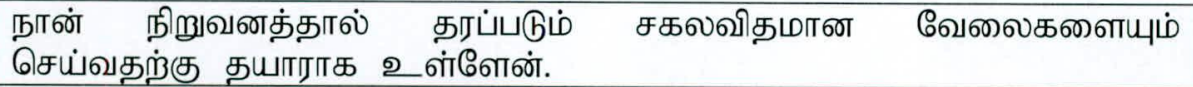 & & & & & \\
\hline 10 & $\begin{array}{l}\text { இன் நிஷுவனம் என்னுடைய } \\
\text { முன்னணியாக திகழ்கின்றது. }\end{array}$ & & & & & \\
\hline
\end{tabular}


பின்வரும் கூற்றுக்கள் தொடர்பாக உங்களின் உடன்படிக்கையினை தெரிவிப்பதற்காக பொருத்தமான இலக்கத்தினை பெட்டியினுள் இ இடுக.

\begin{tabular}{|l|l|}
\hline முற்றாக நிராகரித்தல் & 01 \\
\hline நிராகரித்தல் & 02 \\
\hline கூறமுடியவில்லை & 03 \\
\hline உடன்படுதல் & 04 \\
\hline முழுமையாக உடன்படுதல் & 05 \\
\hline
\end{tabular}

Normative Commitment - கடமை உணர்வான அர்ப்பணிப்பு

\begin{tabular}{|c|c|c|c|c|c|c|}
\hline & விடயம் & 1 & 2 & 3 & 4 & 5 \\
\hline 01 & $\begin{array}{l}\text { இன் நிறுவனத்தில் தொடர்ந்து வேலைசெய்யவேண்டிய } \\
\text { எனக்குண்டு என்பதை உணைக் }\end{array}$ & & & & & \\
\hline 02 & இன்நிறுவனம் என்னுடைய நம்பகத்தன்மையை பாதுகாக்கின்றது. & & & & & \\
\hline 03 & அர்ப்பணிப்பாக வேலைசெய்வதில் சந்தோசமடைகின்றேன். & & & & & \\
\hline 04 & $\begin{array}{l}\text { தற்போதுள்ள நிறுவனத்திற்கு முன்னறிவித்தல் கொடுத்துவிட்டு } \\
\text { பிறிதொரு நிறுவனத்தில் வேலையினை தெரிவு செய்வேன். }\end{array}$ & & & & & \\
\hline 05 & $\begin{array}{l}\text { வேலை தொடர்பான பயிற்சியினை பெறுவதன் காரணமாக அன் } \\
\text { நிறுவனத்தில் தொடர்ந்து பணியாற்ற வேண்டிய கடப்பாடு உள்ளது. }\end{array}$ & & & & & \\
\hline 06 & $\begin{array}{l}\text { தற்போது நான் வேலைசெய்யும் நிறுவனத்தை } \text { விட்டு } \text { விலும்புவதை } \\
\text { விலைலை. }\end{array}$ & & & & & \\
\hline 07 & 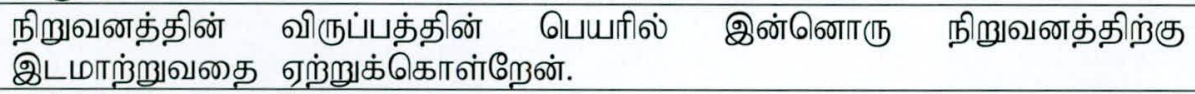 & & & & & \\
\hline 08 & 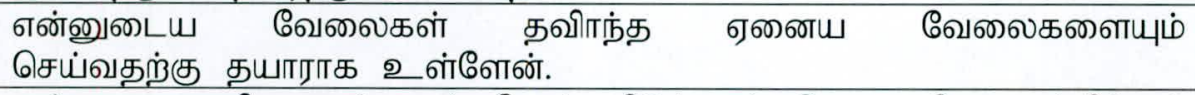 & & & & & \\
\hline 09 & $\begin{array}{l}\text { என்னுடைய நிறுவனத்துடன் போட்டியிடும் எந்தவொரு நிறுவனத்திற்கும் } \\
\text { ஒத்துழைப்பு வழங்கமாட்டேன். }\end{array}$ & & & & & \\
\hline 10 & என்னுடைய கடமையில் கண்ணும்கருத்துமாக உள்ளேன். & & & & & \\
\hline
\end{tabular}

Continuance Commitment - வாழ்வாதாரம் தொடர்பான கடமை

\begin{tabular}{|c|c|c|c|c|c|c|}
\hline & விடயம் & 1 & 2 & 3 & 4 & 5 \\
\hline 01 & 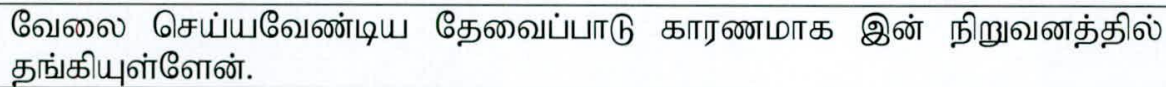 & & & & & \\
\hline 02 & $\begin{array}{l}\text { இன் நிறுவனம் } \quad \text { என்னுடைய } \\
\text { செலுத்துவதாக உணர்கின்றேன். }\end{array}$ & & & & & \\
\hline 03 & $\begin{array}{l}\text { பிறிதொரு வேலை கிடைக்காத நிலையிலும் கூட } \text { எனக்கு } \\
\text { தற்போதுள்ளவேலையை கைவிடுவது சிரமமாக தெரியவில்லை. }\end{array}$ & & & & & \\
\hline 04 & $\begin{array}{l}\text { சிலவேலையில் } \\
\text { உணர்கின்றேன் }\end{array}$ & & & & & \\
\hline 05 & $\begin{array}{l}\text { தற்போயை வருமானத்தினை வேறு நிறுவனத்தில் அல்லது வேறு } \\
\text { தொழில் கிடைக்குமாயின் அங்கு செல்ல விரும்புவேன். }\end{array}$ & & & & & \\
\hline 06 & $\begin{array}{l}\text { நான் பிறிதொரு வேலையை } \quad \text { தேர்ந்தெடுப்பதில் } \\
\text { கொண்டுள்ளேன். }\end{array}$ & & & & & \\
\hline 07 & $\begin{array}{l}\text { இன் நிறுவனத்தில் தொடர்ந்து வேலை செய்யவேண்டுமென்று மேல் } \\
\text { அதிகாரியினால் அழுத்தம் தரப்படவில்லை. }\end{array}$ & & & & & \\
\hline
\end{tabular}




\begin{tabular}{|l|l|l|l|l|l|l|}
\hline 08 & $\begin{array}{l}\text { நான் இன் நிறுவனத்தை விட்டு விலகினாலும் வேறொரு வேலையைய } \\
\text { பெறக்கூடிய வாய்ப்புக்கள் அதிகமாக உள்ளது என உணர்கின்றேன். }\end{array}$ & & & & \\
\hline 09 & $\begin{array}{l}\text { என்னுடைய கல்விதகமை என்னுடைய தொழிலுக்கு பொருத்தமற்றது } \\
\text { என உணர்கின்றேன். }\end{array}$ & & & \\
\hline 10 & $\begin{array}{l}\text { எனக்கு இன் நிறுவனத்தில் தனிப்பட்ட முன்னேற்றத்தற்கு இடமில்லை } \\
\text { என உணர்கின்றேன. }\end{array}$ & & & \\
\hline
\end{tabular}

Job Performance - ஊழியரின் வெளியீடு

\begin{tabular}{|c|c|c|c|c|c|c|}
\hline & விடயம் & 1 & 2 & 3 & 4 & 5 \\
\hline 01 & எனது வேலையை ஒழழுங்கு மறைப்படி செய்கின்றேன். & & & & & \\
\hline 02 & எனது வேலை தொடர்பான பயிற்சியை பெற்றுக்கொள்கின்றேன். & & & & & \\
\hline 03 & நான் குறித்த நேரத்தில் எனது வேலையை முடித்துக்கொள்கின்றேன். & & & & & \\
\hline 04 & $\begin{array}{l}\text { நிறுவன இலக்கை } \\
\text { வழங்குகிறேன். }\end{array}$ & & & & & \\
\hline 05 & எனது சக ஊழியர்கள் வேலை பகிர்வில்பங்களிப் செய்கிறார்கள். & & & & & \\
\hline 06 & $\begin{array}{l}\text { எனக்கு கீழே வேலை } \\
\text { ஊக்குவிக்கின்றேன். }\end{array}$ & & & & & \\
\hline 07 & $\begin{array}{l}\text { நான் எந்தவொரு வேலையையும் மேற்கொள்ள முன் திட்டம் ஒன்றை } \\
\text { தயாரிப்பேன். }\end{array}$ & & & & & \\
\hline 08 & $\begin{array}{l}\text { நான் ஏனையவாகளுடன் வெளிப்படையாகவும் } \\
\text { தொடாபாடலை மேர்மையாகவும் }\end{array}$ & & & & & \\
\hline 09 & $\begin{array}{l}\text { நான் எப்பொழுதும் } \\
\text { வேலை திறமையாக } \quad \text { தொடர்பான } \\
\text { உள்ளேன். }\end{array}$ & & & & & \\
\hline 10 & $\begin{array}{l}\text { நான் சக ஊழியர்களுடன் கலந்தாலோசித்த பின்பே தீர்மானங்களை } \\
\text { மேற்கொள்கின்றே. }\end{array}$ & & & & & \\
\hline
\end{tabular}


Frequency Table

\section{Appendix II}

Table 2.1 Sex

\begin{tabular}{|ll|r|r|r|r|}
\hline & & & & \multicolumn{1}{c|}{$\begin{array}{c}\text { Cumulative } \\
\text { Percent }\end{array}$} \\
\hline Valid & Male & 131 & 47.5 & 47.5 & 47.5 \\
& Female & 145 & 52.5 & 52.5 & 100.0 \\
& Total & 276 & 100.0 & 100.0 & \\
\hline
\end{tabular}

Table 2.2 Age

\begin{tabular}{|rl|r|r|r|r|}
\hline & & & & \multicolumn{1}{c|}{$\begin{array}{c}\text { Cumulative } \\
\text { Percent }\end{array}$} \\
\hline Valid & $<30$ & Frequency & Percent & Valid Percent & 10.5 \\
& $30-35$ & 29 & 10.5 & 10.5 & 21.7 \\
$36-40$ & 31 & 11.2 & 11.2 & 32.6 \\
$41-45$ & 30 & 10.9 & 10.9 & 53.6 \\
$46-50$ & 58 & 21.0 & 21.0 & 74.3 \\
$51-55$ & 57 & 20.7 & 20.7 & 88.8 \\
$56-60$ & 40 & 14.5 & 14.5 & 99.6 \\
$>60$ & 30 & 10.9 & 10.9 & 100.0 \\
Total & 1 & .4 & .4 & \\
\hline
\end{tabular}

Table 2.3 Marital Status

\begin{tabular}{|ll|r|r|r|r|}
\hline & & & & \multicolumn{1}{c|}{$\begin{array}{c}\text { Cumulative } \\
\text { Percent }\end{array}$} \\
\hline Valid & Married & 222 & 80.4 & 80.4 & 80.4 \\
& Single & 54 & 19.6 & 19.6 & 100.0 \\
& Total & 276 & 100.0 & 100.0 & \\
\hline
\end{tabular}

Table 2.4 Occupation

\begin{tabular}{|ll|r|r|r|r|}
\hline & & & & $\begin{array}{c}\text { Cumulative } \\
\text { Percent }\end{array}$ \\
\hline Valid & A/L teacher & 200 & 72.5 & 72.5 & 72.5 \\
& Principal & 70 & 25.4 & 25.4 & 97.8 \\
& Zonal director & 6 & 2.2 & 2.2 & 100.0 \\
& Total & 276 & 100.0 & 100.0 & \\
\hline
\end{tabular}

Table 2.5 School Type

\begin{tabular}{|ll|r|r|r|r|}
\hline & & & & \multicolumn{2}{c|}{$\begin{array}{c}\text { Cumulative } \\
\text { Percent }\end{array}$} \\
\hline Valid & Frequency & Percent & Valid Percent & 2.2 \\
& $1 \mathrm{AB}$ & 148 & 2.2 & 2.2 & 55.8 \\
& $1 \mathrm{C}$ & 122 & 43.6 & 53.6 & 100.0 \\
& Total & 276 & 100.0 & 44.2 & \\
\hline
\end{tabular}

Note- 0 indicates the six zonal directors 
Table 2.6 Distance from home to organization

\begin{tabular}{|ll|r|r|r|r|}
\hline & & & & Cumulative \\
& & Frequency & Percent & Valid Percent & \multicolumn{1}{c|}{ Percent } \\
\hline Valid & $<5$ & 112 & 40.6 & 40.6 & 40.6 \\
& $5-10$ & 85 & 30.8 & 30.8 & 71.4 \\
& $11-15$ & 62 & 22.5 & 22.5 & 93.8 \\
$16-20$ & 13 & 4.7 & 4.7 & 98.6 \\
$21-25$ & 2 & .7 & .7 & 99.3 \\
& $>25$ & 2 & .7 & .7 & 100.0 \\
& Total & 276 & 100.0 & 100.0 & \\
\hline
\end{tabular}

Table 2.7 Mode of transportation

\begin{tabular}{|ll|r|r|r|r|}
\hline & & & & \multicolumn{2}{c|}{$\begin{array}{c}\text { Cumulative } \\
\text { Percent }\end{array}$} \\
\hline Valid & Walk & 24 & 8.7 & 8.7 & 8.7 \\
& Bicycle & 32 & 11.6 & 11.6 & 20.3 \\
& Motor bike & 84 & 30.4 & 30.4 & 50.7 \\
Bus & 96 & 34.8 & 34.8 & 85.5 \\
Train & 23 & 8.3 & 8.3 & 93.8 \\
Others & 17 & 6.2 & 6.2 & 100.0 \\
Total & 276 & 100.0 & 100.0 & \\
\hline
\end{tabular}

Table 2.8 Educational Qualification

\begin{tabular}{|c|c|c|c|c|c|}
\hline & & Frequency & Percent & Valid Percent & $\begin{array}{c}\text { Cumulative } \\
\text { Percent }\end{array}$ \\
\hline \multirow[t]{5}{*}{ Valid } & Diploma & 13 & 4.7 & 4.7 & 4.7 \\
\hline & PGDM & 39 & 14.1 & 14.1 & 18.8 \\
\hline & Degree & 172 & 62.3 & 62.3 & 81.2 \\
\hline & Master degree & 52 & 18.8 & 18.8 & 100.0 \\
\hline & Total & 276 & 100.0 & 100.0 & \\
\hline
\end{tabular}

Table 2.9 Services

\begin{tabular}{|ll|r|r|r|r|}
\hline & Frequency & Percent & Valid Percent & $\begin{array}{c}\text { Cumulative } \\
\text { Percent }\end{array}$ \\
\hline Valid & Non applicable & 176 & 63.8 & 63.8 & 63.8 \\
& SLEAS II & 6 & 2.2 & 2.2 & 65.9 \\
& SLPS II-2 & 11 & 4.0 & 4.0 & 69.9 \\
SLPS 1 & 7 & 2.5 & 2.5 & 72.5 \\
SLPS II-1 & 49 & 17.8 & 17.8 & 90.2 \\
SLTS & 27 & 9.8 & 9.8 & 100.0 \\
Total & 276 & 100.0 & 100.0 & \\
\hline
\end{tabular}


Table 2.10 Work Experience

\begin{tabular}{|ll|r|r|r|r|}
\hline & & & & Cumulative \\
& & Frequency & Percent & Valid Percent & Percent \\
\hline Valid & $<5$ & 42 & 15.2 & 15.2 & 15.2 \\
& $05-10$ & 58 & 21.0 & 21.0 & 36.2 \\
& $11-15$ & 46 & 16.7 & 16.7 & 52.9 \\
& $16-20$ & 51 & 18.5 & 18.5 & 71.4 \\
$21-25$ & 45 & 16.3 & 16.3 & 87.7 \\
& $>25$ & 34 & 12.3 & 12.3 & 100.0 \\
& Total & 276 & 100.0 & 100.0 & \\
\hline
\end{tabular}

Table 2.11 Working zonal education offices in districts

\begin{tabular}{|ll|r|r|r|r|}
\hline & & & & Cumulative \\
& & Frequency & Percent & Valid Percent & \begin{tabular}{c} 
Percent \\
\hline Valid
\end{tabular} Trincomalee \\
& 62 & 22.5 & 22.5 & 22.5 \\
& Batticaloa & 107 & 38.8 & 38.8 & 61.2 \\
& Ampara & 107 & 38.8 & 38.8 & 100.0 \\
& Total & 276 & 100.0 & 100.0 & \\
\hline
\end{tabular}

Table 2.12 Working zonal education offices in zones

\begin{tabular}{|ll|r|r|r|r|}
\hline & Frequency & Percent & Valid Percent & $\begin{array}{c}\text { Cumulative } \\
\text { Percent }\end{array}$ \\
\hline Valid & Trincomalee & 27 & 9.8 & 9.8 & 9.8 \\
& Muthur & 27 & 9.8 & 9.8 & 19.6 \\
Kantale & 9 & 3.3 & 3.3 & 22.8 \\
Batticaloa & 31 & 11.2 & 11.2 & 34.1 \\
Kalkudah & 9 & 3.3 & 3.3 & 37.3 \\
Paddiruppu & 52 & 18.8 & 18.8 & 56.2 \\
Batticaloa central & 14 & 5.1 & 5.1 & 61.2 \\
Kalmunai & 31 & 11.2 & 11.2 & 72.5 \\
Akkaraipattu & 25 & 9.1 & 9.1 & 81.5 \\
Sammanthurai & 14 & 5.1 & 5.1 & 86.6 \\
Ampara & 23 & 8.3 & 8.3 & 94.9 \\
Mahaoya & 6 & 2.2 & 2.2 & 97.1 \\
Dehiattakandiya & 8 & 2.9 & 2.9 & 100.0 \\
Total & 276 & 100.0 & 100.0 & \\
\hline
\end{tabular}


Bar chart

Figure 2.1 Sex

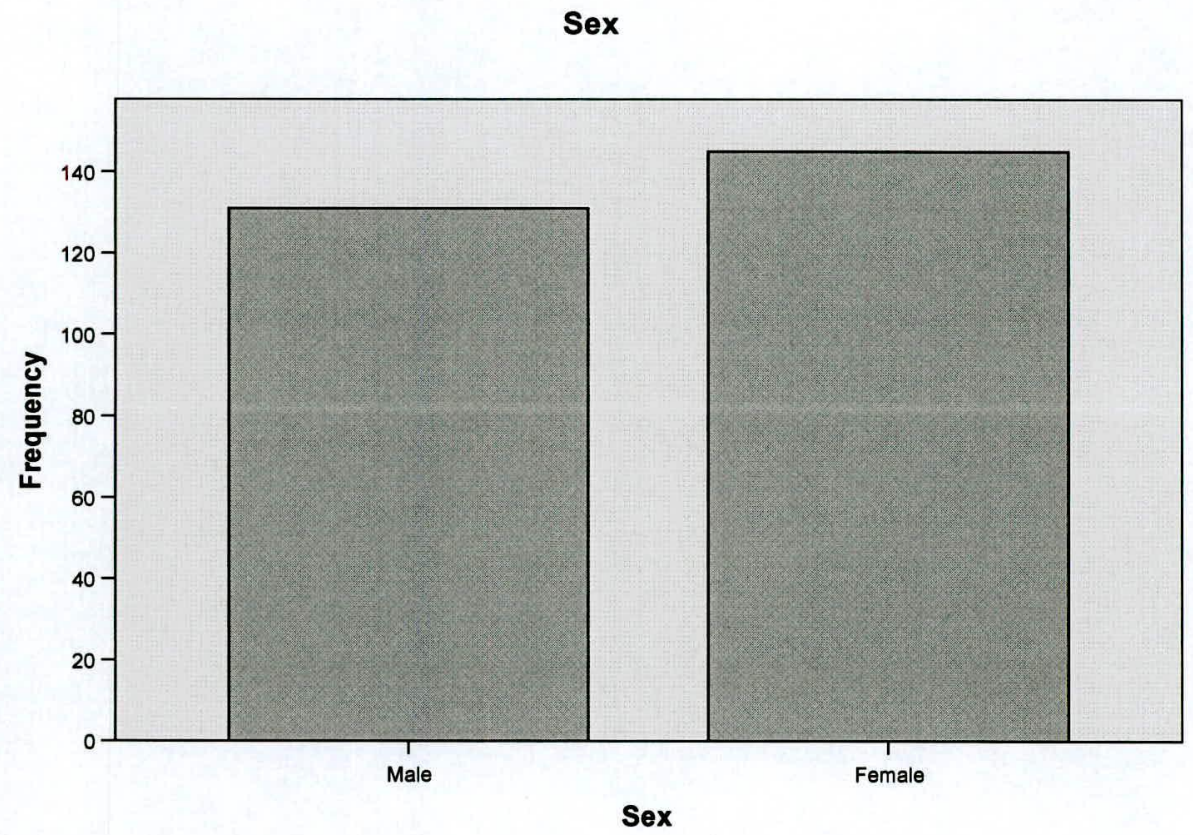

Figure 2.2 Age

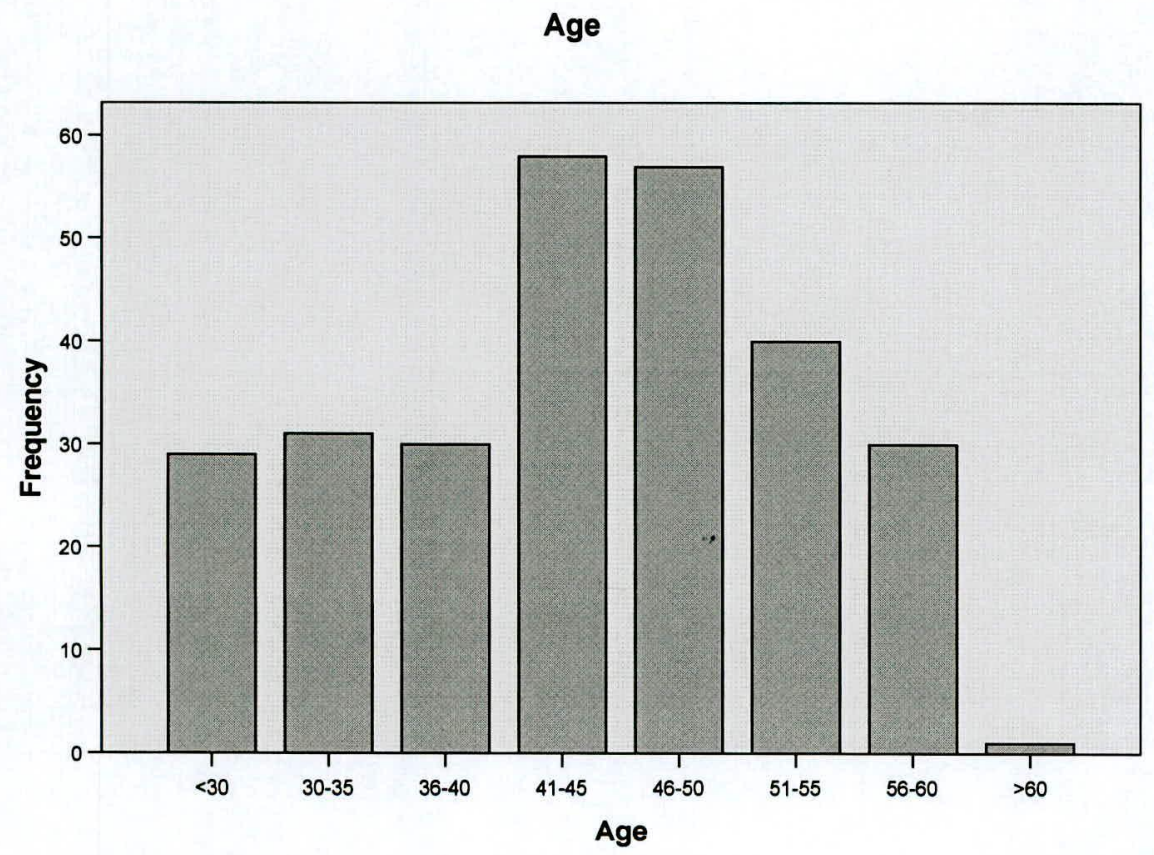


Figure 2.3 Marital Status

\section{Marital status}

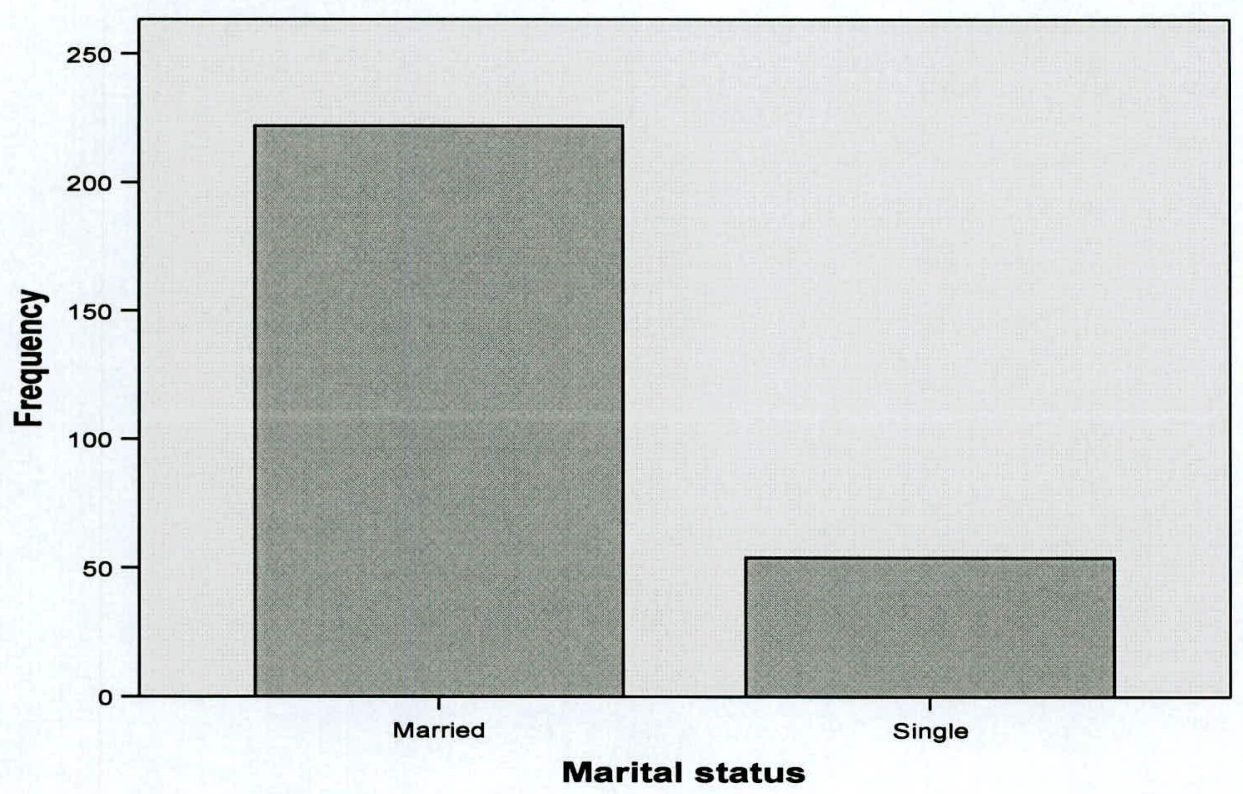

Figure 2.4 Occupation

Occupation

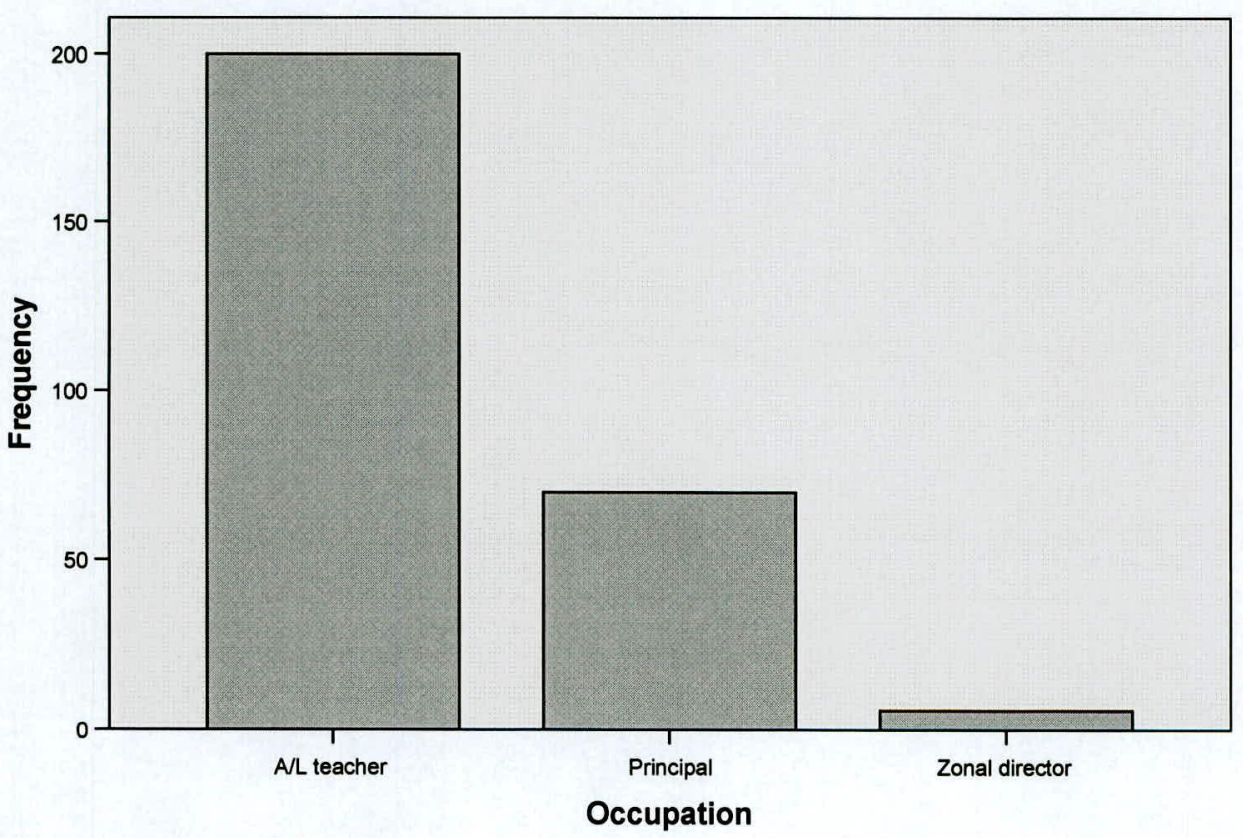


Figure 2.5 School Type

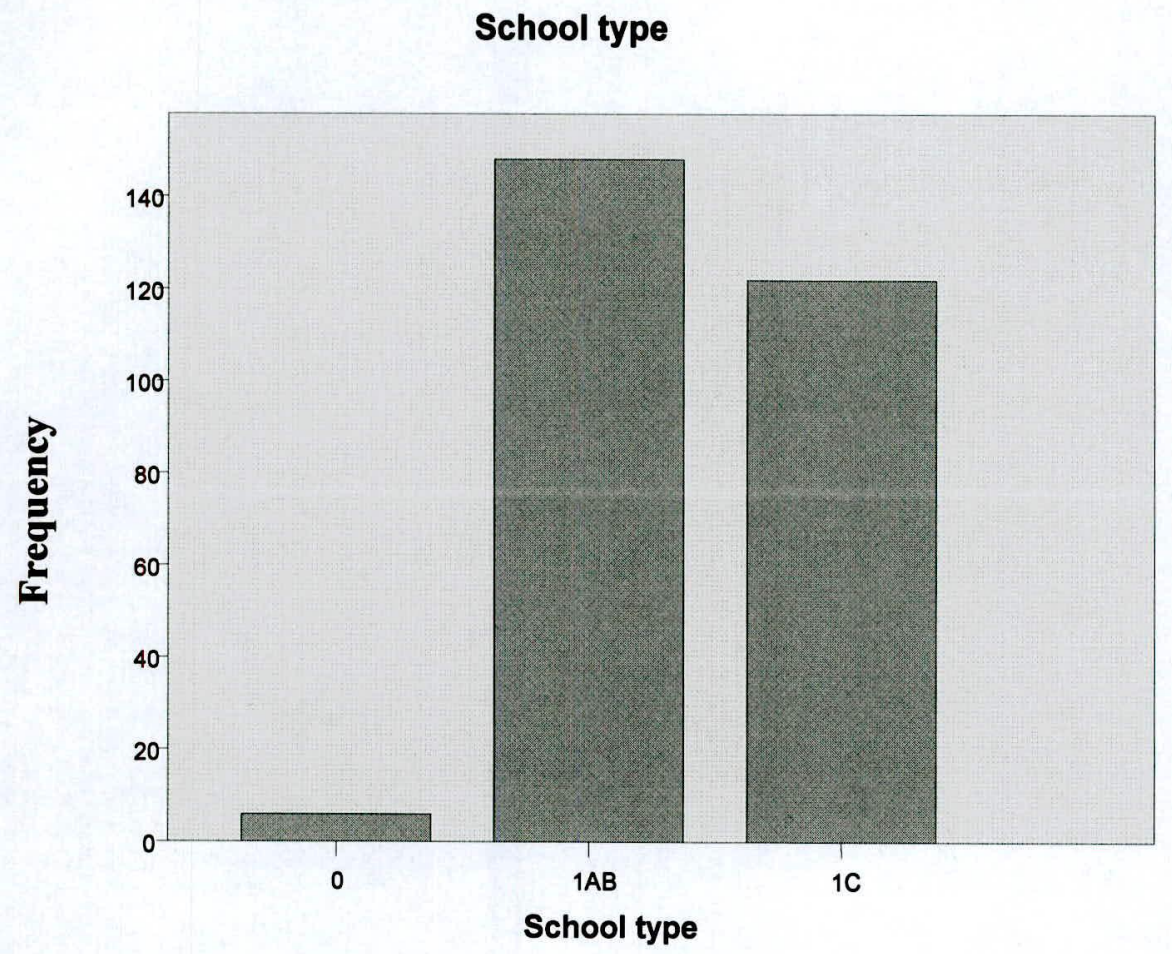

Figure 2.6 Distance from home to organization

Distance from home to organization

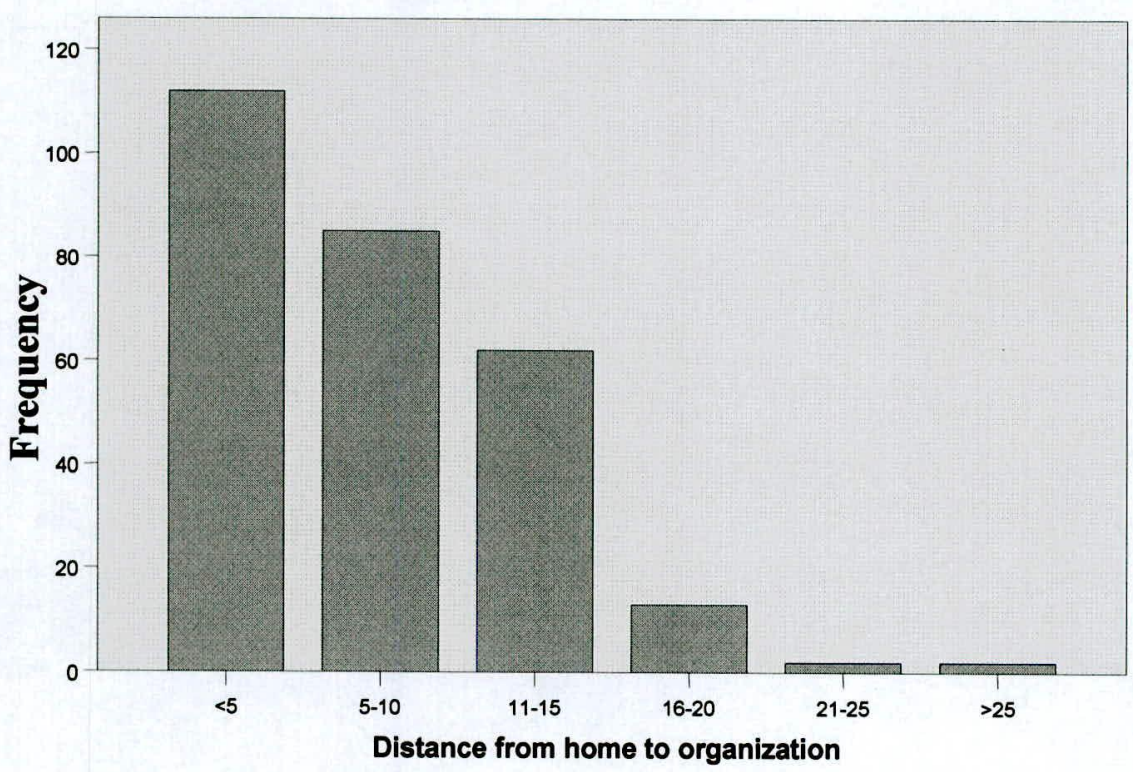


Figure 2.7 Mode of transportation

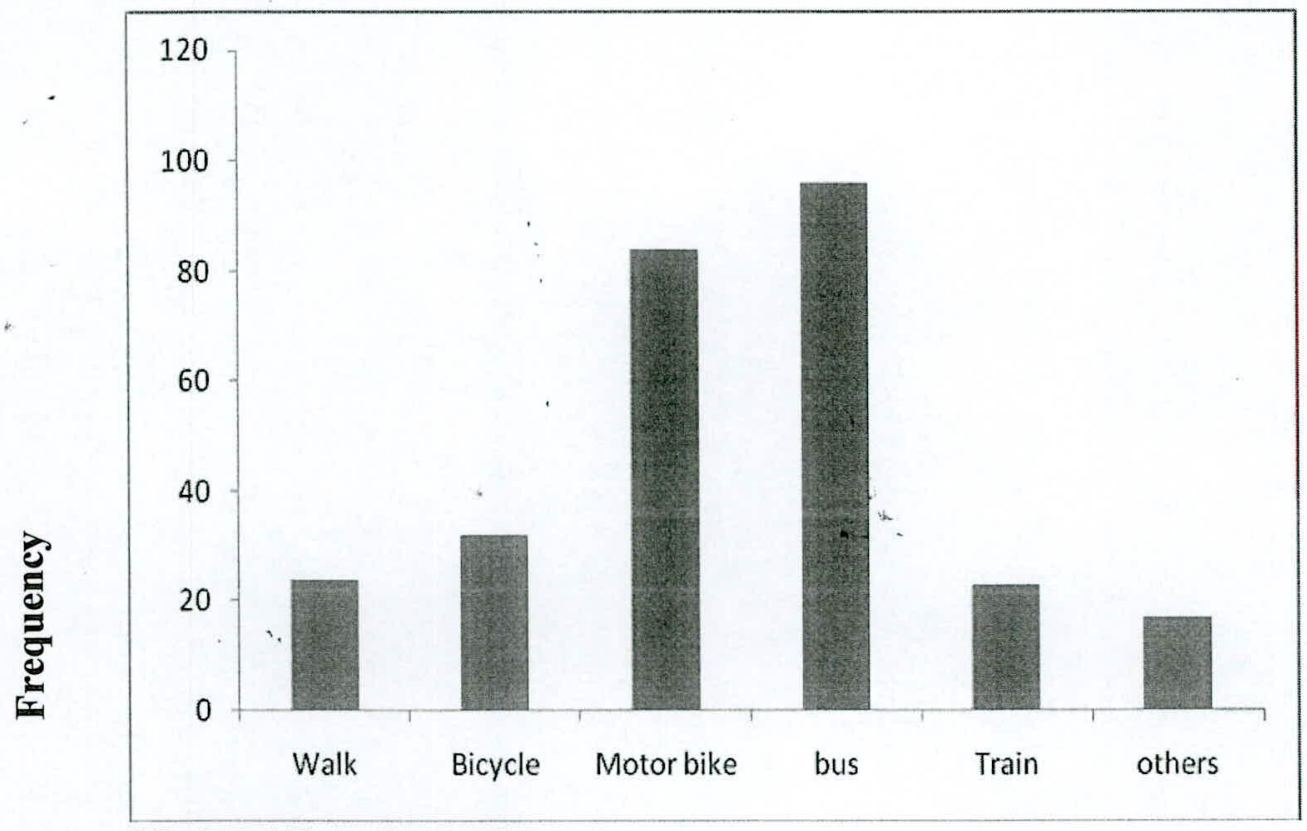

Mode of Transportation

Figure 2.8 Educational Qualification

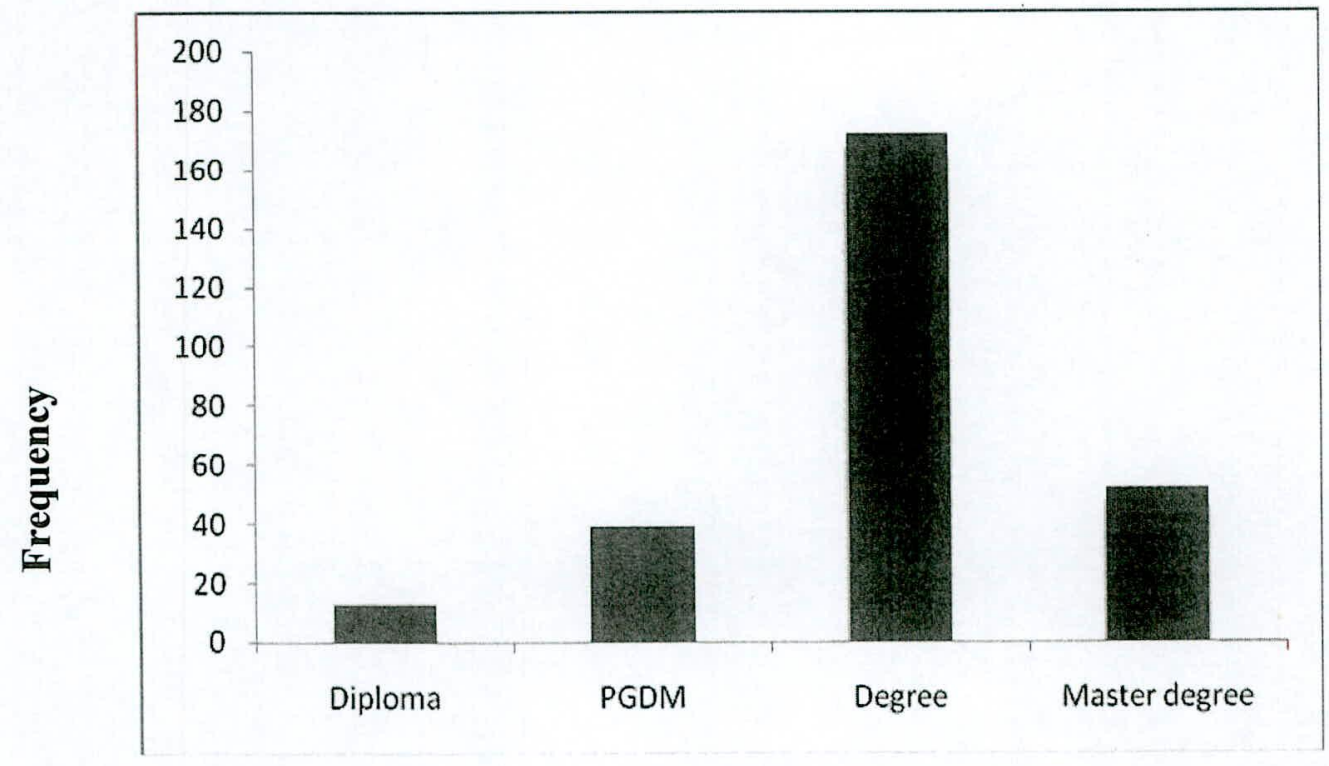

Educational Qualification 
Figure 2.9 Services

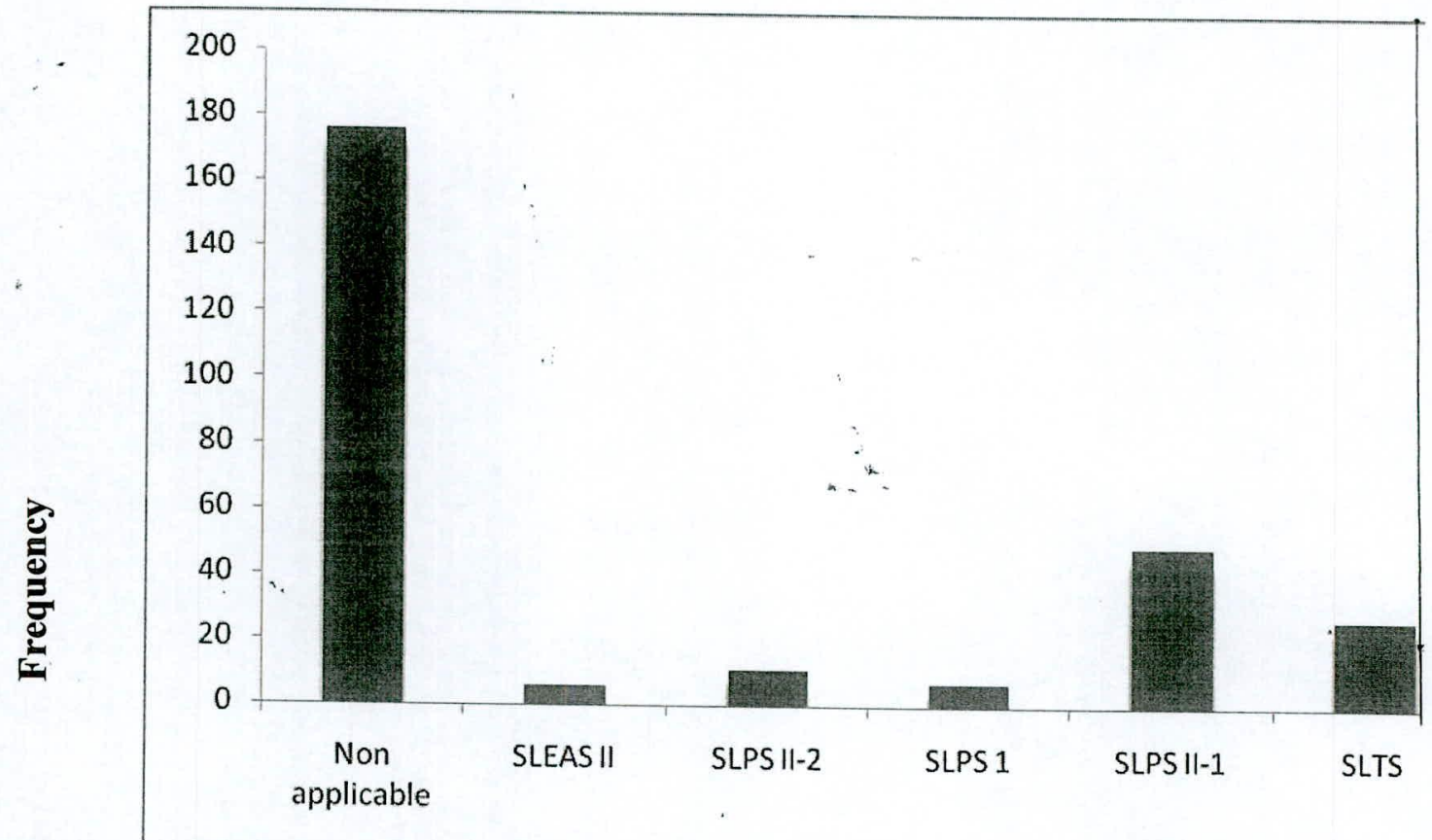

Services

Figure 2.10 Work Experience

Work Experience

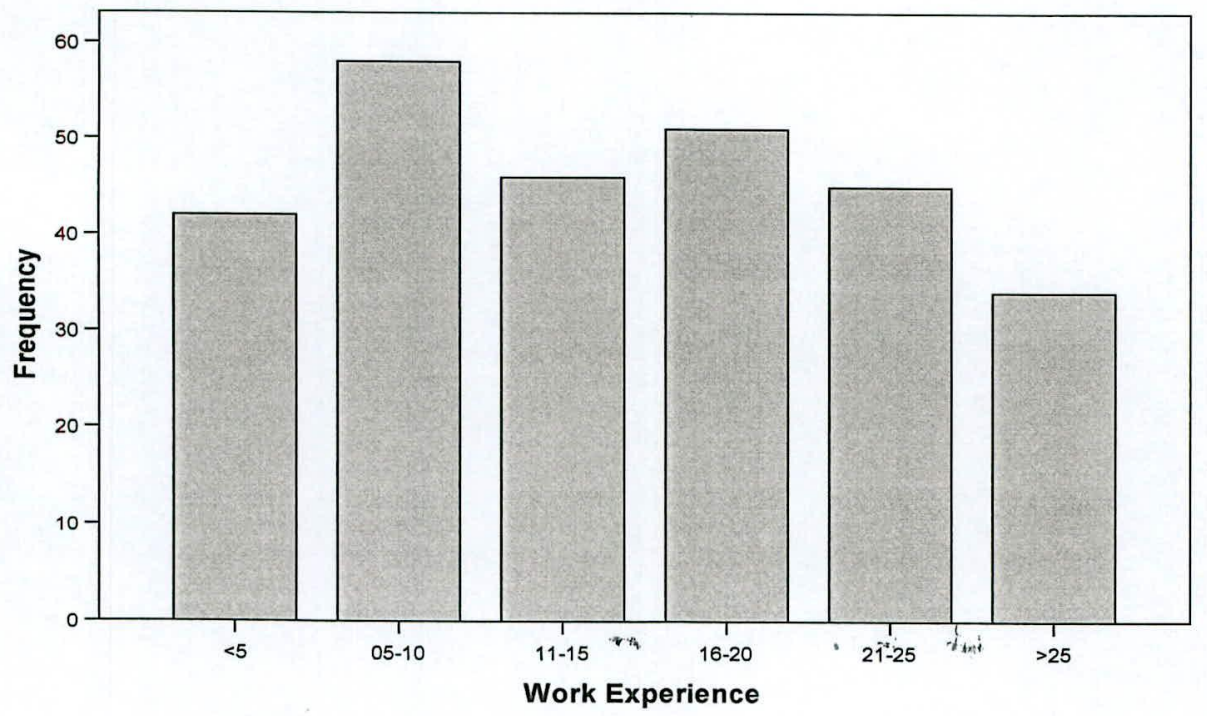


Figure 2.11 Working zonal education offices in districts

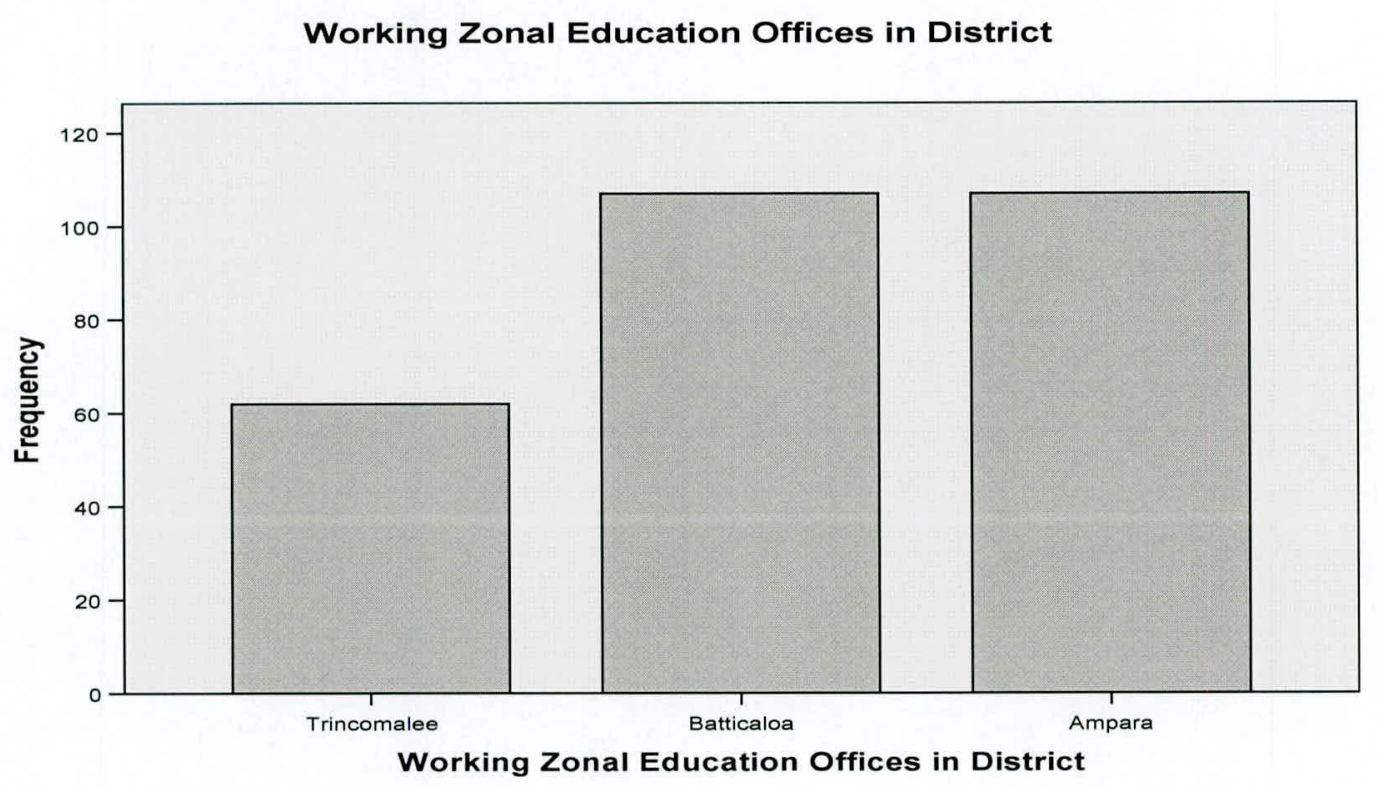

Figure 2.12 Working zonal education offices in zones

Working Zonal Education Offices in Zones

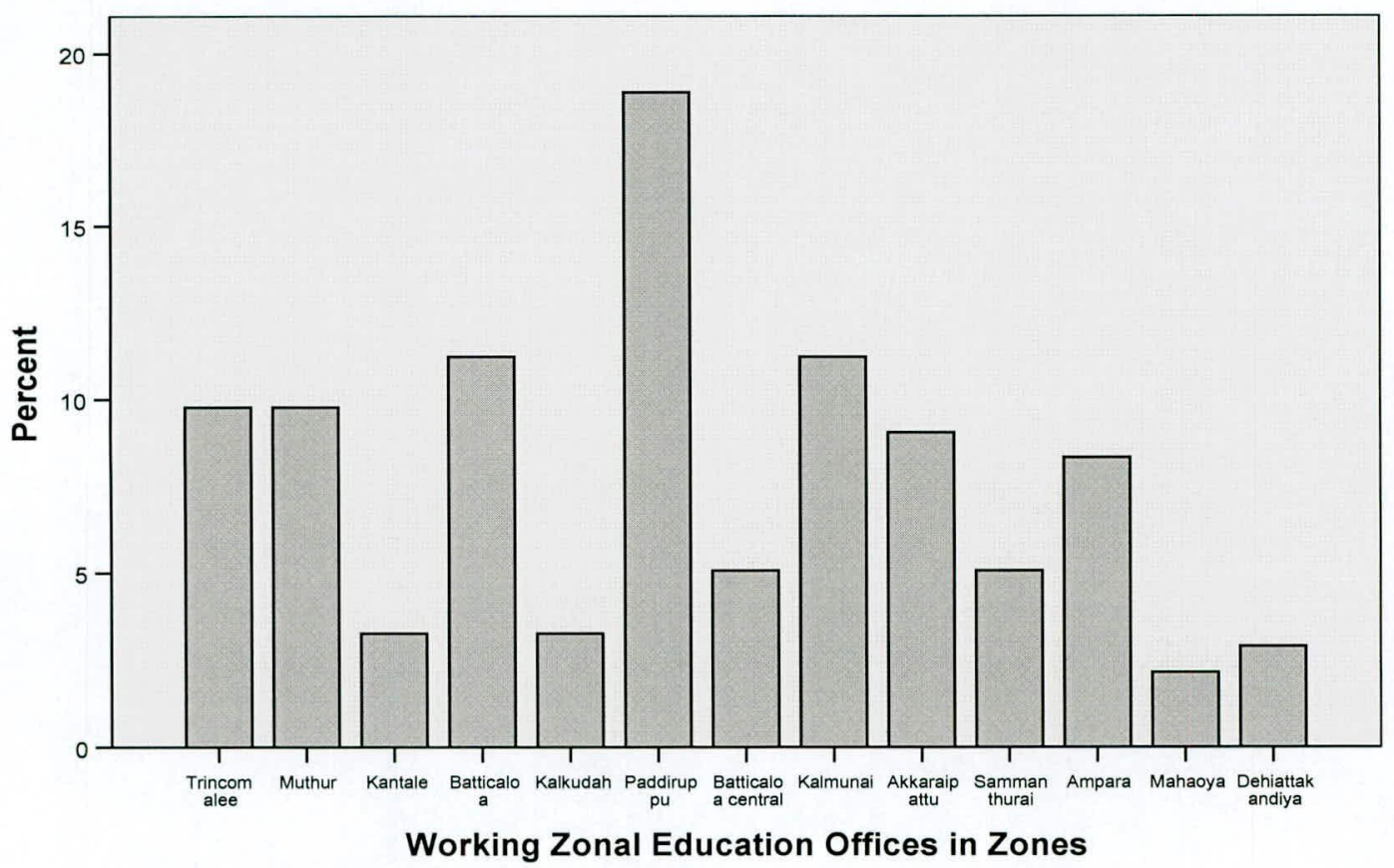


Multiple Regression Analysis

Variables Entered/Removed (b)

\begin{tabular}{|l|l|l|l|}
\hline Model & $\begin{array}{l}\text { Variables } \\
\text { Entered }\end{array}$ & $\begin{array}{l}\text { Variables } \\
\text { Removed }\end{array}$ & Method \\
\hline 1 & $\begin{array}{l}\text { Continuance, } \\
\text { Affective, } \\
\text { Normative(a) }\end{array}$ & & Enter \\
\hline
\end{tabular}

a All requested variables entered.

b Dependent Variable: Performance

Model Summary(b)

\begin{tabular}{|l|l|l|l|l|}
\hline $\begin{array}{l}\text { Mode } \\
1\end{array}$ & R & R Square & $\begin{array}{l}\text { Adjusted } \\
\text { R Square }\end{array}$ & $\begin{array}{l}\text { Std. Error } \\
\text { of the } \\
\text { Estimate }\end{array}$ \\
\hline 1 & .757 (a) & .573 & .569 & .54509 \\
\hline
\end{tabular}

a Predictors: (Constant), Continuance, Affective, Normative

b Dependent Variable: Performance

$\operatorname{ANOVA(b)}$

\begin{tabular}{|l|l|l|l|l|l|l|}
\hline $\begin{array}{l}\text { Mode } \\
1\end{array}$ & & $\begin{array}{l}\text { Sum of } \\
\text { Squares }\end{array}$ & df & $\begin{array}{l}\text { Mean } \\
\text { Square }\end{array}$ & F & Sig. \\
\hline 1 & $\begin{array}{l}\text { Regressio } \\
\text { n }\end{array}$ & 108.586 & 3 & 36.195 & 121.818 & $.000(\mathrm{a})$ \\
& $\begin{array}{l}\text { Residual } \\
\text { Total }\end{array}$ & $\begin{array}{l}80.818 \\
189.404\end{array}$ & 272 & .297 & & \\
& 275 & & & \\
\hline
\end{tabular}

a Predictors: (Constant), Continuance, Affective, Normative

b Dependent Variable: Performance 


\section{Coefficients(a)}

\begin{tabular}{|c|c|c|c|c|c|c|}
\hline \multirow[t]{2}{*}{$\begin{array}{l}\text { Mode } \\
1\end{array}$} & & \multicolumn{2}{|c|}{$\begin{array}{l}\text { Unstandardized } \\
\text { Coefficients }\end{array}$} & \multirow{2}{*}{$\begin{array}{l}\text { Standardized } \\
\text { Coefficients } \\
\text { Beta } \\
\end{array}$} & \multirow[b]{2}{*}{$\mathrm{t}$} & \multirow[b]{2}{*}{ Sig. } \\
\hline & & B & $\begin{array}{l}\text { Std. } \\
\text { Error }\end{array}$ & & & \\
\hline 1 & $\begin{array}{l}\text { (Constant) } \\
\text { Affective } \\
\text { Normative } \\
\text { Continuanc } \\
\text { e }\end{array}$ & $\begin{array}{l}2.848 \\
.322 \\
.313 \\
-.472\end{array}$ & $\begin{array}{l}.244 \\
.046 \\
.042 \\
.062\end{array}$ & $\begin{array}{l}.302 \\
.336 \\
-.346\end{array}$ & $\begin{array}{l}11.654 \\
6.919 \\
7.439 \\
-7.624\end{array}$ & $\begin{array}{l}.000 \\
.000 \\
.000 \\
.000\end{array}$ \\
\hline
\end{tabular}

a Dependent Variable: Performance

\section{Histogram}

\section{Dependent Variable: Performance}

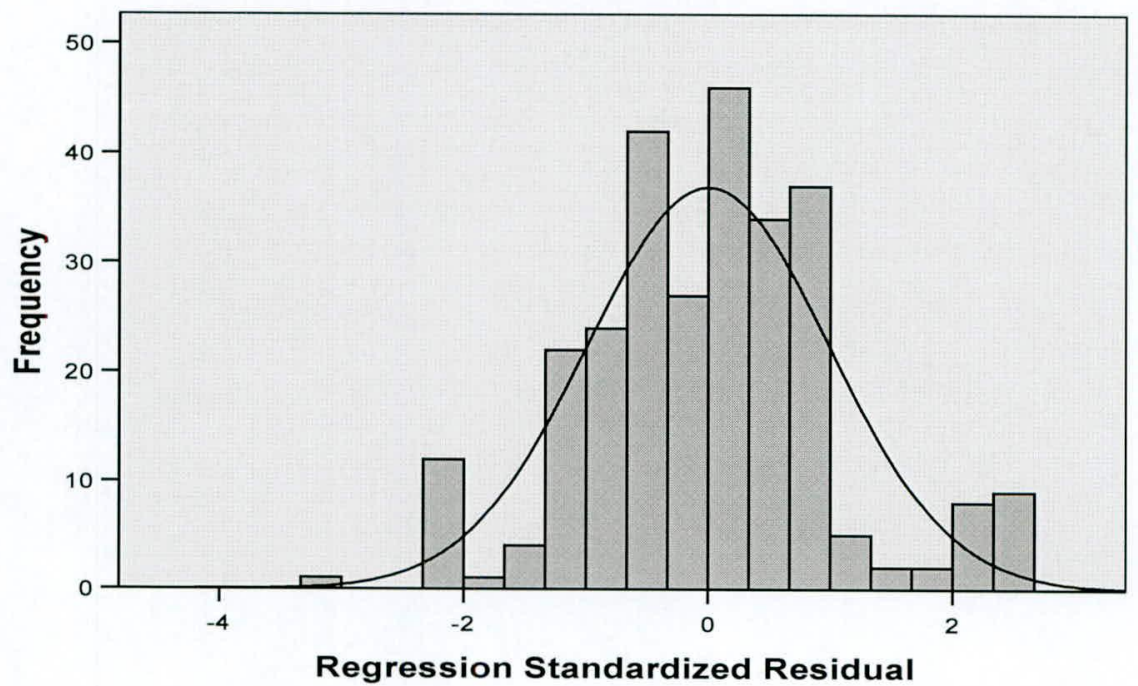


Normal P-P Plot of Regression Standardized Residual

Dependent Variable: Performance

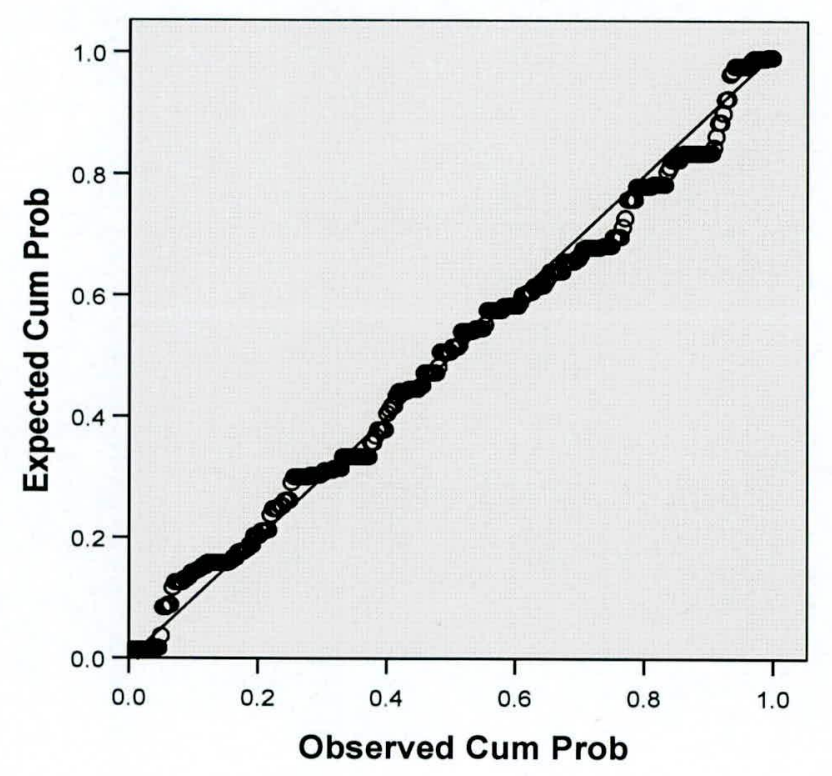

Partial Regression Plot

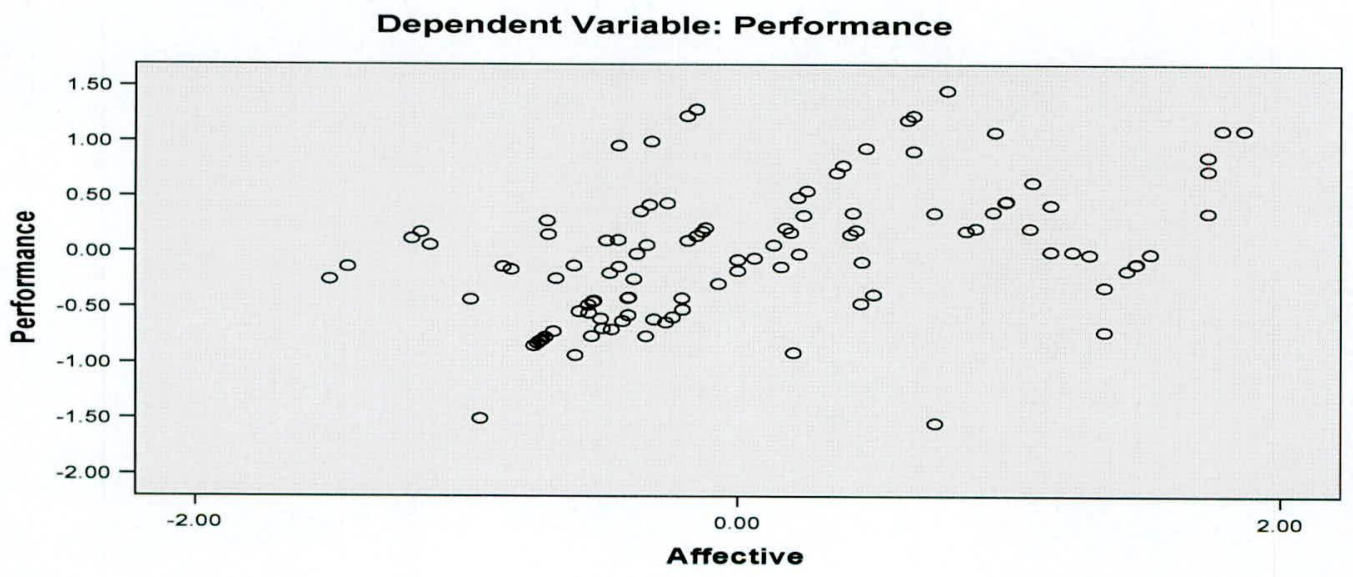




\section{Partial Regression Plot}

\section{Dependent Variable: Performance}

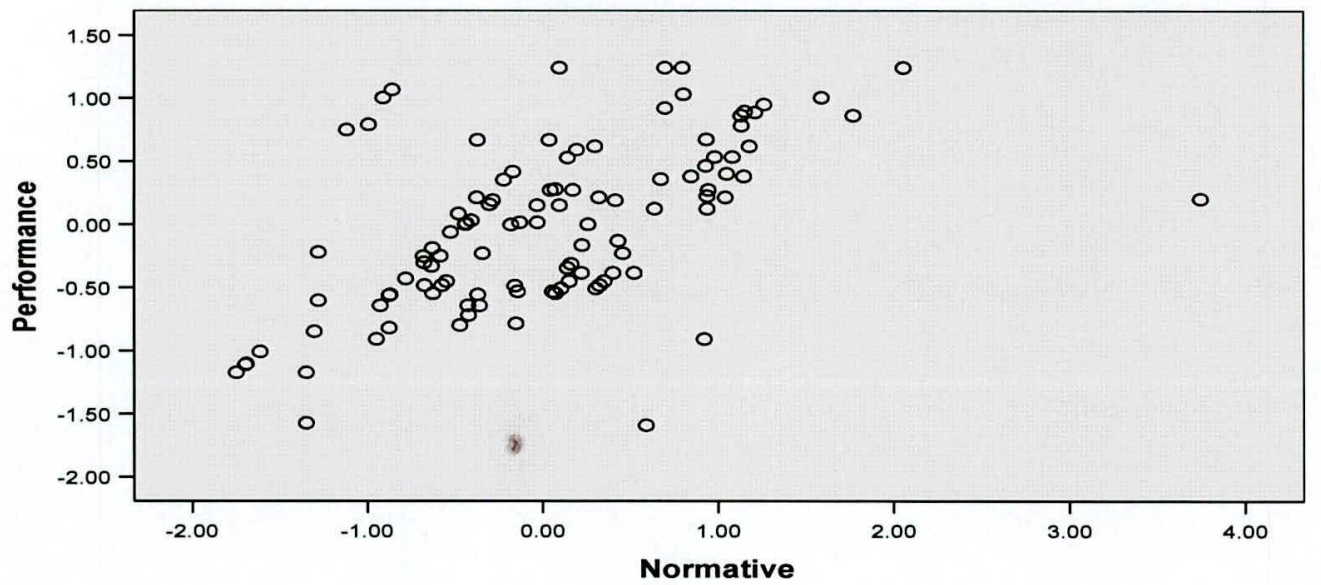

\section{Partial Regression Plot}

\section{Dependent Variable: Performance}

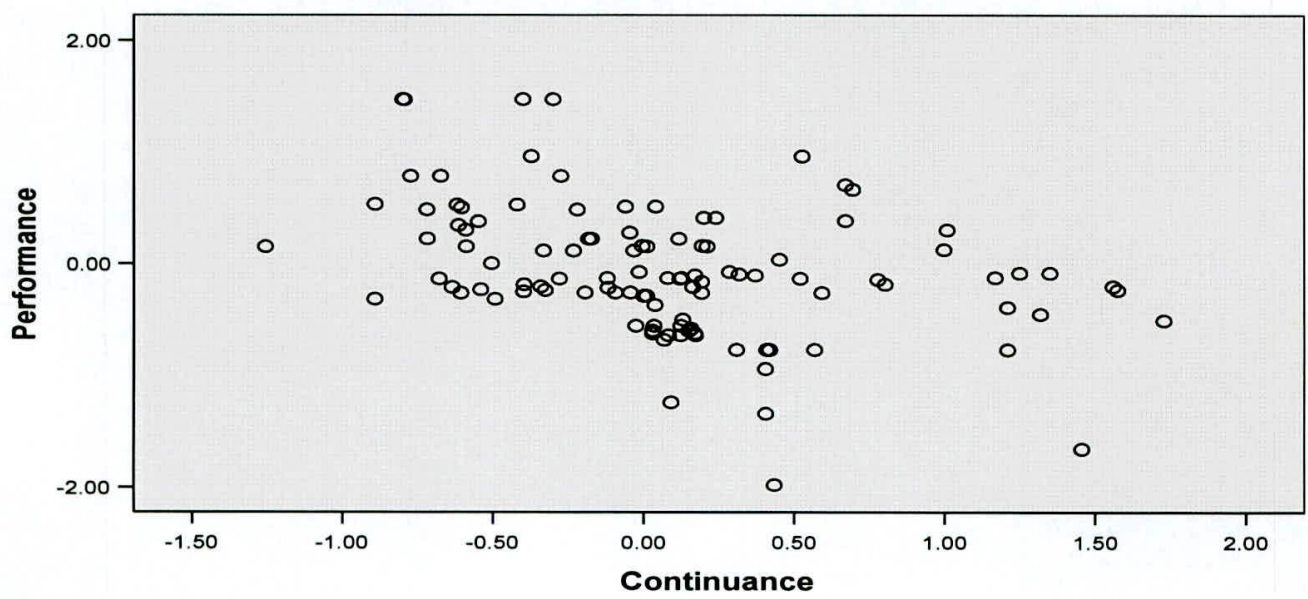

